\title{
GENOMIC INSTABILITY ORIGINATES FROM LEUKEMIA STEM CELLS IN A MOUSE MODEL OF CML-CP
}

\author{
A Dissertation \\ Submitted to \\ the Temple University Graduate Board
}

In Partial Fulfillment

of the Requirements for the Degree of

DOCTOR OF PHILOSOPHY

\author{
By \\ Elisabeth S. Bolton \\ May 2013
}

Examining Committee Members:

Dr. Tomasz Skorski, Advisory Chair, Microbiology and Immunology

Dr. Alexander Tsygankov, Microbiology and Immunology

Dr. Kenneth Soprano, Microbiology and Immunology

Dr. Dan Liebermann, Biochemistry

Dr. Scott Shore, Biochemistry 
(C)

Copyright

2012

by

Elisabeth S. Bolton

All Rights Reserved 


\begin{abstract}
GENOMIC INSTABILITY ORIGINATES FROM LEUKEMIA STEM CELLS IN A MOUSE MODEL OF CML-CP

Elisabeth S. Bolton

Doctor of Philosophy

Temple University 2013

Doctoral Advisoral Committee Chair: Tomasz Skorski, M.D., Ph.D., D.Sc.
\end{abstract}

In chronic myelogenous leukemia (CML), activation of BCR-ABL, the product of the $b c r-a b l$ chimeric gene, leads to constitutive activation of pathways that increase genomic instability through endogenous production of reactive oxygen species (ROS) that cause oxidative DNA damage and inactivate the function of repair proteins leading to unfaithful DNA repair. If misrepaired, oxidative DNA damage, such as 8-oxoguanine (8oxoG), may result in point mutations and/or DNA double-strand breaks (DSBs) leading to drug resistance to the BCR-ABL kinase inhibitor imatinib mesylate (IM) and accumulation of chromosomal aberrations associated with malignant CML progression from a benign chronic phase (CP) to a fatal blast phase (BP).

To determine which population of CML-CP cells, leukemia stem cells (LSCs) and/or leukemia progenitor cells (LPCs), displays elevated levels of ROS and oxidative DNA damage, and whether these elevated levels of ROS and oxidative DNA damage in CML-CP subpopulations result in the accumulation of genomic instability, we employed the tetracycline-inducible SCLtTA/BCR-ABL transgenic mouse model. We showed that LSCs, including the quiescent subpopulation, but not LPCs, displayed elevated levels of ROS and oxidative DNA damage, perhaps due to deregulated expression of genes involved in ROS metabolism, resulting in genomic instability manifested by both point 
mutations and genetic alterations. We also examined the effect of IM on ROS, oxidative DNA damage and genomic instability displayed by CML-CP subpopulations, and determnined that elevated ROS and oxidative DNA damage were not inhibited by IM in quiescent LSCs, nor was genomic instability and deregulated gene expression prevented.

To explore underlying mechanisms, i.e. BCR-ABL expression levels, by which CML-CP cells accumulate genomic instability, we examined the effect of low and high BCR-ABL expression on ROS and oxidative DNA damage in BCR-ABL-transduced human $\mathrm{CD} 34^{+}$cells. We detected elevated ROS and oxidative DNA damage in high BCR-ABL-expressing $\mathrm{CD} 34^{+}$cells compared to low BCR-ABL-expressing cells. Furthermore, BCR-ABL exerted a kinase-dependent effect on ROS-dependent DNA damage.

These data support the hypothesis that genomic instability may originate from LSCs, but do not exclude the potential role of LPCs, and may have important clinical implications for CML treatment since additional genetic aberrations that encode primary resistance may protect LSCs, including the quiescent subpopulation, from eradication by tyrosine kinase inhibitors (TKIs), and the continuous accumulation of genetic errors may trigger disease relapse and progression. 


\section{ACKNOWLEDGMENTS}

First and foremost, I would like to thank my mentor Dr. Tomasz Skorski, who provided exceptional support and guidance in the pursuit of my Ph.D. From Dr. Skorski I learned the importance of experimental design and analysis, and to think independently. Additionally, he afforded numerous opportunities for me to present our research, as well as learn from the research of others, which significantly contributed to my growth as a scientist. His hard work and dedication in studying genomic instability in CML has been inspiring, and I am forever thankful for the opportunity to work under his instruction.

I would also like to thank both past and present members of Dr. Skorski's laboratory, including Shuyue Ren, Mateusz Koptyra, Artur Slupianek, Margaret Nieborowska-Skorska, Kimberly Morales, and Yashodhara Dasgupta, whose mentorship, knowledge, support and friendship have been invaluable to my growth both professionally and personally.

I would like to extend my gratitude to the faculty and staff from the Department of Microbiology and Immunology for providing an outstanding educational experience in the classroom, as well as their time and support throughout my years as a graduate student.

I am abundantly grateful to the distinguished scientists who served as members of my Doctoral Examining Committee: Tomasz Skorski, M.D., Ph.D., D.Sc., Alexander Tsygankov, Ph.D., Kenneth Soprano, Ph.D., Dan Liebermann, Ph.D., and Scott Shore, 
$\mathrm{Ph} . \mathrm{D}$. Their time, energy, insight and encouragement have been instrumental in enhancing my analytical skills and it has been a privilege to learn from their expertise. I would also like to thank all who are mentioned within this work for their collaboration and expertise.

Lastly, I am eternally grateful for the unconditional love, support and patience from my family throughout my graduate studies, including Michael, Mom, Dad, Stephan, Brooke, Olivia, Reilly, Barbara, Mark and Jude. 
For my mother, Beth, whose continuous encouragement and support to pursue higher education enabled me to achieve this milestone.

For my husband, Michael, whose patience and love are boundless. 
TABLE OF CONTENTS

PAGE

ABSTRACT .......................................................................................................................... ii

ACKNOWLEDGMENTS ......................................................................................................... v

DEDICATION.......................................................................................................................... vii

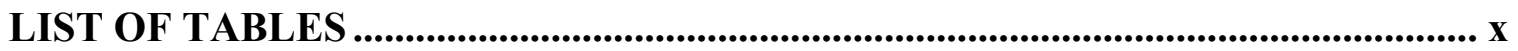

LIST OF FIGURES …............................................................................................................. xi

\section{CHAPTER}

1. INTRODUCTION...................................................................................................... 1

Chronic Myelogenous Leukemia (CML)……………………………...... 1

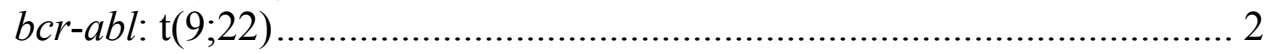

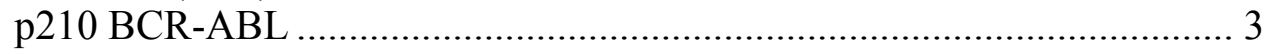

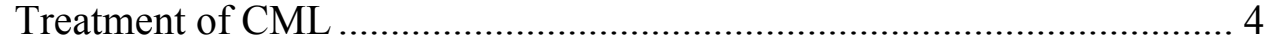

Reactive Oxygen Species (ROS) …………………............................ 6

Oxidative DNA Damage and Repair ....................................................... 10

8-oxoguanine (8-oxoG) and Base Excision Repair (BER) ............ 10

DNA Double Strand Breaks (DSBs) and Repair .......................... 11

BCR-ABL-induced ROS-dependent DNA Damage................................. 12

BCR-ABL Dosage ………………………………………………........ 14

The Tetracycline-inducible (Tet-off) SCLtTA/BCR-ABL Transgenic Mouse Model .................................................................... 14

Rationale and Project Aims …………………………………………..... 15

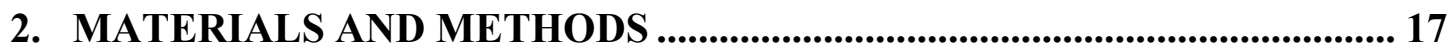

SCLtTA/BCR-ABL Transgenic Mice …………………….................... 17

Genotyping .............................................................................. 17

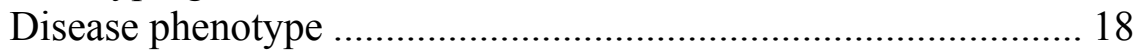

Real-time quantitative reverse transcription polymerase chain reaction (qRT-PCR) …………………………………................ 18

Detection of BM-derived stem and progenitor cells..................... 19 


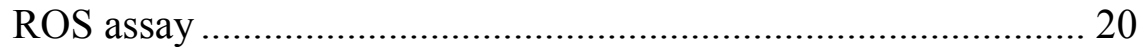

Immunofluorescence: oxidative DNA damage assay ................. 20

Detection of BM-derived quiescent stem cells .......................... 21

In vivo imatinib mesylate (IM) treatment ................................. 23

Detection of BCR-ABL kinase domain mutations ...................... 23

High density single nucleotide polymorphism (SNP) array ........ 25

Microarray analysis of hematopoietic stem cells (HSCs) ............. 26

Human CD34 cells ......................................................................... 27

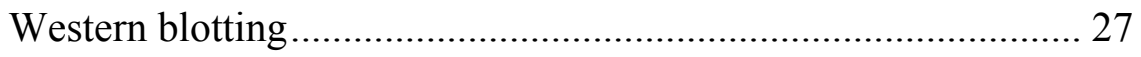

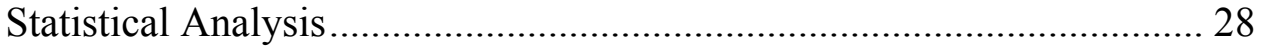

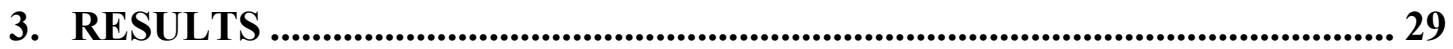

CML-CP Lin ${ }^{-} \mathrm{c}-\mathrm{Kit}^{+} \mathrm{Sca}-1^{+} \mathrm{LSCs}$, including the quiescent population, display elevated levels of ROS and oxidative DNA damage that persist even during IM-inhibition of BCR-ABL kinase ........ 29

Genomic instability originates from CML-CP Lin ${ }^{-c}-\mathrm{Kit}^{+} \mathrm{Sca}-1^{+} \mathrm{LSCs}$ and is not prevented by IM-inhibition of BCR-ABL kinase.

CML-CP Lin ${ }^{-}$- $\mathrm{Kit}^{+} \mathrm{Sca}-1^{+}$LSCs display deregulated expression of genes associated with ROS and DNA repair

BCR-ABL exerts a dose- and kinase-dependent effect on ROS and oxidative DNA damage in BCR-ABL-transduced human CD34 ${ }^{+}$cells

4. DISCUSSION 


\section{LIST OF TABLES}

Table

Page

1. Imatinib-naïve and imatinib-treated induced SCLtTA/BCR-ABL mice harbor leukemia clones expressing imatinib-resistant BCR-ABL kinase domain (KD) mutations.

2. Imatinib-naïve and imatinib-treated induced SCLtTA/BCR-ABL mice accumulate aberrations in genes that regulate ROS levels and DNA repair resulting in resistance to TKIs and progression to CML-AP/BP

3. Microarray analysis of the expression of genes potentially involved in the enhanced levels of ROS and repair of oxidative DNA damage in Lin ${ }^{-}$$\mathrm{Kit}^{+} \mathrm{Sca}-1^{+}$LSCs from induced SCLtTA/BCR-ABL mice in comparison to non-induced counterparts 


\section{LIST OF FIGURES}

Figure

Page

1. Induced SCLtTA/BCR-ABL transgenic mice exhibit a CML-CP-like disease

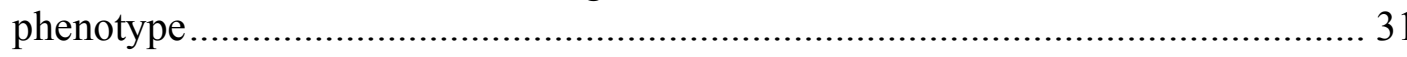

2. Lin $^{-} \mathrm{c}-\mathrm{Kit}^{+} \mathrm{Sca}-1^{+}$LSCs from induced SCLtTA/BCR-ABL transgenic mice display elevated levels of ROS and oxidative DNA damage 34

3. Quiescent Lin ${ }^{-} \mathrm{c}-\mathrm{Kit}^{+} \mathrm{Sca}-1^{+}$LSCs from induced SCLtTA/BCR-ABL transgenic mice display elevated levels of ROS and oxidative DNA damage 35

4. Despite complete inhibition of BCR-ABL kinase, imatinib mesylate (IM) fails to completely inhibit ROS and oxidative DNA damage in quiescent Lin ${ }^{-}$c$\mathrm{Kit}^{+} \mathrm{Sca}-1^{+}$LSCs from induced SCLtTA/BCR-ABL transgenic mice

5. ROS and oxidative DNA damage are propoetional to BCR-ABL protein expression and kinase activity in BCR-ABL-transduced human $\mathrm{CD} 34^{+}$cells 50

6. BCR-ABL kinase-deficient (KD) K1172R mutant does not induce ROS and oxidative DNA damage in transduced human $\mathrm{CD} 34^{+}$cells 


\section{CHAPTER 1}

\section{INTRODUCTION}

\section{Chronic Myelogenous Leukemia (CML)}

Chronic myelogenous leukemia (CML) is a clonal myeloproliferative disorder initiated by the acquisition of the $b c r-a b l$ translocation in the hematopoietic stem cell (HSC) and propagated by the hematopoietic progenitor cell (HPC) that is characterized by three stages of disease progression: chronic phase (CP), accelerated phase (AP), and blast phase (BP). CML-CP is characterized by the expansion of myeloid granulocytes in the bone marrow, spleen, and peripheral blood [1]. More specifically, discordant maturation of leukemia stem cells (LSCs) with a slight delay in maturation within the myeloid compartment combined with a decrease in apoptosis of myeloid cells contributes to increased myeloid mass in the bone marrow where all stages of myeloid maturation are present; the result is a hypercellular bone marrow that is devoid of fat [2]. Additionally, defective adherence of immature myeloid cells to the bone marrow stroma results in their premature release into circulation leading to the expansion of myeloid cells into the spleen and peripheral blood [3]. Furthermore, plasma levels of growth factors are significantly increased to modulate angiogenesis and increase vascularity within the bone marrow [4]. Regardless of the biological effects of CML-CP, the majority of patients have fully competent immune systems, are asymptomatic, and often diagnosed during routine physical examination $[5,6]$. However, when symptoms ensue, CML-CP patients may experience fatigue, weight loss, bleeding, sweats, and abdominal discomfort due to splenomegaly and hepatomegaly [7]. 
After 3-5 years, the majority of CML-CP patients will progress to a transitional CML-AP, which is characterized by an increasing arrest of myeloid maturation and associated with the detection of an increased number of cytogenetic abnormalities [8]. Within 1-2 years, CML-AP patients will progress to a terminal CML-BP, characterized by an uncontrollable, rapid expansion of chemotherapy-refractory blast cells associated with the emergence of additional genetic lesions, and symptoms such as fever and bone pain, increased risk of infection and bleeding, and massive splenomegaly $[1,8,9]$. CMLBP resembles acute leukemia and can be characterized as myeloid in two-thirds of patients or lymphoid in one-third of patients, but is rarely characterized as a mixed myeloid-lymphoid phenotype [9-11]. CML-BP persists for approximately 3-6 months ultimately ending in death [8].

In the United States, approximately 5,430 new cases of CML are estimated for 2012, of which more than $11 \%$ are estimated to end in death [12]. CML represents approximately $12 \%$ of all leukemias and $15-20 \%$ of adult leukemias, affecting 1.6 out of 100,000 adults every year with a slight male preponderance (1.4 male:1 female) $[8,12]$. CML rarely affects children and incidence increases with age; the median age at diagnosis is 65 years [13]. Though CML has no known etiology there is increased incidence in those exposed to radiation [14]. The median survival of CML patients without treatment is approximately 5-6 years [10].

\section{bcr-abl: t $(9 ; 22)$}

In 1960, Nowell and Hungerford detected a similar minute chromosome, termed the Philadelphia chromosome, in peripheral blood cells and/or bone marrow cells among 
7 patients diagnosed with CML; however, no other chromosomal abnormality was detected in these patients suggesting a causal relationship [15]. More than a decade later, Janet Rowley deduced that the Philadelphia chromosome was the result of a translocation between the long arms of chromosomes $22(22 q)$ and $9(9 q)$ resulting in a shortened chromosome $22 \mathrm{q}^{-}$and an elongated chromosome $9 \mathrm{q}^{+}$; results were consistent in 9 patients analyzed with quinacrine fluorescence and Giemsa staining [16]. In 1982, de Klein et al. discovered that the translocation between chromosomes $22 q$ and $9 q$ was reciprocal through detection of the $c$-abll gene from $9 \mathrm{q}$ on $22 \mathrm{q}^{-}$in CML patients, suggesting a role for the $a b l$ gene in CML [17], and just two years later, Groffen et al. detected a sequence of the chromosomal breakpoint cluster region (from the $b c r$ gene) on $22 \mathrm{q}^{-}$in seventeen of nineteen CML patients, suggesting a role for the $b c r$ gene in CML [18]. Shortly thereafter, the juxtaposition of the $b c r$ and $a b l$ genes on $22 q^{-}$was confirmed, as well as the determination that this genetic juxtaposition resulted in a fused transcript and subsequent expression of the 210 kilodalton BCR-ABL protein $[19,20]$. Research since has broadly focused on deducing pathways regulated by p210 BCR-ABL.

\section{p210 BCR-ABL}

$\mathrm{BCR}-\mathrm{ABL}$ is a cytoplasmic non-receptor tyrosine kinase (TK) that harbors deregulated kinase activity manifested by constitutive autophosphorylation leading to the recruitment of adaptor proteins, phosphorylation of signaling molecules and activation of downstream signaling events required for oncogenic transformation [21]. More specifically, BCR-ABL kinase upregulates cell proliferation through enhanced expression of phosphoproteins and diminshed expression of tyrosine phosphatases [22], decreases 
apoptosis through modulation of apoptotic pathways [23-29], increases cytokineindependent growth through enhanced expression of growth factors (GFs) and their receptors [30-36], decreases adhesion to bone marrow stroma and produces cytoskeletal abnormalities [37-41].

$\mathrm{BCR}$ promotes the dimerization/tetramerization of BCR-ABL thereby facilitating autophosphorylation and constitutively activating ABL tyrosine kinase resulting in an increase in phosphotyrosine residues on BCR-ABL creating binding sites for the $\mathrm{SH} 2$ domains of other proteins, which can then be phosphorylated on tyrosine residues and thus activated $[42,43]$. There are a variety of cell signaling pathways and cytoskeletal proteins through which BCR-ABL chronically activates and mediates transformation, proliferation, survival, and adhesion: RAS-MAPK, JAK-STAT, and PI3K/AKT [22].

\section{Treatment of CML}

In the 1950s, CML patients were treated with busulfan, an oral alkylating agent that damages and disrupts DNA structure leading to cytotoxicity; however, busulfan was associated with severe and prolonged myelosuppression, and it took another 20 years for treatment with fewer adverse side effects to be employed [44]. Hydroxyurea was largely used as first-line treatment in the 1970s, which produced rapid hematologic responses and increased survival in CML patients over busulfan. Although both busulfan and hydroxyurea induced complete hematologic responses (CHR) in CML patients, neither prevented patients from progressing to terminal CML-BP [45].

Interferon-alpha (IFN- $\alpha$ ) exerts a wide range of anti-leukemic effects on the immune system (anti-proliferative, anti-angiogenic) and greatly enhances survival of 
CML patients over cytotoxic agents [46]. IFN- $\alpha$ induces complete cytogenetic responses (CCyR) in CML patients [47-49], which are enhanced further in combination treatment with cytarabine, a subcutaneously-administered form of hydroxyurea [50, 51]. However, IFN- $\alpha$ has moderate to severe side effects that may not be tolerated well by many.

While the only curative treatment for CML is bone marrow transplant, the discovery of BCR-ABL-targeted therapy with imatinib mesylate (IM; Gleevec ${ }^{\circledR}$ ) has revolutionized the treatment of CML. IM is a potent and selective inhibitor for $\mathrm{ABL}$ tyrosine kinase, platelet-derived growth factor receptor (PDGFR) and c-Kit receptor [5254]. In CML, IM binds to the ATP-binding site of BCR-ABL tyrosine kinase and stabilizes it in its inactive conformation thereby preventing its catalytic activity of autophosphorylation and tyrosine phosphorylation of downstream substrates [55]. Ultimately, IM induces apoptosis and/or exerts an anti-proliferative effect on dividing CML cells [56, 57]. IM treatment has achieved complete hematologic responses (CHRs) in the majority of CML-CP patients, cytogenetic responses (CyRs) in about half of CML-CP patients, and molecular responses (MR) in a small cohort of CML-CP patients [58]; additionally, long-term treatment with IM has prolonged survival and responses in CML-CP patients [59-61]. Furthermore, IM has induced CHRs and CyRs in patients who have progressed to $\mathrm{CML}-\mathrm{AP} / \mathrm{BP}[62,63]$.

Despite successful clinical outcomes achieved in CML patients treated with IM, there are multiple mechanisms of both primary and secondary resistance that cause patients to relapse and progress to advanced disease phases. Kinase domain mutations have been detected in $90 \%$ of CML patients who relapse [64]. More specifically, varying levels of resistance to IM are conferred by more than 90 different point mutations of 
more than 55 residues in the $b c r-a b l$ gene that disrupt binding of IM to the ABL tyrosine kinase (TK) domain, thereby preventing kinase inhibition [65-68]. Other mechanisms of IM resistance include gene amplification [69], overexpression of the BCR-ABL transcript [55], overexpression of Src family kinases [70, 71], overexpression of efflux proteins [72], under-expression influx proteins, and clonal cytogenetic evolution [73]. Upon developing resistance to IM, dose escalation with IM or treatment with second-generation tyrosine kinase inhibitors (TKIs) may be employed.

Dasatinib (Sprycel ${ }^{\circledR}$ ) is a dual Src/Abl kinase inhibitor that is significantly more potent than IM by binding to both the inactive and active conformations of BCR-ABL [74-76]; in addition, dasatinib targets a more primitive population of progenitor cells than IM, but not the quiescent fraction [77]. Nilotinib $\left(\right.$ Tasigna $\left.^{\circledR}\right)$ is a derivative of IM that also inhibits the inactive conformation of BCR-ABL, however, displays a better fit in the ATP-binding pocket, and, therefore, exerts greater potency than IM $[75,78]$. Both dasatinib and nilotinib induce hematologic, cytogenetic, and molecular responses in CML patients of all phases and in some who display various mechanisms of IM resistance, with the exception of the T315I kinase domain mutation [79-86].

\section{Reactive Oxygen Species (ROS)}

Reactive Oxygen Species (ROS) are molecules containing unpaired electrons within a molecular orbital that confer the reactivity of the molecule [87]. ROS play roles in biological functions and can act as second messengers to regulate activities of redoxsensitive enzymes and signaling molecules to promote cell growth and regulate gene expression $[88,89]$. ROS are produced endogenously, perhaps in response to 
hematopoietic growth factors, through oxidative metabolism and the electron transport reaction by which electrons are leaked to and accepted by molecular oxygen $\left(\mathrm{O}_{2}\right)$ [89-93]. Univalent, bivalent, and trivalent reduction of molecular oxygen $\left(\mathrm{O}_{2}\right)$ results in the production of superoxide anion radical $\left(\bullet \mathrm{O}_{2}{ }^{-}\right)$, hydrogen peroxide $\left(\mathrm{H}_{2} \mathrm{O}_{2}\right)$, and hydroxyl radical $(\bullet \mathrm{OH})$, respectively $[94]$.

The one-electron reduction of molecular oxygen $\left(\mathrm{O}_{2}\right)$ yields the production of superoxide anion radical $\left(\bullet \mathrm{O}_{2}{ }^{-}\right)$. Though short-lived, $\bullet \mathrm{O}_{2}^{-}$can exert damage in vivo. $\bullet \mathrm{O}_{2}{ }^{-}$ can behave as a reducing agent, through a metal-catalyzed Haber-Weiss reaction, or an oxidizing agent. When $\bullet \mathrm{O}_{2}{ }^{-}$behaves as a reducing agent, the catalytic activity of metal ions, i.e. $\mathrm{Fe}^{3+}$, bound to biomolecules mediated by $\bullet \mathrm{O}_{2}{ }^{-}$generates hydroxyl radical $(\bullet \mathrm{OH})$, which then exerts a damaging effect on a target molecule, i.e. DNA. When $\bullet \mathrm{O}_{2}{ }^{-}$ behaves as an oxidizing agent, $\mathrm{Cu}^{2+}$ or $\mathrm{Fe}^{3+}$ catalyzes the decomposition of $\bullet \mathrm{O}_{2}^{-}$to $\mathrm{O}_{2}$, where $\mathrm{O}_{2}{ }^{-}$is a precursor to $\mathrm{Cu}^{3+}$ and $\mathrm{Fe}^{4+}$ formation, which are strong oxidants involved in oxidative damage [95-98].

The one-electron reduction of superoxide anion radical $\left(\bullet \mathrm{O}_{2}{ }^{-}\right)$yields the production of hydrogen peroxide $\left(\mathrm{H}_{2} \mathrm{O}_{2}\right)$, however, $\bullet \mathrm{O}_{2}{ }^{-}$also can be dismutated to $\mathrm{H}_{2} \mathrm{O}_{2}$ via superoxide dismutases (SODs) [99]. $\mathrm{H}_{2} \mathrm{O}_{2}$ is relatively stable by comparison to $\bullet \mathrm{O}_{2}^{-}$, and can both induce tyrosine phosphorylation and inhibit protein tyrosine phosphatase (PTPase) activity; in fact, oxidation of cysteine residues in the active site of PTPases leads to loss of enzymatic activity $[100,101]$.

The one-electron reduction of hydrogen peroxide $\left(\mathrm{H}_{2} \mathrm{O}_{2}\right)$ yields the production of hydroxyl radical $(\bullet \mathrm{OH})$, however, the metal-catalyzed reduction of $\mathrm{H}_{2} \mathrm{O}_{2}$ via the Fenton reaction also leads to the generation of $\bullet \mathrm{OH}[102-106]$. $\bullet \mathrm{OH}$ reacts by one of three 
mechanisms: hydrogen abstraction, electron transfer, and addition reactions; for example, - $\mathrm{OH}$ adds to the double bonds of DNA bases or abstracts a hydrogen atom from each of the 5 carbon atoms of $2^{\prime}$ deoxyribose [107]. Most often, however, $\bullet \mathrm{OH}$ abstracts carbonbound hydrogen atoms non-selectively to produce another radical of lower reactivity [91]. $\bullet \mathrm{OH}$ is highly reactive and therefore reacts close to its site of formation. $\bullet \mathrm{OH}$ attack on membrane lipid can lead to severe damage of the membrane, whereas attack on DNA bases or the deoxyribosyl backbone of DNA can lead to the generation of oxidative products resulting in damaged bases or strand breaks, respectively [108].

In normal cells, ROS are counteracted by antioxidants that quench or reduce ROS to less reactive substrates to prevent damage of biomolecules, and reduce tyrosine phosphorylation thereby counteracting the signaling effects of ROS. Although there are multiple systems, both enzymatic and non-enzymatic, involved in ROS detoxification, ROS can interact with and damage cellular components, such as lipids, proteins, DNA bases and the deoxyribosyl backbone of DNA, leading to base modification and/or DNA double-strand breaks (DSBs), and inactivate the function of DNA repair proteins leading to unfaithful repair and genomic instability $[92,106,109]$. Altogether, oxidative stress can lead to DNA lesions and genomic mutations [110].

There are many sources of electron transport and ROS generation within the cell: mitochondria, membrane NADPH oxidases, cytochrome P450, xanthine oxidase, microsomes and peroxisomes [111-113]. The majority of superoxide anion radical $\left(\bullet \mathrm{O}_{2}{ }^{-}\right)$ production occurs within the mitochondria, which is responsible for ATP production and cellular respiration through the electron transport chain (ETC) where electrons are passed between molecules to produce energy. Even under normal conditions, redox carriers 
within the mitochondrial ETC can leak single electrons to molecular oxygen $\left(\mathrm{O}_{2}\right)$ and convert it into $\bullet \mathrm{O}_{2}{ }^{-}$[114-116]. The primary site of damage from mitochondrial $\bullet \mathrm{O}_{2}{ }^{-}$is mitochondrial DNA (mtDNA), which, if extensive, will eventually shut down the mitochondria. The major sites of ROS production within the mitochondrial ETC are Complexes I through V, however, there are many other sources of ROS present within the mitochondria with varying sub-mitochondrial localization [117-120].

NADPH oxidases are plasma membrane-associated enzymes that, when activated, take $\mathrm{NAD}(\mathrm{P}) \mathrm{H}$ from the hexose monophosphate shunt in the cytoplasm and pass electrons to molecular oxygen $\left(\mathrm{O}_{2}\right)$ to produce superoxide anion radical $\left(\bullet \mathrm{O}_{2}{ }^{-}\right)$within the plasma membrane or to its outer surface $[121,122]$. NADPH oxidases generate significant amounts of ROS and play an important role in the respiratory burst of immune cells providing oxidizing agents for microbicidal action, as well as exerting potential damage to molecules and cellular components [123, 124]. Cytochrome P-450, whose primary role is to detoxify compounds into less toxic products through oxidation and hydroxylation, is the terminal component of the monoxygenase system found within the endoplasmic reticulum (ER); during these oxidation and hydroxylation reactions, electrons may be leaked onto $\mathrm{O}_{2}$ leading to the formation of $\bullet \mathrm{O}_{2}{ }^{-}$[125]. Xanthine oxidase is a molybdenum iron-sulfur flavin hydroxylase that catalyzes the hydroxylation of purines, for example, the reaction of hypoxanthine to xanthine, resulting in the reduction of $\mathrm{O}_{2}$ to $\bullet \mathrm{O}_{2}{ }^{-}$, and xanthine to uric acid, resulting in the reduction of $\mathrm{O}_{2}$ to hydrogen peroxide $\left(\mathrm{H}_{2} \mathrm{O}_{2}\right)[126,127]$. Microsomes produce the majority of $\mathrm{H}_{2} \mathrm{O}_{2}$ at hyperoxia sites and peroxisomes produce $\mathrm{H}_{2} \mathrm{O}_{2}$ via oxidation of fatty acids [98, 128]. 


\section{Oxidative DNA Damage and Repair}

DNA damage can induce transcriptional changes, activation of cell cycle checkpoints, DNA repair and/or apoptosis [92]. There are multiple pathways that exist to repair DNA damage, yet each DNA repair mechanism targets a specific type(s) of DNA damage. In normal cells, DNA damage response pathways are tightly regulated, however, misrepair of DNA damage may result in mutation and disease $[129,130]$.

\section{8-oxoguanine (8-oxoG) and Base Excision Repair (BER)}

Due to an electron-rich purine structure and the lowest oxidation potential of all four nucleotides, guanine is preferentially attacked by free radicals [131, 132]. More specifically, hydroxyl radical $(\bullet \mathrm{OH})$ can add to guanine at carbon 4,5 , and 8 positions; however, the one-electron oxidation of the hydroxylated C8 radical yields 7,8-dihydro-8oxoguanine (8-oxoguanine; 8-oxoG) [133-135]. 8-oxoG is easily formed, pro-mutagenic, and has an even lower oxidation potential than guanine thereby permitting an even higher reactivity with free radicals [136-140]. 8-oxoG is produced abundantly in vivo and therefore is used as a biomarker of oxidative DNA damage [140-142].

Repair of DNA base damage occurs primarily by base excision repair (BER), however, misrepair could result in mutation, such as base substitution and deletion, thereby promoting carcinogenesis [143-145]. BER is stimulated upon alkylation, oxidation, or deamination of bases forming non-bulky lesions [130]. Glycosylase and endonuclease enzymes are responsible for the repair of human 8-oxoG lesions [146]. More specifically, oxidized guanine is recognized and cleaved by a DNA glycosylase (OGG1, OGG2) and released from the sugar-phosphate backbone; then the onenucleotide gap is filled by Polymerase $\beta$ and ligated [130]. Misrepair of 8-oxoG can 
result in loss of base pairing specificity, misreading of adjacent pyrimidines, or insertion of adenine opposite the lesion resulting in $\mathrm{GC} \rightarrow \mathrm{TA}$ transversions $[135,147]$. If misrepaired, 8-oxoG can even result in the formation of DNA double-strand breaks (DSBs) $[106,148]$.

\section{DNA Double-Strand Breaks (DSBs) and Repair}

DNA double-strand breaks (DSBs) are the most dangerous type of DNA damage, and may result from both exogenous sources, i.e. irradiation and chemotherapy, and endogenous sources, i.e. recombination and ROS [129]. In response to DSBs, ATM kinase induces cell cycle arrest by activation of cell cycle checkpoints through downstream effectors that mediate repair, arrest or apoptosis $[149,150]$. There are two primary mechanisms of DSB repair: homologous recombination (HR) and nonhomologous end joining (NHEJ). HR is a highly accurate pathway that uses homologous DNA as a template, whereas NHEJ directly ligates the broken ends of DNA without using any DNA template and may be accompanied by the loss of a few or long stretches of nucleotides [129, 130, 151-153]. In fact, Karanjawala et al. showed that both free radicals and aberrant NHEJ result in increased DNA DSBs [106]. Repair pathway selection depends, in part, on cell cycle stage; NHEJ is the predominant DSB repair pathway in $G_{0}, G_{1}$ and early $S$ phase, whereas $H R$ is most prevalent during $S$ and $G_{2}$ phases $[130,154]$. ATM/ATR-dependent phosphorylation of histone H2AX at Ser139 ( $\gamma$ $\mathrm{H} 2 \mathrm{AX}$ ) rapidly occurs around DSBs and spreads into adjacent chromatin to attract downstream proteins for efficient DSB repair [155-157]. Therefore, DSB repair can be inferred from the formation of foci containing DNA repair-associated proteins and chromatin modifications, i.e. $\gamma$-H2AX, where the number of repair foci correlates with 
the number of DSBs $[150,158]$. Aberrations in pathways regulating the DNA damage response include delayed checkpoint activation, which may result in the misrepair of DSBs leading to chromosomal aberrations $[130,150]$.

\section{BCR-ABL-induced ROS-dependent DNA Damage}

BCR-ABL displays chronic activation of signaling pathways (RAS, PI3K, STAT) that lead to elevated levels of ROS and create an imbalance between ROS production and ROS scavenging. In fact, BCR-ABL mimics some signaling events activated by growth factors (GFs) and growth factor receptors (GFRs), and activation of BCR-ABL, GFs and GFRs coincides with an increase of intracellular ROS levels in hematopoietic cells [90, 159, 160]. Additionally, the tyrosine phosphorylation patterns of signaling proteins induced by BCR-ABL transformation and hydrogen peroxide $\left(\mathrm{H}_{2} \mathrm{O}_{2}\right)$ stimulation overlap; in contrast, cellular PTPase activity is decreased by both BCR-ABL and $\mathrm{H}_{2} \mathrm{O}_{2}$ in hematopoietic cell lines [160]. Increase in ROS is believed to be due directly to BCRABL kinase activity since both ROS and BCR-ABL kinase activity are inhibited by IM [160], and it appears that increased ROS amplify BCR-ABL signaling through a positive feedback loop. However, ROS levels also may be regulated partially by the bone marrow microenvironment, which provide additional stimuli for survival and self-renewal.

Elevated ROS in BCR-ABL-transformed cells depend on mechanisms that regulate glucose metabolism and is linked to the mitochondrial electron transport chain (ETC) $[160,161]$; furthermore, BCR-ABL-transformed cells exert a "Warburg effect", which contributes to elevated ROS production through hyperactive glucose metabolism 
thereby fueling the mitochondrial ETC [162]. Additionally, BCR-ABL-transformed cells enhance and regulate glucose uptake $[163,164]$.

BCR-ABL induces elevated levels of intracellular ROS through increased glucose metabolism in a PI3K/mTOR-dependent manner [161, 165]. Furthermore, BCR-ABL activates PI3K/AKT and RAS/ERK pathways through recruitment of GRB2/GAB2 complex to autophosphorylated residue Y177 in BCR, and GAB2 phosphorylationdependent activation of PI3K is associated with superoxide formation [166]. BCR-ABL regulates expression of both MYC and HIF-1, which transcriptionally control many glycolytic enzymes, through RAS and AKT, and PI3K/mTOR activation, respectively [167-170]. Lastly, complex formation of BCR-ABL with VAV leads to activation of RAC, an important regulatory subunit of NADPH oxidase [171, 172].

BCR-ABL stimulates genomic instability through enhanced DNA repair, prolonged activation of the $\mathrm{G}_{2} / \mathrm{M}$ checkpoint to extend time for DNA repair, and inhibition of pro-apoptotic pathways [173-181]. More specifically, BCR-ABL elevated ROS levels resulting in 8-oxoG and DSB formation, and promoted enhanced yet unfaithful DNA repair resulting in mutation [182-184]. Therefore, it seems that BCR$\mathrm{ABL}$ acquires more mutations than non-transformed cells because there is greater DNA damage and more enhanced yet less faithful DNA repair. Altogether, BCR-ABL kinase chronically activates survival pathways (RAS, PI3K, and STAT) [92], stimulates ROS production that enhances signaling and causes DNA damage in CML cells $[160,182$, $185,186]$ and alters DNA repair mechanisms $[160,174-177,187-191]$ resulting in genomic instability responsible for mutation associated with drug resistance and disease progression. 


\section{BCR-ABL Dosage}

Expression of BCR-ABL is associated with a mutator phenotype; therefore, upregulation of BCR-ABL may cause an increase in genetic instability and mutation capable of driving disease progression and IM resistance [175, 180, 184]. Expression of BCR-ABL mRNA [192-196] and protein [197] increases with disease progression and has been associated with the development of resistance to IM [69, 198-203]. Elevated BCR-ABL in cell lines is also sufficient to mediate drug resistance [204]. Furthermore, BCR-ABL transcripts and protein kinase are found at the highest levels in the most primitive cells, although consequences of BCR-ABL expression may lead to diverse effects in different cell types [205]. These findings suggest that high expression of BCRABL may underlie mechanisms of CML progression and drug resistance, of which ROS and oxidative DNA damage are the primary suspects.

\section{The Tetracycline-inducible (tet-off) SCLtTA/BCR-ABL Transgenic Mouse Model}

In 2005, Daniel Tenen's group developed conditional transgenic mice where p210 BCR-ABL expression was targeted in the stem and progenitor cells of murine bone marrow using the tet-off system to induce a CML-like disease phenotype [206]. First, they developed a construct consisting of the SV40 minimal promoter and the rabbit $\beta$ globin intron 2. Downstream, the tetracycline transactivator protein (tTA) with poly A sequence was placed under the control of the murine stem cell leukemia $(S C L)$ gene $3^{\prime}$ enhancer, which restricted expression within adult murine bone marrow to hematopoietic stem and progenitor cells, and megakaryocytes [207, 208]. This fragment was purified and injected into the pronucleus of BDF mice. Previously, they generated TRE-BCR- 
ABL mice [209]. They developed a construct consisting of a tetracycline-responsive element (TRE) and the cytomegalovirus (CMV) promoter; downstream, p210 BCR-ABL was placed under the control of the TRE, followed by rabbit $\beta$-globin intron 8 , and a poly A sequence. This fragment was purified and injected into the pronucleus of $\mathrm{FVB} / \mathrm{N}$ mice. To generate the SCLtTA/BCR-ABL double-transgenic murine line, male SCLtTA BDF mice were crossbred with female TRE-BCR-ABL FVB/N mice [206]. To date, this is the only mouse model of CML that initiates BCR-ABL expression at the level of the hematopoietic stem cell (HSC).

\section{Rationale and Project Aims}

There are two major obstacles in the treatment of CML: disease progression and drug resistance, both of which are a consequence of genomic instability. CML-CP is initiated by the leukemia stem cell (LSC) but is propagated by the leukemia progenitor cell (LPC), yet either population may exhibit drug resistance. Furthermore, disease progression to CML-BP is inevitable if CML-CP is either untreated or drug resistance is acquired through point mutation and/or additional chromosomal aberrations.

To determine which population of CML-CP cells, LSCs and/or LPCs, displays elevated levels of ROS and oxidative DNA damage, and whether these elevated levels of ROS and oxidative DNA damage in CML-CP subpopulations result in the accumulation of genomic instability, we employed the tetracycline-inducible SCLtTA/BCR-ABL transgenic mouse model. We also examined the effect of the BCR-ABL kinase inhibitor imatinib mesylate (IM) on ROS, oxidative DNA damage and genomic instability displayed by CML-CP subpopulations. Additionally, to explore underlying mechanisms, 
i.e. BCR-ABL expression levels, by which CML-CP cells accumulate genomic instability, we examined the effect of low and high BCR-ABL expression on ROS and oxidative DNA damage in BCR-ABL-transduced human $\mathrm{CD} 34^{+}$cells.

Based on the accumulation of evidence, we suspect that both LSCs and LPCs display elevated levels of ROS and oxidative DNA damage that, when combined with unfaithful DNA repair mechanisms, results in genomic instability responsible for drug resistance associated with point mutations in the BCR-ABL kinase domain and CML progression associated with additional cytogenetic abnormalities. Furthermore, we suspect that levels of BCR-ABL expression and kinase activity may play a role in determining levels of ROS and oxidative DNA damage. 


\section{CHAPTER 2}

\section{MATERIALS AND METHODS}

\section{SCLtTA/BCR-ABL transgenic mice \\ Genotyping}

Transgenic mice were generously provided by Steffen Koschmieder (University of Aachen, Germany). Mice were provided with drinking water supplemented with tetracycline hydrochloride $(0.5 \mathrm{~g} / \mathrm{L})$ (Sigma-Aldrich, Saint Louis, MO). Transgenic mice were identified by polymerase chain reaction (PCR) of tail snip DNA. DNA isolation and purification from mice tails were performed using the REDExtract-N-Amp Tissue PCR Kit (Sigma, Saint Louis, Missouri), and genotyping for the SCLtTA and p210 BCR/ABL transgenes was performed using transgene-specific primers (Eurofins MWG Operon, Huntsville, AL). 2X GoTaq polymerase Master Mix (Promega, Madison, WI) was used to amplify both SCLtTA and $\mathrm{p} 210 B C R / A B L$ transgenes. $B C R / A B L$-specific primers (forward: 5'-GAGCGTGCAGAGTGGAGGGAGAACA-3'; reverse: 5'-

GGTACCAGGAGTGTTTCTCCAGACTG-3') amplified a 500 basepair-long fragment using amplification conditions of 40 cycles at $94^{\circ} \mathrm{C}$ for 45 seconds, $55^{\circ} \mathrm{C}$ for 1 minute, and $72^{\circ} \mathrm{C}$ for 1 minute. SCLtTA-specific primers $\left(t T A: 5^{\prime}-\right.$

TTTCGATCTGGACATGTTGG-3'; SCL: 5'-AGAACAGAATTCAGGGTCTTCCTT$3^{\prime}$ ) yielded a 750 basepair product using amplification conditions consisting of 40 cycles at $94^{\circ} \mathrm{C}$ for 40 seconds, $60.5^{\circ} \mathrm{C}$ for 1 minute, and $72^{\circ} \mathrm{C}$ for 1 minute. PCR products were run in a 1.5\% agarose gel containing ethidium bromide, and visualized using the Gel Doc $^{\mathrm{TM}} \mathrm{XR}+$ Molecular Imager ${ }^{\circledR}$ System (Bio-Rad, Hercules, CA). 


\section{Disease phenotype}

Transgenic mice were euthanized by $\mathrm{CO}_{2}$ inhalation followed by cervical dislocation. Peripheral blood (PB) was collected via cardiac puncture using a heparinized needle and syringe. Spleens (SPL) were removed, photographed (Sony Cyber-shot ${ }^{\circledR}$ Digital Camera W220), weighed (Sartorius BP211D, Goettingen, Germany), and then mashed to obtain cells in suspension. Bone marrow cells (BMCs) were flushed from tibias and femurs with culture medium and subjected to density separation by Lympholyte M (Cedarlane, Hornby, Canada) to remove erythrocytes. Enucleated red blood cells (RBCs) were lysed from total PBCs with ACK lysis buffer $\left(0.15 \mathrm{M} \mathrm{NH}_{4} \mathrm{Cl}\right.$, $0.01 \mathrm{M} \mathrm{KHCO} 3,0.1 \mathrm{mM}$ EDTA $\cdot \mathrm{Na}_{2} \cdot 2 \mathrm{H}_{2} 0, \mathrm{pH}$ 7.2-7.4). All cells were washed and resuspended in cold $1 \mathrm{X}$ phosphate-buffered saline (PBS) containing $1.0 \% \mathrm{BSA}$ and purified rat anti-mouse CD16/CD32 (FcR $\gamma$ III/II) antibody and incubated on ice for 10 minutes, followed by incubation with rat anti-mouse fluorescein isothiocyanate (FITC)conjugated Ly-6G/C (Gr-1), phycoerythrin (PE)-conjugated CD11b (Mac-1), allophycocyanin (APC)-conjugated CD45R/B220, and PE-cyanin7 (PE-Cy $\left.{ }^{\mathrm{TM}} 7\right)$ conjugated CD3, or APC-conjugated Ter-119 and PE-conjugated CD41 (BD PharMingen, San Diego, CA) for 30 minutes in $4^{\circ} \mathrm{C}$, and fixed with $1 \%$ paraformaldehyde (PFA) in 1X PBS. Cells were analyzed with FACS within 24-48 hours.

\section{Real-time quantitative reverse transcription polymerase chain reaction (qRT-PCR)}

qRT-PCR was conducted by Mirle Schemionek (University of Aachen, Germany), as described previously [210]. Isolation of DNase-treated RNA was performed using RNeasy ${ }^{\circledR}$ Mini Kit or RNeasy ${ }^{\circledR}$ Micro Kit for BM and SPL, respectively (Quiagen, Hilden, Germany). RNA isolation was followed by cDNA synthesis using the 
Moloney murine leukemia virus (M-MLV) reverse transcriptase from Promega

(Promega, Mannheim, Germany) following the manufacturer's protocol. For detection of p210 BCR-ABL transcripts, a real-time taqman assay (Eurogentec, Cologne, Germany) and Taqman Universal PCR Master Mix (Applied Biosystems, Darmstadt, Germany) were used in combination with the ABI 7500 Fast Real-Time PCR system (Applied Biosystems, Darmstadt, Germany). As an internal standard, the expression level of glyceraldehyde-3-phosphate dehydrogenase (GAPDH) was used.

\section{Detection of BM-derived stem and progenitor cells}

BMCs from transgenic mice were flushed from tibias and femurs with Iscove's modified Dulbecco's medium (IMDM) (Mediatech, Manassas, VA) containing 10\% FBS (Gibco, Grand Island, NY), 1X antibiotic-antimycotic solution (Mediatech, Manassas, VA), and pretested minimal concentrations of interleukin-3 (IL-3) and stem cell factor (SCF) required to maintain proliferation and viability, and subjected to density separation to remove erythrocytes by using Lympholyte M (Cedarlane, Hornby, Canada). Cells were resuspended in culture medium and placed in culture flasks to be incubated in 5\% $\mathrm{CO}_{2}$ and $37^{\circ} \mathrm{C} .24-48$ hours later cells were washed and resuspended in warm $1 \mathrm{X}$ PBS plus $1 \%$ BSA and stained with rat anti-mouse APC-conjugated lineage antibody cocktail, PE-conjugated CD117 (c-Kit), and PE-Cy ${ }^{\mathrm{TM}}$ 7-conjugated Ly-6A/E (Sca-1) for 30 minutes in $37^{\circ} \mathrm{C}$ (BD PharMingen, San Diego, CA). 1 X $10^{6}$ cells were assayed for ROS production; remaining cells were sorted for stem $\left(\mathrm{Lin}^{-} \mathrm{c}-\mathrm{Kit}^{+} \mathrm{Sca}-1^{+}\right)$and progenitor $\left(\mathrm{Lin}^{-}\right.$

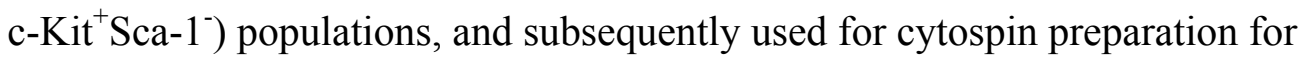
immunofluorescence to assay for oxidative DNA damage. 


\section{ROS assay}

Levels of intracellular reactive oxygen species (ROS) were analyzed in cells cultured in the presence of pretested minimal concentrations of IL-3 and SCF required to maintain viability and proliferation using the redox-sensitive fluorochromes dihydroethidium (DHE) to detect cellular $\bullet \mathrm{O}_{2}{ }^{-}$(Sigma-Aldrich, Saint Louis, MO), Redox Sensor ${ }^{\mathrm{TM}}$ Red CC-1 to detect $\bullet \mathrm{O}_{2}{ }^{-} / \mathrm{H}_{2} \mathrm{O}_{2}$ (Molecular Probes, Eugene, OR), and $2^{\prime}, 7^{\prime}-$ dichlorodihydrofluorescein-diacetate to detect $\mathrm{H}_{2} \mathrm{O}_{2} / \bullet \mathrm{OH}$ (DCFDA). Briefly, cells were washed and resuspended in warm 1X PBS, then incubated with 5-10 $\mu \mathrm{M}$ of fluorochrome for $10-15$ minutes in $37^{\circ} \mathrm{C}$. Next, samples were washed and resuspended in cold $1 \mathrm{X}$ PBS, and analyzed using the $\mathrm{BD}^{\mathrm{TM}}$ FACSCanto or LSR II flow cytometry systems (BD Biosciences, San Jose, CA).

\section{Immunofluorescence: oxidative DNA damage assay}

Cytospins were prepared from cell suspensions containing 1\% bovine serum albumin (BSA) (Sigma-Aldrich, Saint Louis, MO) or 2\% FBS using the Thermo Shandon Cytospin 3 (Harlow Scientific, Arlington, MA). Cellspots were fixed with 4\% formaldehyde for 20 minutes, then washed and permeabilized with $0.02 \%$ Triton X-100 and blocked with 2\% BSA for 45 minutes. Cellspots were then incubated with 1:1001:200 monoclonal anti-8-oxoguanine (8-oxoG) (Chemicon, Temecula, CA) or antiphopsho-histone H2A.X (Ser139) (Upstate, Temecula, CA) primary antibodies for 1 hour, followed by washing and blocking for 15 minutes. 1:4000-1:2000 Alexa Flour ${ }^{\circledR}$ 594 or 488 goat anti-mouse IgG secondary antibody (Molecular Probes, Eugene, OR) was applied for 45 minutes to detect nuclear localization of 8-oxoG lesions and DNA DSBs; simultaneously, DNA was counterstained with 1:2000 blue-fluorescent nucleic 
acid stain 4',6'-diamidino-2-phenylindole (DAPI), dihydrochloride (Molecular Probes, Eugene, OR). Cellspots were washed and fixed again before being treated with SlowFade ${ }^{\circledR}$ Gold antifade reagent (Molecular Probes, Eugene, OR) and mounted with a coverslip. Fixation took place at room temperature (RT), whereas all other steps were carried out at $37^{\circ} \mathrm{C}$. Specific staining was visualized using an inverted Olympus IX70 fluorescence microscope (Olympus America, Melville, NY) equipped with a 100 X/1.35 numeric aperture UPlan Apo objective and Cooke Sensicam QE camera (Cooke, Auburn Hills, MI). A series of 3-dimensional images of each cell was stored in SlideBook software version 3.0.1 (Intelligent Imaging Innovations, Denver, CO). Deconvolution was applied to increase the resolution and contrast of the images, as described [174]. A collection of 3-dimensional images describing individual cells was converted to a one 2dimensional photomicrograph. 2-dimensional photomicrographs of 8-oxoG lesions underwent further analysis using Adobe Photoshop (Adobe Systems, San Jose, CA) before final quantification of nuclear lesions in Slidebook.

\section{Detection of BM-derived quiescent stem cells}

BMCs from transgenic mice were flushed from tibias and femurs with IMDM supplemented with $10 \%$ FBS, $1 \%$ antibiotic, and pretested minimal concentrations of IL3 and SCF, and then subjected to density separation by Lympholyte M (Cedarlane, Hornby, Canada) to remove erythrocytes. Cells were incubated overnight (12-16 hours) in serum-free medium (SFM) consisting of IMDM, 0.1\% bovine serum albumin (BSA), and $1 \mathrm{X}$ antibiotic/antimycotic solution. Cells then were stained with rat anti-mouse APC-

or PerCP-Cy ${ }^{\mathrm{TM}}$ 5.5-conjugated lineage antibody cocktail (BD PharMingen, San Diego, CA) and sorted for lineage-negative ( Lin $\left.^{-}\right)$cells. Sorted cells were washed and 
resuspended in 1X PBS and stained with $2 \mu \mathrm{M}$ carboxyfluorescein diacetate, succinimidyl ester (CFSE) (Molecular Probes, Eugene, OR) or Cell Proliferation Dye (CPD) eFluor ${ }^{\circledast}$ 670 (eBioscience, San Diego, CA) for 15 minutes at $37^{\circ} \mathrm{C}$. Cells were washed with cold 1X PBS containing $10 \% \mathrm{FBS}$, and then cultured in IMDM containing $10 \% \mathrm{FBS}$, pretested minimal concentrations of IL-3 and SCF, and 1X antibiotic/antimycotic solution. A portion of cells stained with either CFSE or CPD eFluor ${ }^{\circledR} 670$ were cultured with demecolcine solution (Sigma, St. Louis, MO) to serve as a positive control for quiescence. Cells were recovered, washed, resuspended in warm 1X PBS plus 1\% BSA and stained with fluorochrome-conjugated cell surface receptors: rat anti-mouse APC- or PerCP-Cy ${ }^{\mathrm{TM}}$ 5.5-conjugated lineage antibody cocktail, PerCP-Cy ${ }^{\mathrm{TM}} 5.5$ - or PE-conjugated $\mathrm{CD} 117$ (c-Kit), and PE-Cy ${ }^{\mathrm{TM}} 7$-conjugated Ly-6A/E (Sca-1) for 30 minutes in $37^{\circ} \mathrm{C}$ (BD PharMingen, San Diego, CA). Following cell surface receptor staining, assays for detecting phosphotyrosine levels, ROS (described above), and 8-oxoG in $\mathrm{CFSE}^{\max }$ or CPD eFluor ${ }^{\circledast} 670^{\max }$ Lin $^{-}$c-Kit ${ }^{+}$Sca- $1^{+}$cells were conducted and analyzed by FACS.

\section{Phosphotyrosine}

Cells were washed with warm 1X PBS, then resuspended and fixed in BD Cytofix/Cytoperm ${ }^{\mathrm{TM}}$ solution for 15 minutes at RT. Cells were washed once with BD Perm/Wash ${ }^{\mathrm{TM}}$ buffer and then resuspended and permeabilized in fresh BD Perm/Wash ${ }^{\mathrm{TM}}$ for 15 minutes at RT. Cells were washed once with BD Perm/Wash ${ }^{\mathrm{TM}}$ then resuspended in fresh BD Perm/Wash ${ }^{\mathrm{TM}}$ containing phosphotyrosine antibody for 30 minutes at RT. Cells were washed once with, then resuspended in fresh, cold 1X PBS for FACS analysis. 


\section{8-oxoG}

Cells were washed with warm $1 \mathrm{X}$ PBS, then resuspended and fixed in $4 \%$ PFA in 1X PBS for 10 minutes at RT. Cells were washed once with $1 \mathrm{X}$ wash concentrate and then resuspended and permeabilized in $0.2 \%$ Tween in $1 \mathrm{X}$ PBS for 10 minutes at RT. Cells were washed once with $1 \mathrm{X}$ wash concentrate then resuspended in $1 \mathrm{X}$ wash concentrate containing FITC-conjugated 8-oxoguanine antibody (Biotrin, Dublin, Ireland) for 1 hour at RT. Cells were washed once with, then resuspended in fresh, cold 1X PBS for FACS analysis.

\section{In vivo imatinib mesylate (IM) treatment}

In vivo IM treatment of transplanted recipient mice was conducted by Mirle Schemionek (University of Aachen, Germany), as described previously [210]. IM treatment was performed starting 4 weeks after transplantation, over a 4-week period. IM (LC Laboratories) was dissolved in water and applied by oral gavage, using $100 \mathrm{mg} / \mathrm{kg}$ body weight twice daily.

\section{Detection of BCR-ABL kinase domain mutations}

Total BM or SPL cells were extracted from non-induced and induced SCLtTA/BCR-ABL mice, and subjected to density separation to remove erythrocytes by using Lympholyte M (Cedarlane, Hornby, Canada). Cells were stained with rat antimouse APC-conjugated lineage antibody cocktail (BD PharMingen, San Diego, CA) and sorted for Lin ${ }^{-}$cells within 24 hours. For D-HPLC and ASO-PCR, Lin ${ }^{-}$BMCs were washed once with 1XPBS then resuspended/shredded in $1 \mathrm{~mL}$ TRIzol ${ }^{\circledR}$ reagent (Invitrogen) by repetitive pipetting with syringe and $20 \mathrm{G}$ needle to extract total RNA, which was then frozen at $-20^{\circ} \mathrm{C}$. 


\section{Denaturing high performance liquid chromatography (D-HPLC)}

D-HPLC was conducted by Martin Mueller (Medical Faculty of Mannheim, Heidelberg University, Mannheim, Germany), as described previously [211]. Briefly, cDNA was synthesized from total RNA with random hexamer primers and reverse transcriptase, from which three overlapping fragments spanning the entire BCR-ABL KD were amplified by nested PCR and analyzed by D-HPLC followed by bidirectional sequencing to characterize BCR-ABL KD mutations.

\section{Allele-specific oligonucleotide ligation-polymerase chain reaction (ASOL-PCR)}

ASOL-PCR was conducted by Thoralf Lange and Jacqueline Maier (University of Leipzig, Germany), as described previously [212-214]. cDNA was synthesized from total RNA with random hexamer primers and reverse transcriptase, from which BCR-ABL sequences were amplified by PCR, and then followed by stringent high temperature hybridization to the PCR product of 2 probes which span one mutation region of interest. Each probe consists of an ABL-hybridizing sequence flanked by a PCR primer-binding site, whereas only the first probe carries the point mutation at its $3^{\prime}$ end while the $5^{\prime}$ end of the second probe corresponds to the neighboring base. A high temperature ligation reaction joins the 2 probes only when there is no mismatch at the mutation site. The yield of the ligated probe is determined by real-time PCR using primers complementary to the primer binding sites at the non-ligated ends of the two probes. PCR amplifications for 5 of the most common BCR-ABL KD mutations (G250E, Y253H, E255K, T315I, F359V) were performed using individual allele-specific $3^{\prime}$ primers complementary to the respective mutations on $A B L$. 


\section{Selection and sequencing of IM-resistant colonies}

Lin $^{-} \mathrm{BM}$ or SPL cells were cultured in IMDM supplemented with $10 \%$ FBS and $1 \%$ antibiotic/antimycotic solution containing $1 \mu \mathrm{M}$ IM for 7 days. Viable cells were then plated in semisolid methylcellulose medium in the absence of growth factors and in the presence of $1 \mu \mathrm{M}$ IM for another 7 days to allow colony formation of individual IMresistant clones. IM-resistant single colonies were selected then expanded in vitro in IMDM supplemented with 10\% FBS, $1 \mathrm{X}$ antibiotic/antimycotic solution and ideal concentrations of IL-3 and SCF required to stimulate proliferation. As described previously [184], total RNA was extracted and reverse transcribed into cDNA using random hexamers and MMLV transcriptase. cDNA was amplified using primers specific for the human c-ABL KD (forward: 5'-CGCAACAAGCCCACTGTC-3'; reverse: 5'TCCACTTCGTCTGAGATACTGGATT-3'). Amplified fragments were sequenced at University of Pennsylvania using the c-ABL KD reverse primer.

\section{High density single nucleotide polymorphism (SNP) array}

BMCs from transgenic mice were flushed from tibias, femurs, and humeri with culture medium and subjected to density separation by Lympholyte M (Cedarlane, Hornby, Canada) to remove erythrocytes. High molecular weight (HMW) genomic DNA (gDNA) was extracted from FACS-sorted $\mathrm{Lin}^{-} \mathrm{BMCs}$ or total BMCs and/or SPL using DNeasy Tissue Kit (Qiagen, Maryland) according to manufacturer's protocol, and resuspended in $75 \mu \mathrm{Ls} 2 \mathrm{mM}$ Tris $\cdot \mathrm{Cl}, 0.1 \mathrm{mM}$ EDTA buffer. 250ngs of HMW gDNA was run against a lambda DNA marker on a $0.5 \%$ agarose gel containing ethidium bromide and visualized using the Gel Doc ${ }^{\mathrm{TM}} \mathrm{XR}+$ Molecular Imager ${ }^{\circledR}$ System (Bio-Rad, Hercules, CA). The quantity and quality of HMW gDNA was assessed using the ND-1000 
spectrophotometer (NanoDrop $^{\circledR}$, Wilmington, DE). 3-5 $\mu$ gs of HMW gDNA for application to Affymetrix GeneChips was processed at the Jackson Laboratory (Bar Harbor, Maine) to compare mouse DNA samples, as described [215]. The specific GeneChips used are capable of detecting polymorphisms in 623,124 well-characterized mouse SNPs. SNP calls were based on the C57BL/6J background and generated using the BRLMM-P algorithm. Annotated data were analyzed by Hans-Ulrich Klein (University of Muenster, Germany).

\section{Microarray Analysis of hematopoietic stem cells (HSCs)}

Microarray was conducted by Mirle Schemionek (University of Aachen, Germany), as described previously [210], and analyzed by Hans-Ulrich Klein (University of Muenster, Germany). BM-derived cells were isolated from 3 induced SCLtTA/BCRABL mice and 3 non-induced mice for controls. 5000 Lin $^{-} \mathrm{c}-\mathrm{Kit}^{+} \mathrm{Sca}-1^{+}$stem cells were FACS-sorted directly into RNA extraction buffer. After addition of carrier RNA, RNA was DNAse-treated, extracted, and frozen at $-80^{\circ} \mathrm{C}$. Linear amplification of less than 20 ng of total RNA was conducted [216]. The yield of biotinylated cRNA from purified stem cells of each mouse ranged between 15 and $25 \mu \mathrm{g}$. A total of $15 \mu \mathrm{g}$ of the biotinylated cRNA was hybridized to Affymetrix Mouse Genome 4302.0 GeneChips covering approximately 45,000 transcripts. After hybridization at $45^{\circ} \mathrm{C}$ for 16 hours, the GeneChips were analyzed using an Affymetrix GeneChip ${ }^{\circledR}$ Scanner 3000. Individual genes were analyzed using the MicroArraySuite 5.0 software for calculation of the presence or absence of calls and the D-chip Software. 361 genes were changed at least 1.5 -fold $(P<0.05$ according to Mann-Whitney test) in expression when induced mice were compared to non-induced mice. For evaluating the functional significance of altered 
gene expression, a pathway analysis was performed, using Ingenuity Pathway Analysis software 7.0 (IPA, Ingenuity Systems).

\section{Human $\mathrm{CD34}^{+}$cells}

$\mathrm{CD} 34^{+}$fractions of human bone marrow cells (BMCs) obtained from healthy donors were infected with pMIG-GFP retroviral construct containing empty vector (MIG R1), p210BCR-ABL (MIG 210), or p210BCR-ABL(K1172R) (MIG KD) cDNA by Hardik Modi (City of Hope National Medical Center, Duarte, CA), as described previously [217], and were generously provided by Ravi Bhatia (City of Hope National Medical Center, Duarte, CA). Cells were maintained in IMDM (Mediatech, Manassas, VA) containing 10\% FBS (Gibco, Grand Island, NY), 1X antibiotic-antimycotic solution (Mediatech, Manassas, VA), and pretested minimal concentrations of SCF and granulocyte macrophage-colony stimulating factor (GM-CSF) required to maintain viability and proliferation, and incubated in $5 \% \mathrm{CO}_{2}$ and $37^{\circ} \mathrm{C} .48$ hours later the $15 \%$ lowest and highest GFP-expressing cells, or total GFP-positive cells were either unsorted and analyzed for ROS levels by FACS (described above), or FACS-sorted into the $20 \%$ lowest and highest GFP-expressing cells, or total GFP-positive cells, then analyzed by Western blot and for oxidative DNA damage by immunofluorescence (described above).

\section{Western blotting}

Cells were washed with cold $1 \mathrm{X}$ PBS and resuspended in 1X sodium dodecyl sulfate (SDS) buffer with $\beta$-mercaptoethanol. Samples were boiled for 2-3 minutes and then sonicated for 10-15 seconds. Proteins were separated by electrophoresis on a $9.0 \%$ SDS-polyacrylamide gel, transferred to a nitrocellulose membrane, and probed with 
monoclonal 1:200 anti-c-Abl (Ab-3) (Calbiochem, Gibbstown, NJ), 1:1000 antiphosphotyrosine, clone 4G10 (Upstate, Temecula, CA), 1:2000 anti- $\beta$-Actin (Abcam, Cambridge, MA), and polyclonal 1:500 anti-GFP (FL) (Santa Cruz, Santa Cruz, CA) primary antibodies. Monoclonal antibodies were countered with IRDye ${ }^{\circledR} 800 \mathrm{CW}$ goat anti-mouse IgG secondary antibody, whereas polyclonal antibodies were countered with $\operatorname{IRDye}^{\circledast} 680$ donkey anti-rabbit IgG secondary antibody $(1: 10,000)$. Blots were analyzed with the Odyssey Infrared Imaging System (Li-Cor, Lincoln, NE).

\section{Statistical analysis}

Data are expressed as mean \pm standard deviation (SD). Statistical analyses were performed using the unpaired Student $t$ test or Mann-Whitney $\mathrm{U}$ test; $P$ values equal to or less than 0.05 were considered significant. 


\section{CHAPTER 3}

\section{RESULTS}

\section{CML-CP Lin c-Kit ${ }^{+}$Sca-1 ${ }^{+}$LSCs, including the quiescent population, display elevated levels of ROS and oxidative DNA damage that persist even during IM- inhibition of BCR-ABL kinase}

Koschmieder et al. previously showed that up to $31 \%$ of induced SCLtTA/BCR-

ABL mice exhibited a mixed myeloid/lymphoid disease phenotype suggestive of progression to lymphoid blast crisis [206]. Since we were interested in examining how hematopoietic cell subpopulations display levels of ROS and oxidative DNA damage during CML-CP, and how these levels translate into genomic instability, we utilized mice expressing CML-CP disease phenotype only.

qRT-PCR from the BM $(6.296 \pm 1.647)$ and SPL $(4.602 \pm 1.512)$ of induced SCLtTA/BCR-ABL mice displayed BCR-ABL mRNA expression, whereas BCR-ABL mRNA expression from the BM $(0.000260 \pm 0.000230, \mathrm{p}=0.003)$ and $\operatorname{SPL}(0 \pm 0$, $\mathrm{p}=0.006$ ) of non-induced mice was either nearly undetectable or not detectable (N.D.); results are representative of 2 experiments from 3 mice per group (Figure 1A, left panel). qRT-PCR from Lin ${ }^{-} \mathrm{c}-\mathrm{Kit}^{+} \mathrm{Sca}-1^{+}$stem $(0.146 \pm 0.0365)$ and $\mathrm{Lin}^{-} \mathrm{c}-\mathrm{Kit}^{+} \mathrm{Sca}-1^{-}$progenitor $(0.0203 \pm 0.00402)$ cells of induced SCLtTA/BCR-ABL mice displayed BCR-ABL mRNA expression, whereas BCR-ABL mRNA expression from $\mathrm{Lin}^{-}{ }^{-}-\mathrm{Kit}^{+} \mathrm{Sca}-\mathrm{1}^{+}$stem $(0$ $\pm 0, \mathrm{p}=0.002)$ and Lin $^{-} \mathrm{c}-\mathrm{Kit}^{+} \mathrm{Sca}-1^{-}$progenitor $(0.000453 \pm 0.000785, \mathrm{p}=0.001)$ cells of non-induced mice was either N.D. or nearly undetectable (Figure 1A, right panel). Furthermore, Lin $^{-} \mathrm{c}-\mathrm{Kit}{ }^{+} \mathrm{Sca}-1^{+}$leukemia stem cells (LSCs) displayed significantly higher levels of BCR-ABL mRNA expression compared to $\mathrm{Lin}^{-} \mathrm{c}-\mathrm{Kit}^{+} \mathrm{Sca}^{-1}{ }^{-}$leukemia progenitor cells (LPCs) from induced SCLtTA/BCR-ABL mice $(\mathrm{p}=0.004)$, thereby 
mimicking a feature of human CML-CP which is characterized by elevated BCR-ABL mRNA expression in $\mathrm{Lin}^{-\mathrm{CD}} 34^{+} \mathrm{CD} 38^{-}$LSCs compared to $\mathrm{Lin}^{-} \mathrm{CD} 34^{+} \mathrm{CD} 38^{+}$LPCs [218]. Additionally, elevated BCR-ABL transcripts in human CML-CP stem cells are independent of $b c r-a b l$ gene amplification, a phenomenon often associated with disease progression and prolonged exposure to IM [77, 200, 201, 219, 220]. However, we did not determine $b c r-a b l$ gene copy number in induced SCLtTA/BCR-ABL mice, so we cannot exclude the possibility that elevated transcript levels may be due to multiple copies of the BCR-ABL transgenes.

Induced SCLtTA/BCR-ABL mice displayed splenomegaly (264.864 mgs \pm 101.633) compared to non-induced mice (124.551 mgs $\pm 23.918, \mathrm{p}<0.001)$ (Figure 1B). Induced SCLtTA/BCR-ABL mice displayed expansion of mature $\mathrm{Gr}^{+} / \mathrm{CD} 11 \mathrm{~b}^{+}(53.190$ $\pm 8.111)$ and immature $\mathrm{Gr} 1^{\text {low }} / \mathrm{CD}_{1} 1 \mathrm{~b}^{+}(27.253 \pm 4.491)$ granulocytes, and a decrease of B220 ${ }^{+} \mathrm{B}$ cells $(1.957 \pm 0.232)$ and Ter $119^{+}$erythrocytes $(9.873 \pm 3.048)$ in the BM, compared to non-induced mice $\left(\mathrm{Gr}^{+} / \mathrm{CD} 11 \mathrm{~b}^{+}: 30.230 \pm 0.721, \mathrm{p}=0.008 ; \mathrm{Gr} 1^{\text {low }} / \mathrm{CD} 11 \mathrm{~b}^{+}\right.$: $8.443 \pm 0.595, \mathrm{p}=0.002 ; \mathrm{B} 220^{+}: 18.190 \pm 2.183, \mathrm{p}<0.001 ;$ Ter1 $19^{+}: 34.883 \pm 0.889$ $\mathrm{p}<0.001$ ) (Figure 1C, left panel). Induced SCLtTA/BCR-ABL mice displayed expansion of mature $\mathrm{Gr}^{+} / \mathrm{CD} 11 \mathrm{~b}^{+}(13.510 \pm 2.701)$ and immature $\mathrm{Gr} 1^{\text {low }} / \mathrm{CD} 11 \mathrm{~b}^{+}(7.537 \pm 2.189)$ granulocytes, Ter $119^{+}$erythrocytes $(34.307 \pm 8.774)$, and $\mathrm{CD} 41^{+}$megakaryocytes $(9.777$ $\pm 2.673)$, and a decrease of $\mathrm{B} 220^{+} \mathrm{B}$ cells $(23.040 \pm 10.718)$ in the SPL, compared to non-induced mice $\left(\mathrm{Gr}^{+} / \mathrm{CD} 11 \mathrm{~b}^{+}: 2.2 \pm 0.111, \mathrm{p}=0.002 ; \mathrm{Gr} 1^{\mathrm{low}} / \mathrm{CD} 11 \mathrm{~b}^{+}: 1.207 \pm 0.384\right.$, $\mathrm{p}=0.008 ; \operatorname{Ter} 119^{+}: 8.260 \pm 2.1, \mathrm{p}=0.007 ; \mathrm{CD}^{+} 1^{+}: 2.410 \pm 0.145, \mathrm{p}=0.009 ; \mathrm{B} 220^{+}: 44.267$ $\pm 6.305, \mathrm{p}=0.042$ ) (Figure 1C, center panel). Induced SCLtTA/BCR-ABL mice displayed expansion of mature $\mathrm{Gr}^{+} / \mathrm{CD} 11 \mathrm{~b}^{+}(29.533 \pm 4.141)$ granulocytes and $\mathrm{CD} 41^{+}$ 

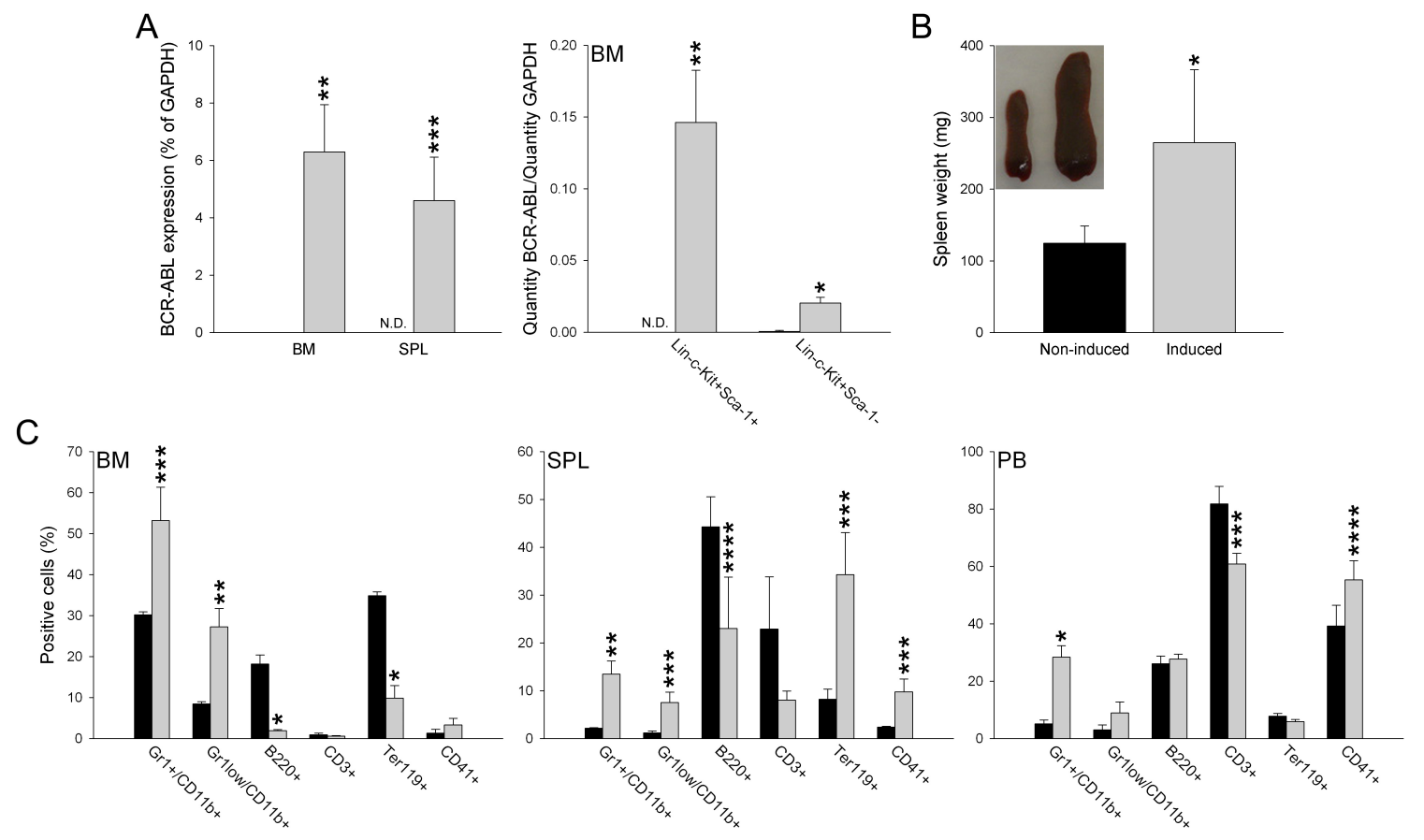

Figure 1. Induced SCLtTA/BCR-ABL transgenic mice exhibit a CML-CP-like disease phenotype. (A) BCR-ABL mRNA expression relative to the housekeeping gene GAPDH in non-induced (black bars) and induced (gray bars) mice by qRT-PCR ; $=3$ mice per group, N.D.=not detected. left panel: $\mathrm{BCR}-\mathrm{ABL}$ mRNA expression from bone marrow (BM) and spleen (SPL) cells; right panel: BCR-ABL mRNA expression in BMderived Lin ${ }^{-}-\mathrm{Kit}^{+} \mathrm{Sca}-1^{+}$stem and Lin ${ }^{-} \mathrm{c}-\mathrm{Kit}^{+} \mathrm{Sca}-1^{-}$progenitor cells. (B) Spleen weight in non-induced $(\mathrm{n}=58)$ and induced $(\mathrm{n}=55)$ mice; inset: representative spleens. (C) Percentage of mature $\left(\mathrm{Gr}^{+} / \mathrm{Mac}^{+} 1^{+}\right)$and immature $\left(\mathrm{Gr} 1^{\text {low }} / \mathrm{Mac}^{-} 1^{+}\right)$granulocytes, B cells $\left(\mathrm{B} 220^{+}\right)$, T cells $\left(\mathrm{CD}^{+}\right)$, erythrocytes $\left(\right.$Ter119 $\left.{ }^{+}\right)$and megakaryocytes $\left(\mathrm{CD} 41^{+}\right)$in $\mathrm{BM}$ (left panel), SPL (center panel) and peripheral blood ( $\mathrm{PB}$ (right panel) from non-induced (black bars) and induced mice (gray bars), as measured by FACS analysis; $n=3$ mice per group. Data are expressed as mean \pm standard deviation (SD). ${ }^{*} \mathrm{p} \leq 0.001,{ }^{* *} \mathrm{p} \leq 0.005$, ${ }^{* * *} \mathrm{p} \leq 0.01,{ }^{* * * *} \mathrm{p} \leq 0.05$ in comparison to non-induced counterparts. 
megakaryocytes $(55.367 \pm 6.646)$, and a decrease of $\mathrm{CD}^{+} \mathrm{T}$ cells $(60.867 \pm 3.710)$ in the $\mathrm{PB}$, compared to non-induced mice $\left(\mathrm{Gr} 1^{+} / \mathrm{CD} 11 \mathrm{~b}^{+}: 5.3 \pm 1.442, \mathrm{p}<0.001 ; \mathrm{CD} 41^{+}: 39.267\right.$ $\pm 7.222, \mathrm{p}=0.047 ; \mathrm{CD}^{+}: 81.8 \pm 6.083, \mathrm{p}=0.007$ ) (Figure $1 \mathrm{C}$, right panel). As expected, differences in Ter $119^{+}$erythrocytes from PB were not detected among non-induced and induced mice due to the experimental application of ACK lysis buffer, which also may have resulted in overall increased percentages of the other cell types detected in both groups.

BCR-ABL tyrosine kinase is associated with elevated levels of ROS and oxidative DNA damage in both murine and human BCR-ABL-transformed cell lines in comparison to non-transformed cell lines [160, 182, 184]; similarly, both ROS and oxidative DNA damage are elevated in primary CML-CP and CML-BP cells in comparison to counterparts from healthy donors [184]. Most recently, NieborowskaSkorska et al. published that ROS and oxidative DNA damage are elevated in human $\mathrm{CD}^{+} 4^{+}$progenitor cell-enriched and $\mathrm{CD} 34^{+} \mathrm{CD} 38^{-}$stem cell-enriched populations of CML-CP patient cells in comparison to counterparts from healthy donors [221].

To determine the effects of BCR-ABL expression on ROS in murine BM-derived

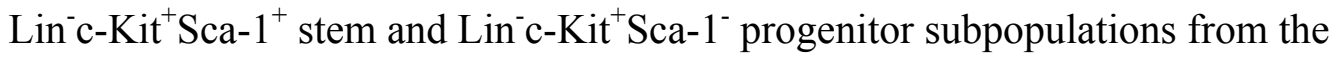
SCLtTA/BCR-ABL mouse model of CML-CP we applied the redox-sensitive fluorochrome dichlorofluorescein diacetate (DCFDA) to detect $\mathrm{H}_{2} \mathrm{O}_{2} / \bullet \mathrm{OH}$ and analyzed cells by FACS (Figure 2A). Lin $^{-} \mathrm{c}-\mathrm{Kit}^{+} \mathrm{Sca}-1^{+}$LSCs from induced SCLtTA/BCR-ABL mice displayed elevated levels of $\mathrm{H}_{2} \mathrm{O}_{2} / \bullet \mathrm{OH}(59,550 \pm 7,030)$ compared to non-induced Lin $^{-} \mathrm{c}-\mathrm{Kit}^{+} \mathrm{Sca}-1^{+}$stem cells $(47,150 \pm 1,640 ; \mathrm{p}=0.001)$. Furthermore, Lin $^{-} \mathrm{c}-\mathrm{Kit}^{+} \mathrm{Sca}-1^{+}$ LSCs from induced mice displayed elevated levels of $\mathrm{H}_{2} \mathrm{O}_{2} / \bullet \mathrm{OH}$ compared to induced 
Lin $^{-}{ }^{-}-\mathrm{Kit}^{+}{ }^{+} \mathrm{Sca}-1^{-}{ }^{-}$LPCs $(35,590 \pm 14,640 ; \mathrm{p}=0.026)$. Non-induced Lin ${ }^{-} \mathrm{c}-\mathrm{Kit}^{+} \mathrm{Sca}-1^{+}$stem cells also displayed elevated levels of $\mathrm{H}_{2} \mathrm{O}_{2} / \bullet \mathrm{OH}$ compared to non-induced Lin'c$\mathrm{Kit}^{+} \mathrm{Sca}-1^{-}$progenitor cells $(32,240 \pm 4,120 ; \mathrm{p}<0.001)$, which suggests that non-induced stem cells inherently harbor greater ROS levels than non-induced progenitor cells. Unlike the aforementioned recent finding that ROS are elevated in the human $\mathrm{CD} 34^{+}$progenitor cell-enriched population of CML-CP patient cells in comparison to counterparts from healthy donors [221], induced $\mathrm{Lin}^{-} \mathrm{c}-\mathrm{Kit}^{+} \mathrm{Sca}-1^{-} \mathrm{LPCs}$ failed to significantly elevate ROS levels above non-induced Lin ${ }^{-} \mathrm{c}-\mathrm{Kit}^{+} \mathrm{Sca}-{ }^{-}{ }^{-}$progenitor cells, perhaps due to sub-threshold levels of BCR-ABL expression; therefore, further experiments on this subpopulation were deemed unnecessary.

To determine the effects of BCR-ABL expression on oxidative DNA damage in murine hematopoietic Lin ${ }^{-} \mathrm{c}-\mathrm{Kit}{ }^{+} \mathrm{Sca}-1^{+}$stem cells from the SCLtTA/BCR-ABL mouse model of CML-CP we quantified nuclear staining of antibodies against 8-oxoguanine (8oxoG) to detect oxidative lesions and histone $\gamma-\mathrm{H} 2 \mathrm{AX}$ to detect DSBs (Figure 2B). Lin ${ }^{-} \mathrm{c}-$ $\mathrm{Kit}^{+} \mathrm{Sca}-1^{+}$LSCs from induced SCLtTA/BCR-ABL mice displayed elevated levels of 8oxoG $(2.222 \pm 2.064)$ compared to non-induced Lin $^{-} \mathrm{c}-\mathrm{Kit}^{+} \mathrm{Sca}-1^{+}$stem cells $(1.693 \pm$ 1.354, $\mathrm{p}=0.011$ ) (Figure 2B, left panel). Similarly, Lin ${ }^{-c}-\mathrm{Kit}^{+} \mathrm{Sca}-1^{+} \mathrm{LSCs}$ from induced mice displayed elevated levels of $\gamma$-H2AX foci $(14.355 \pm 8.974)$ compared to noninduced Lin ${ }^{-} \mathrm{-}-\mathrm{Kit}^{+} \mathrm{Sca}-1^{+}$stem cells $(10.611 \pm 6.466 ; \mathrm{p}<0.001)$ (Figure 2B, right panel). A wide range of 8-oxoG lesions and DSBs were detected in both non-induced and induced $\mathrm{Lin}^{-} \mathrm{c}-\mathrm{Kit}^{+} \mathrm{Sca}-\mathrm{1}^{+}$stem cells, leading to overlapping standard deviations (S.D.) among these two groups; however, the number of DSBs depend on cell cycle stage with the lowest number detected in $\mathrm{G}_{0} / \mathrm{G}_{1}$ and the highest number detected $\mathrm{S}$ and $\mathrm{G}_{2} / \mathrm{M}$ [182]. 
Regardless, due to the large number of cells analyzed per group and the consistently higher levels of oxidative DNA damage detected in induced $\mathrm{Lin}^{-} \mathrm{c}-\mathrm{Kit}^{+} \mathrm{Sca}-{ }^{+} \mathrm{LSCs}^{\mathrm{a}}$ significant trend was detected.
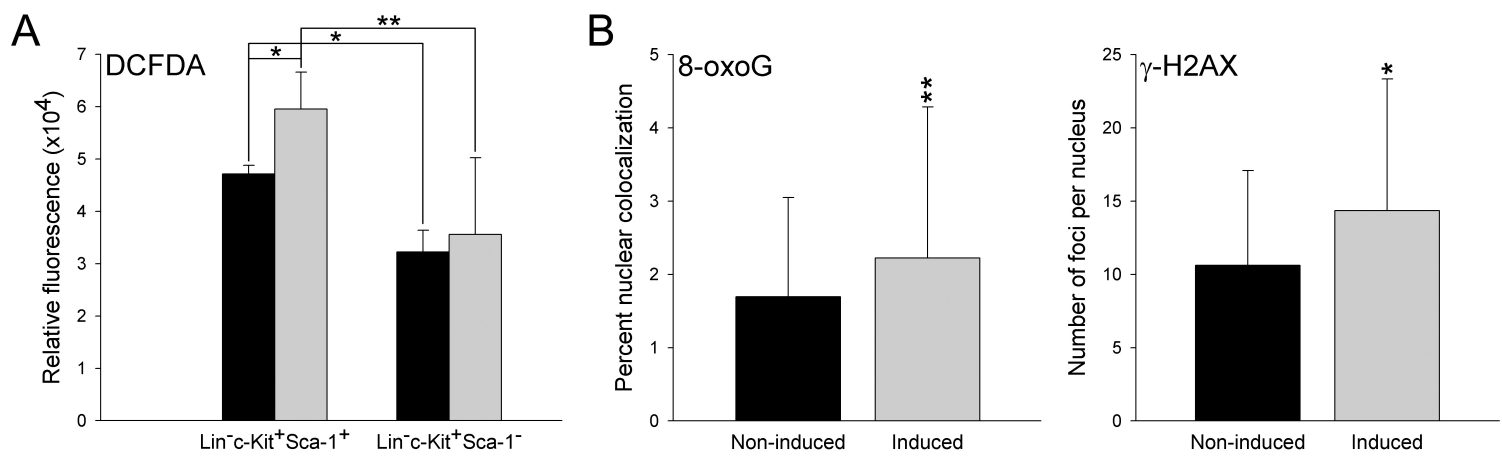

Figure 2. Linc-Kit $^{+}{ }^{-} \mathrm{Sca}^{+}{ }^{+}$LSCs from induced SCLtTA/BCR-ABL transgenic mice display elevated levels of $\mathbf{R O S}$ and oxidative DNA damage. (A) $\mathrm{H}_{2} \mathrm{O}_{2} / \bullet \mathrm{OH}$ were detected in BM-derived Lin ${ }^{-} \mathrm{c}-\mathrm{Kit}^{+} \mathrm{Sca}-{ }^{+}{ }^{+}$stem and $\mathrm{Lin}^{-} \mathrm{c}-\mathrm{Kit}^{+} \mathrm{Sca}-1^{-}$progenitor cells from non-induced (black bars, $n=7$ ) and induced (gray bars, $n=4$ ) mice with DCFDA and analyzed by FACS. (B) left panel: 8 -oxoG $(n=163$ cells from 5 non-induced mice, $n=110$ cells from 4 induced mice) and right panel: $\gamma-\mathrm{H} 2 \mathrm{AX}$ ( $\mathrm{n}=162$ non-induced and $\mathrm{n}=279$ induced cells possessing $\geq 5$ foci each; $n=4$ mice per group) were detected by immunofluorescence in DAPI-counterstained nuclei of BM-derived Lin ${ }^{-} \mathrm{c}-\mathrm{Kit}^{+} \mathrm{Sca}-1^{+}$ stem cells. Data are expressed as mean \pm standard deviation (SD). ${ }^{*} p \leq 0.001,{ }^{*} p \leq 0.05$ in comparison to non-induced counterparts.

Nieborowska-Skorska et al. recently published that ROS and oxidative DNA damage are elevated in the quiescent $\mathrm{CD}^{+} 4^{+}$progenitor cell-enriched population of CMLCP patient cells in comparison to counterparts from healthy donors [221]. To determine the effects of BCR-ABL expression on ROS in murine BM-derived quiescent Lin ${ }^{-c}-$ $\mathrm{Kit}^{+} \mathrm{Sca}-1^{+}$stem cells from the SCLtTA/BCR-ABL mouse model of CML-CP we applied the redox-sensitive fluorochromes dihydroethidium (DHE) and Redox Sensor CC-1 (CC1) to detect cellular $\bullet \mathrm{O}_{2}{ }^{-}$and $\bullet \mathrm{O}_{2}{ }^{-} / \mathrm{H}_{2} \mathrm{O}_{2}$, respectively, in CFSE ${ }^{\text {max }}$ cells and analyzed cells by FACS (Figure 3A). CFSE ${ }^{\max } \mathrm{Lin}^{-} \mathrm{c}-\mathrm{Kit}^{+} \mathrm{Sca}-1^{+} \mathrm{LSC}$ from induced SCLtTA/BCRABL mice displayed elevated levels of cellular $\bullet \mathrm{O}_{2}^{-}(7,636 \pm 2,187)$ compared to 
$\mathrm{CFSE}^{\max } \mathrm{Lin}^{-} \mathrm{c}-\mathrm{Kit}^{+} \mathrm{Sca}-1^{+}$stem cells from non-induced mice $(3,079 \pm 520 ; \mathrm{p}<0.001)$

(Figure 3A, left panel). Similarly, $\mathrm{CFSE}^{\mathrm{max}} \mathrm{Lin}^{-} \mathrm{c}-\mathrm{Kit}^{+} \mathrm{Sca}-1^{+} \mathrm{LSCs}$ from induced mice displayed elevated levels of $\bullet \mathrm{O}_{2}{ }^{-} / \mathrm{H}_{2} \mathrm{O}_{2}(7,269 \pm 1,563)$ compared to $\mathrm{CFSE}^{\mathrm{max}} \mathrm{Lin}^{-} \mathrm{c}$ $\mathrm{Kit}^{+} \mathrm{Sca}-1^{+}$stem cells from non-induced mice $(4,409 \pm 868 ; \mathrm{p}=0.026)$ (Figure $3 \mathrm{~A}$, right panel).
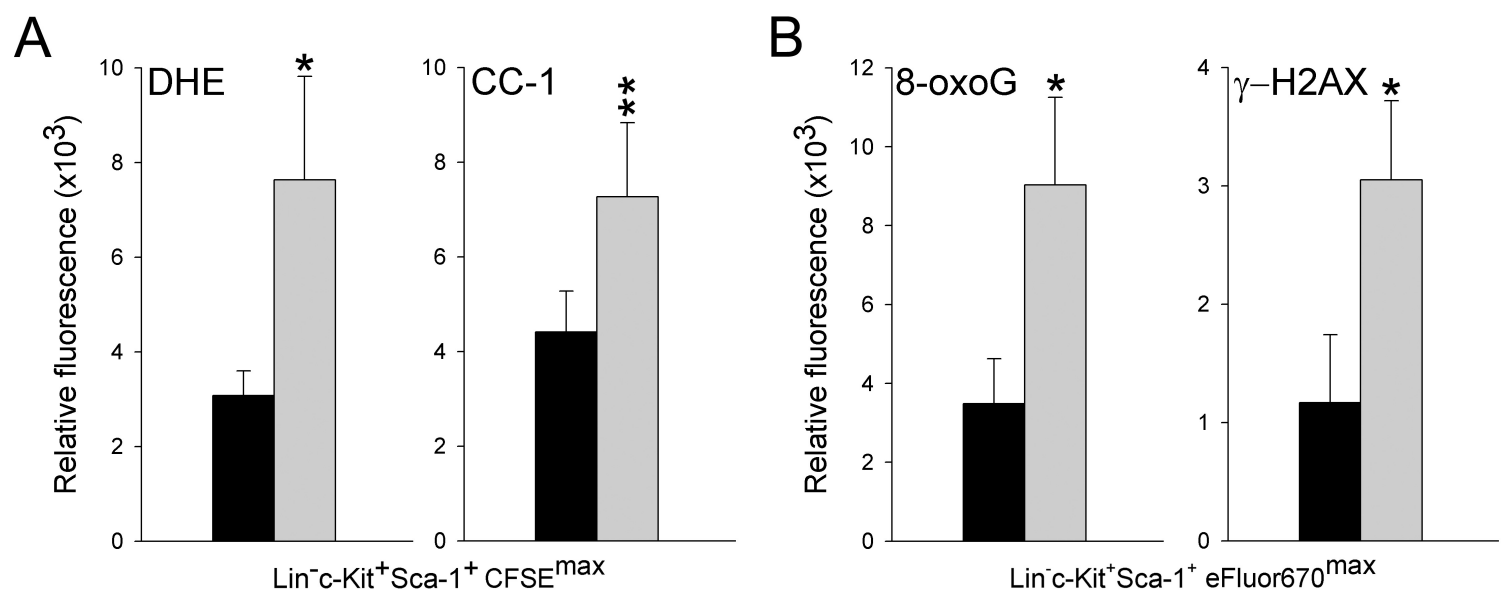

Figure 3. Quiescent Linc-Kit ${ }^{+}$Sca-1 ${ }^{+}$LSCs from induced SCLtTA/BCR-ABL transgenic mice display elevated levels of ROS and oxidative DNA damage. (A) Cellular $\bullet \mathrm{O}_{2}{ }^{-}$and $\bullet \mathrm{O}_{2}{ }^{-} / \mathrm{H}_{2} \mathrm{O}_{2}$ were detected in BM-derived CFSE ${ }^{\max }$ Lin $^{-}{ }^{-}-\mathrm{Kit}^{+} \mathrm{Sca}-1^{+}$ stem cells from non-induced (black bars, $\mathrm{n}=7$ and $\mathrm{n}=4$ mice, respectively) and induced (gray bars, $\mathrm{n}=3$ mice per group) mice with DHE (left panel) and Redox Sensor Red CC-1 (right panel), respectively, and analyzed by FACS. (B) 8-oxoG (left panel) and $\gamma$-H2AX (right panel) were detected in BM-derived CPD eFluor $670^{\text {max }}$ Lin $^{-} \mathrm{c}-\mathrm{Kit}^{+} \mathrm{Sca}-1^{+}$stem cells from non-induced ( $\mathrm{n}=5$ mice per group) and induced ( $\mathrm{n}=5$ and $\mathrm{n}=6$ mice, respectively) mice, and analyzed by FACS. Data are expressed as mean \pm standard deviation (SD). ${ }^{*} p \leq 0.001,{ }^{* *} \mathrm{p} \leq 0.05$ in comparison to non-induced counterparts.

To determine the effects of BCR-ABL expression on oxidative DNA damage in murine BM-derived quiescent Lin $^{-} \mathrm{c}^{-\mathrm{Kit}^{+}} \mathrm{Sca}_{-1}{ }^{+}$stem cells from the SCLtTA/BCR-ABL mouse model of CML-CP we detected fluorochrome-conjugated anti-8-oxoG and antihistone $\gamma-\mathrm{H} 2 \mathrm{AX}$ antibodies, respectively, in CPD eFluor $670^{\max }$ cells and analyzed cells by FACS (Figure 3B). CPD eFluor $670^{\max } \mathrm{Lin}^{-} \mathrm{c}-\mathrm{Kit}^{+} \mathrm{Sca}-1^{+} \mathrm{LSCs}$ from induced 
SCLtTA/BCR-ABL mice displayed elevated levels of 8-oxoG $(9,036 \pm 2,219)$ compared to $\mathrm{CPD}$ eFluor $670^{\max } \mathrm{Lin}^{-} \mathrm{c}-\mathrm{Kit}^{+} \mathrm{Sca}-1^{+}$stem cells from non-induced mice $(3,490 \pm 1,133$; $\mathrm{p}=0.001$ ) (Figure 3B, left panel). Similarly, CPD eFluor $670^{\max }$ Lin $^{-} \mathrm{c}-\mathrm{Kit}^{+} \mathrm{Sca}-1^{+} \mathrm{LSCs}$ from induced mice displayed elevated levels of $\gamma$-H2AX foci $(3,052 \pm 666)$ compared to CPD eFluor $670^{\max }$ Lin $^{-} \mathrm{c}-\mathrm{Kit}^{+} \mathrm{Sca}-1^{+}$stem cells from non-induced mice $(1,168 \pm 574$; $\mathrm{p}<0.001$ ) (Figure 3B, right panel).

Although IM eradicates most dividing CML cells, quiescent $\mathrm{CD}_{3} 4^{+}$cells from CML-CP patients are insensitive to IM [56]. To test whether elevated ROS and oxidative DNA damage were underlying insensitivity to IM in BM-derived quiescent Lin`c$\mathrm{Kit}^{+} \mathrm{Sca}-1^{+}$stem cells, we detected ROS and oxidative DNA damage in untreated (-IM) and treated $(+\mathrm{IM})$ cells from both non-induced and induced mice. First, we applied a fluorochrome-conjugated antibody detecting cellular protein tyrosine phosphorylation in CPD eFluor $670^{\max }$ cells to confirm that BCR-ABL kinase activity was inhibited by IM in murine BM-derived quiescent Lin $^{-} \mathrm{c}-\mathrm{Kit}^{+} \mathrm{Sca}-1^{+}$stem cells from the SCLtTA/BCR-ABL mouse model of CML-CP (Figure 4A). As expected, CPD eFluor $670^{\text {max }}$ Lin $^{-} \mathrm{c}-\mathrm{Kit}^{+} \mathrm{Sca}-1^{+}$ LSCs from induced SCLtTA/BCR-ABL mice displayed elevated levels of tyrosine phosphorylation $(5,026 \pm 2,074)$ compared to non-induced CPD eFluor $670^{\text {max }}$ Lin $^{-c}-$ $\mathrm{Kit}^{+} \mathrm{Sca}-1^{+}$stem cells $(1,179 \pm 712 ; \mathrm{p}=0.006)$. Furthermore, IM inhibited tyrosine phosphorylation in CPD eFluor $670^{\text {max }}$ Lin $^{-} \mathrm{c}-\mathrm{Kit}^{+} \mathrm{Sca}-1^{+} \mathrm{LSCs}$ from induced mice $(2,004$ $\pm 473 ; \mathrm{p}=0.003$ compared to induced/untreated CPD eFluor $670^{\max } \mathrm{Lin}^{-} \mathrm{c}-\mathrm{Kit}^{+} \mathrm{Sca}-1^{+}$ LSCs) to levels of non-induced CPD eFluor $670^{\text {max }}$ Lin $^{-} \mathrm{c}-\mathrm{Kit}^{+} \mathrm{Sca}-1^{+}$stem cells treated with IM $(1,222 \pm 744)$. 
To determine the effects of IM-inhibition on ROS in murine BM-derived quiescent Lin ${ }^{-}$-Kit ${ }^{+} \mathrm{Sca}-1^{+}$LSCs from the SCLtTA/BCR-ABL mouse model of CML-CP we applied the redox-sensitive fluorochrome DCFDA to detect $\mathrm{H}_{2} \mathrm{O}_{2} / \bullet \mathrm{OH}$ in CPD eFluor $670^{\max }$ cells (Figure 4B). CPD eFluor $670^{\max }$ Lin $^{-} \mathrm{c}-\mathrm{Kit}^{+} \mathrm{Sca}-1^{+}$LSCs from induced SCLtTA/BCR-ABL mice displayed elevated levels of $\mathrm{H}_{2} \mathrm{O}_{2} / \bullet \mathrm{OH}(12,019 \pm 2,581)$ compared to non-induced CPD eFluor $670^{\text {max }}$ Lin $^{-} \mathrm{c}-\mathrm{Kit}^{+} \mathrm{Sca}-1^{+}$stem cells $(3,465 \pm 533$; $\mathrm{p}<0.001)$. IM significantly inhibited levels of $\mathrm{H}_{2} \mathrm{O}_{2} / \bullet \mathrm{OH}$ in CPD eFluor $670^{\max }$ Linc$\mathrm{Kit}^{+} \mathrm{Sca}-1^{+}$LSCs from induced mice $(5,703 \pm 1,320 ; \mathrm{p}=0.02$ compared to induced/untreated CPD eFluor $670^{\max } \mathrm{Lin}^{-} \mathrm{c}-\mathrm{Kit}^{+} \mathrm{Sca}-1^{+} \mathrm{LSCs}$ ), however, not to levels of
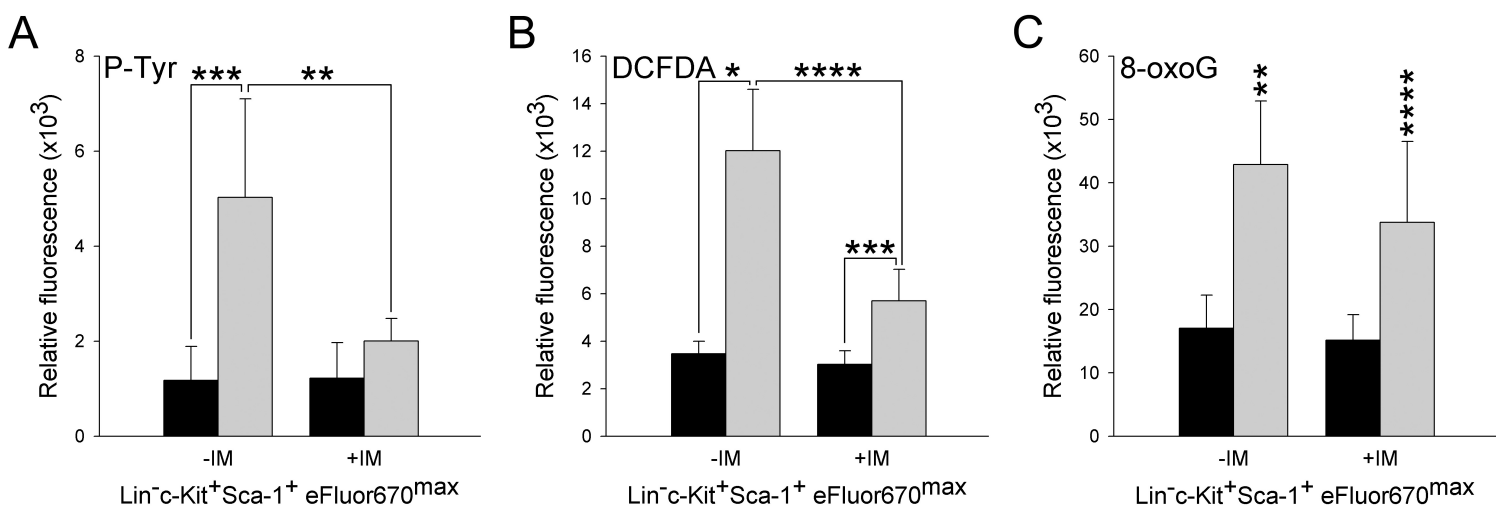

Figure 4. Despite complete inhibition of BCR-ABL kinase, imatinib mesylate (IM) fails to completely inhibit ROS and oxidative DNA damage in quiescent Lin c$\mathrm{Kit}^{+}{ }^{+} \mathrm{Cca}_{-1}^{+}$LSCs from induced SCLtTA/BCR-ABL transgenic mice. Lineagenegative BMCs from non-induced (black bars) and induced (gray bars) mice were untreated (-IM) or treated (+IM) with 2 consecutive doses of $1 \mu \mathrm{M}$ IM. (A) Phosphotyrosine (P-Tyr) was measured in CPD eFluor $670^{\text {max }} \mathrm{Lin}^{-} \mathrm{c}-\mathrm{Kit}^{+} \mathrm{Sca}-1^{+}$cells from non-induced $(n=4)$ and induced $(n=7)$ mice, and analyzed by FACS. (B) $\mathrm{H}_{2} \mathrm{O}_{2} / \bullet \mathrm{OH}$ were detected in CPD eFluor $670^{\max } \mathrm{Lin}^{-} \mathrm{c}^{-\mathrm{Kit}^{+}} \mathrm{Sca}-1^{+}$cells from non-induced $(\mathrm{n}=5)$ and induced $(\mathrm{n}=3)$ mice with DCFDA, and analyzed by FACS. (C) 8-oxoG was measured in CPD eFluor $670^{\max }$ Lin $^{-}$c-Kit ${ }^{+}$Sca- $1^{+}$cells from non-induced $(n=5)$ and induced $(n=4)$ mice, and analyzed by FACS. Data are expressed as mean \pm standard deviation (SD). *p $\leq 0.001, * * \mathrm{p} \leq 0.005, * * * \mathrm{p} \leq 0.01, * * * * \mathrm{p} \leq 0.05$ in comparison to non-induced counterparts. 
non-induced CPD eFluor $670^{\max }$ Lin $^{-}$- $-\mathrm{Kit}^{+} \mathrm{Sca}-1^{+}$cells treated with $\mathrm{IM}(3,027 \pm 572$; $\mathrm{p}=0.006$ )

To determine the effects of IM-inhibition on oxidative DNA damage in murine BM-derived quiescent Lin $^{-} \mathrm{c}-\mathrm{Kit}{ }^{+} \mathrm{Sca}-1^{+}$LSCs from the SCLtTA/BCR-ABL mouse model of CML-CP we applied a fluorochrome-conjugated antibody detecting 8-oxoG in CPD eFluor $670^{\max }$ cells (Figure 4C). In accordance with Figure 3B (left panel), CPD eFluor $670^{\max }$ Lin $^{-} \mathrm{c}-\mathrm{Kit}{ }^{+} \mathrm{Sca}-1^{+}$LSCs from induced SCLtTA/BCR-ABL mice displayed elevated levels of 8-oxoG $(42,870 \pm 10,055)$ compared to non-induced CPD eFluor $670^{\max }$ Lin $^{-1}$ $\mathrm{Kit}^{+} \mathrm{Sca}-1^{+}$stem cells $(17,066 \pm 5,233 ; \mathrm{p}=0.002)$. However, IM failed to significantly inhibit formation of 8-oxoG in CPD eFluor $670^{\text {max }}$ Linc-Kit $^{-}$Sca- $1^{+}$LSCs from induced mice $(33,767 \pm 12,752)$; in fact, post-treatment 8-oxoG levels remained significantly above those of non-induced CPD eFluor $670^{\max } \mathrm{Lin}^{-} \mathrm{c}-\mathrm{Kit}^{+} \mathrm{Sca}-1^{+}$stem cells treated with $\operatorname{IM}(15,175 \pm 4,033 ; \mathrm{p}=0.017)$.

These data show that induced $\mathrm{Lin}{ }^{-} \mathrm{c}-\mathrm{Kit}{ }^{+} \mathrm{Sca}-1^{+}$leukemia stem cells (LSCs), including the quiescent fraction, from the tetracycline-inducible SCLtTA/BCR-ABL transgenic mouse model of CML-CP, display elevated levels of ROS, including superoxide anion radical $\left(\bullet \mathrm{O}_{2}{ }^{-}\right)$, hydrogen peroxide $\left(\mathrm{H}_{2} \mathrm{O}_{2}\right)$ and hydroxyl radical $(\bullet \mathrm{OH})$, and oxidative DNA damage, including 8-oxoguanine and DNA double-strand breaks (DSBs), and that these precursors to genomic instability are not inhibited by treatment with the small molecule tyrosine kinase inhibitor imatinib mesylate (IM). 


\section{Genomic instability originates from CML-CP $\mathrm{Lin}^{-} \mathrm{c}-\mathrm{Kit}^{+} \mathrm{Sca}-1^{+} \mathrm{LSCs}$ and is not prevented by IM-inhibition of BCR-ABL kinase}

Different mechanisms inducing both primary and secondary resistance against the BCR-ABL inhibitor IM have been identified, however, the majority of cases are due to point mutations within the $\mathrm{ABL}$ kinase domain $(\mathrm{KD})$ leading to impaired ability to bind IM $[55,68,69]$. To examine whether or not elevated ROS and oxidative DNA damage in $\mathrm{Lin}^{-} \mathrm{c}-\mathrm{Kit}^{+} \mathrm{Sca}-1^{+}$LSCs from both untreated (-IM) and treated (+IM) induced SCLtTA/BCR-ABL mice resulted in genomic instability manifested by point mutations in the BCR-ABL KD, we employed three increasingly sensitive methods of detection on BM- and/or SPL-derived lineage-negative cells: D-HPLC (denaturing high performance liquid chromatography), ASOL-PCR (allele-specific oligonucleotide ligation-polymerase chain reaction), and sequencing of resistant colonies.

D-HPLC failed to detect KD mutations in both untreated and treated induced SCLtTA/BCR-ABL mice (0/7 and 0/5, respectively). However, ASOL-PCR detected two KD mutations in one out of seven untreated, induced mice: E255K and T315I. ASOLPCR also detected one KD mutation (T315I) in one out of five treated induced mice. Two of the five untreated induced mice that harbored detectable mutations as determined by sequencing of IM-resistant colonies harbored two mutations each (E255K and T315I; T315I and H396P) though from different clones. Three of the five induced untreated mice that harbored detectable mutations as determined by sequencing of IM-resistant colonies harbored one mutation each: T315I or H396P. Two of the seven untreated induced mice failed to form resistant colonies though they conferred growth factor independence in vitro. 
Total RNA from 9 IM-treated mice was submitted for mutation analysis by DHPLC and ASOL-PCR. 3 out of 9 mice were IM-treated for 4 weeks before cells were isolated for RNA extraction, whereas 6 out of 9 mice were IM-treated for 4 weeks, followed by 3 weeks without treatment to permit leukemic expansion of cells. BCR-ABL amplification was not accomplished in 4 of the 9 mice, all from the second group of IMtreated mice; therefore, these 4 samples were not included in the total number of mice analyzed. The T315I mutation that was detected by ASOL-PCR was from 1 out of 2 mice from the second treatment group.

As expected, there were no detectable mutations in total mRNA from untreated non-induced mice using D-HPLC or ASOL-PCR (0/4 mice, not shown). Furthermore, Lin cells from untreated non-induced mice failed to confer growth factor independence in vitro prior to plating cells in methylcellulose, thereby suggesting the absence of resistant colonies. Also, we extracted BMCs from untreated non-induced SCLtTA/BCR$\mathrm{ABL}$ mice that were maintained with tetracycline-supplemented drinking water in vivo, and then induced BCR-ABL expression in vitro by culturing Lin BMCs without tetracycline for one week. Although these cells exhibited growth factor independence they failed to exhibit resistance upon in vitro incubation with IM, thus confirming that point mutations did not arise as a result of in vitro culture.

Table 1. Imatinib-naïve and imatinib-treated induced SCLtTA/BCR-ABL mice harbor leukemia clones expressing imatinib-resistant BCR-ABL kinase domain (KD) mutations.

\begin{tabular}{|c|c|c|c|}
\hline Assay: Sensitivity & Mice $^{\mathrm{a}}$ & Detection $^{b}$ & KD mutations \\
\hline \multirow[t]{2}{*}{ D-HPLC: $10^{-2}-10^{-3}$ (wt:mutant mRNA) } & -IM & $0 / 7$ & - \\
\hline & $+\mathrm{IM}$ & $0 / 5$ & - \\
\hline \multirow[t]{2}{*}{ ASOL-PCR: $10^{-3}$ (wt: mutant mRNA); $10^{-3}$ (cells) } & -IM & $1 / 7$ & E255K, T315I \\
\hline & $+\mathrm{IM}$ & $1 / 5$ & T315I \\
\hline Sequencing of IM-resistant colonies: $10^{-6}$ (cells) & -IM & $5 / 7$ & E255K, T315I, H396P \\
\hline
\end{tabular}


Copy number alterations (CNAs) have been detected in many CML patient samples by single nucleotide polymorphism (SNP) and cytogenetic hybridization (CGH) arrays and associated with resistance to tyrosine kinase inhibitors (TKIs) and/or progression from CML-CP to CML-AP/BP [222-226]. To examine whether or not elevated ROS and oxidative DNA damage in $\mathrm{Lin}^{-} \mathrm{c}-\mathrm{Kit}^{+} \mathrm{Sca}-1^{+} \mathrm{LSCs}$ from induced SCLtTA/BCR-ABL mice exhibiting CML-CP resulted in genomic instability manifested by CNAs in specific genes, we employed high density SNP array [215] of high molecular weight (HMW) genomic DNA (gDNA) extractions from the Lin ${ }^{-}$BMCs of 8 untreated (IM), induced and 4 untreated, non-induced mice, and 4 tail gDNA samples from untreated, induced mice. SNP results from induced Lin $^{-} \mathrm{BM}$ gDNA were compared to non-induced Lin ${ }^{-} \mathrm{BM}$ and/or induced tail gDNA in order to deduce copy number losses (CNLs) and gains (CNGs) in candidate genes that either regulate ROS levels and DNA repair, or candidate genes previously reported to be associated with TKI-resistance (TKIR) and/or CML progression.

In untreated, induced SCLtTA/BCR-ABL mice we detected CNAs in many genes that regulate ROS levels (Table 2). More specifically, we detected CNAs in many genes encoding proteins involved in the mitochondrial respiratory chain (MRC). NADH dehydrogenase-ubiquinone genes ( $N d u f s 2, N d u f a 412)$ encode proteins that are subunits of Complex I (NADH-ubiquinone oxidoreductase), an integral inner membrane multiprotein complex of the mitochondrial ETC that reversibly oxidizes NADH in a reaction coupled to a proton pump that generates transmembrane potential and results in $\bullet \mathrm{O}_{2}{ }^{-}$ generation into the mitochondrial matrix in the presence of NADH and tightly bound ubiquinone, which acts as a redox shuttle between the Fe-S centers and $\mathrm{O}_{2}[116,227]$; 
therefore, $\mathrm{CNGs}$ in $N d u$ family genes may lead to enhanced $\bullet \mathrm{O}_{2}{ }^{-}$production. The $\alpha$ ketoglutarate dehydrogenase complex is tightly associated with the matrix side of the inner mitochondrial membrane and catalyzes the oxidation of $\alpha$-ketoglutarate to succinyl$\mathrm{CoA}$ using $\mathrm{NAD}^{+}$as an electron acceptor which may lead to the production of $\bullet \mathrm{O}_{2}{ }^{-}$and $\mathrm{H}_{2} \mathrm{O}_{2}$ [228]. The $\alpha$-ketoglutarate dehydrogenase complex is composed of three enzymes, one of which is $\alpha$-ketoglutarate dehydrogenase, also known as oxoglutarate dehydrogenase ( $O g d h)$; therefore, $\mathrm{CNG}$ of $O g d h$ may result in enhanced production of - $\mathrm{O}_{2}{ }^{-}$and $\mathrm{H}_{2} \mathrm{O}_{2}$. Complex III (ubiquinone-cytochrome $c$ reductase) is an enzyme complex oxidizing coenzyme $\mathrm{Q}$ during the "Q-cycle", using cytochrome $c$ as an electron acceptor, coupled to the translocation of protons to generate transmembrane potential [116, 229]. Complex III is a major producer of $\bullet \mathrm{O}_{2}{ }^{-}$, due to an unstable semiquinone formed in the Qo site, to both the mitochondrial matrix and cytosolic side, which can easily be dismutated to $\mathrm{H}_{2} \mathrm{O}_{2}$ [230-235]. Ubiquinol cytochrome c reductase 10 (Uqcr 10) encodes a subunit of Complex III, therefore, $\mathrm{CNG}$ of $\mathrm{Uqcr} 10$ may lead to enhanced $\bullet \mathrm{O}_{2}{ }^{-}$ production. Monoamine oxidases are located in the outer mitochondrial membrane and catalyze the oxidation of biogenic amines accompanied by robust $\mathrm{H}_{2} \mathrm{O}_{2}$ release [116]; CNGs in two genes encoding family members of monoamine oxidase (Maoa, Maob) may lead to enhanced production of $\mathrm{H}_{2} \mathrm{O}_{2}$. Glutathione-S-transferase A3 (Gsta3) encodes an enzyme involved in ROS detoxification; it catalyzes the conjugation of ROS with the reduced form of glutathione (GSH) by acting as an electron acceptor. CNL of Gsta3 may result in net gain of mitochondrial ROS due to loss of antioxidant activity, leading to mitochondrial lipid peroxidation [236]. 
In addition to CNAs detected in mitochondrial-associated genes that may regulate ROS levels, we detected CNGs in endoplasmic reticulum (ER)-associated genes that may regulate ROS levels. Cytochrome P-450 is the terminal component of the monoxygenase system within the ER that detoxifies compounds into less toxic products through oxidation and hydroxylation reactions, during which electrons may be leaked onto $\mathrm{O}_{2}$ leading to the formation of $\bullet_{2}^{-}{ }^{-}[125]$. Therefore, CNGs in multiple genes encoding different family members of cytochrome P450 (Cyp4a12a, Cyp4f39, Cyp24a1) may lead to enhanced production of $\bullet \mathrm{O}_{2}$.

In untreated, induced SCLtTA/BCR-ABL mice we detected CNAs in many genes that regulate DNA repair (Table 2). RecQ helicases function in DNA replication, recombination and repair; more specifically, they have specific roles in DSB repair, mismatch repair (MMR) and base excision repair (BER) [237]. Therefore, CNLs of RecQ family members (Recql, Recql5) may result in the aberrant repair of DSBs leading to chromosomal translocations and/or megabase deletions of DNA, and/or mismatched basepairs and oxidative lesions leading to point mutations. Ring finger proteins act as tumor suppressors and recruit necessary repair proteins to DSB formation sites [238]; therefore, CNL of Rnf40 may lead to aberrant DSB repair. The X-ray repair crosscomplementing protein $1(\mathrm{Xrccl})$ interacts with various substrates involved in BER and single strand break (SSB) repair [239]; CNG in Xrccl may result in enhanced, yet unfaithful, DNA repair — an effect associated with BCR-ABL activity.

Additionally, we submitted gDNA extracted from the total BM and SPL of 3 treated (+IM), induced SCLtTA/BCR-ABL mice and compared SNP array results to gDNA extracted from the total BM of 3 untreated, non-induced mice. Samples within 
each group were pooled prior to the array to account for low cell number (due to in vivo IM-treatment) resulting in poor gDNA yield. In IM-treated, induced SCLtTA/BCR-ABL mice we detected CNAs in many genes that regulate both ROS levels and DNA repair. Complex IV (cytochrome c oxidase) is a terminal component of the mitochondrial ETC which adds four electrons onto $\mathrm{O}_{2}$ in a series of reduction reactions, each of which may yield the formation of $\bullet \mathrm{O}_{2}^{-}[123]$. CNGs were detected in multiple genes encoding subunits of cytochrome c oxidase (Cox6b2, $\operatorname{Cox} 18)$, which may result in the enhanced production of $\bullet \mathrm{O}_{2}{ }^{-} \cdot \mathrm{Mcm} 9$ encodes a DNA helicase crucial for effective HR [240]; therefore, CNL of $M c m 9$ may be associated with defective DSB repair. Poly (ADPribose) polymerase proteins are involved in the repair of DNA strand breaks and maintain telomere length of chromosomes [241]. Consequently, CNG in Parp4 may result in enhanced, yet unfaithful, DNA strand break repair and/or telomere lengthening resulting in enhanced survival of leukemia cells.

We detected CNAs in many genes previously associated with TKI-resistance and disease progression to CML-AP/BP in both untreated and IM-treated, induced SCLtTA/BCR-ABL mice (Table 2). CNGs in multiple genes encoding downstream effectors of BCR-ABL kinase signaling were detected: rac- $\gamma$ serine/threonine protein kinase 3 (Akt3), rho/rac guanine nucleotide exchange factor 2 (Arhgef2), mitogenactivated protein kinase 1 (Mapk1), protein kinase c $\alpha$ (Prkca), and platelet-derived growth factor receptor $\beta$ (Pdgfrb). Furthermore, CNL in dual specificity phosphatase 18 (Dusp18) may potentiate further BCR-ABL kinase signaling. WD repeat-containing protein $5(W d r 5)$ may mediate self-renewal [242]; therefore, $\mathrm{CNG}$ in $W d r 5$ may contribute to the enhanced self-renewal capacity associated with blastic transformation of 
CML. Gain-of-function mutations in the isocitrate dehydrogenase 1 (Idhl) gene modify myeloid cell development and promote leukemogenesis [243], thus supporting the concept that $\mathrm{CNG}$ of $I d h 1$ could contribute to CML progression. Ikaros zinc finger family $1(I k z f l)$ is an important regulator of lymphoid development; loss of $I k z f l$ activity was associated previously with lymphoblastic transformation of CML, thus supporting the potential role of CNL in disease progression [244]. Overexpression of Zinc finger protein (Zfp423) is associated with blastic transformation of CML [245]; thus, CNG of Zfp423 also may play a role in disease progression. Lastly, CNLs in multiple genes encoding known tumor suppressors were detected: dachshund homolog (Dach1), transformation related protein 53 (Trp53), and retinoblastoma $(R b 1)$, thereby amplifying BCR-ABLmediated transformation.

We detected CNAs in many genes regulating ROS levels and DNA repair, as well as genes previously associated with TKI-resistance and disease progression in human CML, in both untreated and IM-treated, induced SCLtTA/BCR-ABL leukemia cells. Although there appears to be biased distribution of CNAs detected in untreated, induced

Table 2. Imatinib-naïve and imatinib-treated induced SCLtTA/BCR-ABL mice accumulate aberrations in genes that regulate ROS levels and DNA repair resulting in resistance to TKIs and progression to CML-AP/BP

\begin{tabular}{|c|c|c|c|}
\hline \multirow[t]{2}{*}{ CNA } & \multirow[t]{2}{*}{ Mice $^{\mathrm{a}}$} & \multicolumn{2}{|c|}{ Candidate genes } \\
\hline & & ROS and DNA repair & TKI-R and CML-AP/BP \\
\hline \multirow[t]{2}{*}{ CNLs } & $-\mathrm{IM}$ & Gsta3, Recql, Recql5, Rnf40 & $\begin{array}{c}\text { Cabin1, Ccdc91, Csf3r, Dach1, Ddx11, } \\
\text { Dusp18, Eng, Ift74, Ikzf1, Mapk8ip1, } \\
\text { Pik3c2g, Recql, Rere, Rnf40, Sugt1, } \\
\text { Tesk1, Trp53 }\end{array}$ \\
\hline & $+\mathrm{IM}$ & Mcm9 & Asfla, Map3k7, Mcm9, Rars2, Rb1 \\
\hline \multirow[t]{2}{*}{ CNGs } & $-\mathrm{IM}$ & $\begin{array}{c}\text { Cyp4a12a, Cyp4f39, Cyp24a1, Maoa, } \\
\text { Maob, Ndufs2, Ndufa412, Ogdh, } \\
\text { Uqcr10, Xrcc1 }\end{array}$ & $\begin{array}{l}\text { Abcc3, Akt3, Arhgef2, Card14, Cep170, } \\
\text { Gabpb2, Idh1, Mapk1, Nup85, Nup18, } \\
\text { Pax6, Pi4ka, Prkca, Psmd1, Ptbp2, } \\
\text { Spire1, Ush2a, Usp37, Wdr5, Zfp 423 }\end{array}$ \\
\hline & $+\mathrm{IM}$ & Cox6b2, Cox18, Parp 4, Recql5 & Nup85, Pax6, Pdgfrb, Ptpn14,Wdr26 \\
\hline
\end{tabular}

${ }^{a}$ Induced mice were untreated (-) or treated (+) with imatinib mesylate (IM) as described in Materials and Methods 
mice, we analyzed nearly three times as many samples in this small cohort $(n=8$

untreated, induced mice versus $n=3$ IM-treated, induced mice) and we cannot exclude the possibility of detecting a greater number of different CNAs associated with ROS, DNA repair, TKI-R, and CML-AP/BP if we had analyzed more IM-treated, induced mice.

These data show that elevated levels of precursors to genomic instability, i.e. ROS and oxidative DNA damage, displayed by induced Lin $^{-} \mathrm{c}-\mathrm{Kit}^{+} \mathrm{Sca}-1^{+}$leukemia stem cells (LSCs), including the quiescent fraction, from the tetracycline-inducible SCLtTA transgenic mouse model of CML-CP result in the accumulation of genetic mutations including, but not limited to, point mutations in the BCR-ABL kinase domain and alterations in genes previously associated with resistance to tyrosine kinase inhibitors (TKIs) and progression from a relatively benign CML-CP to CML-AP/BP human patients. Additionally, the accumulation of genomic instability is not inhibited by the small molecule tyrosine kinase inhibitor imatinib mesylate (IM). Furthermore, alterations in genes associated with ROS, i.e. gains in genes that contribute to ROS formation and losses in genes that inhibit ROS formation, and DNA repair may be underlying factors leading to elevated levels of ROS, oxidative DNA damage and genomic instability originating from these induced LSCs.

\section{CML-CP Lin ${ }^{-}$-Kit ${ }^{+}$Sca-1 $^{+}$LSCs display deregulated expression of genes associated with ROS and DNA repair}

To identify molecular mechanisms underlying enhanced levels of ROS and oxidative DNA damage resulting in genomic instability of $\mathrm{Lin}^{-} \mathrm{c}-\mathrm{Kit}^{+} \mathrm{Sca}-1^{+} \mathrm{LSC}$ from induced SCLtTA/BCR-ABL mice, we performed gene expression profiling of Microarray data previously generated by Steffen Koschmieder's group [210]. A list of selected genes 
with more than 1.5-fold change in expression levels associated with regulation of ROS levels and DNA repair is shown in Table 3. We detected enhanced expression of genes encoding polyamine oxidase (Paox) and a subunit of cytochrome c oxidase (Cox6a2) of Complex IV of the MRC in induced LSCs, which may result in enhanced levels of $\mathrm{H}_{2} \mathrm{O}_{2}$ and $\bullet \mathrm{O}_{2}{ }^{-}$, respectively $[123,246]$. Furthermore, we detected decreased expression of genes encoding pyruvate kinase, liver and red blood cell $(P k l r)$ and glutathione-stransferase $\mu 2$ (Gstm2); both pyruvate and glutathione are ROS scavengers, therefore, down-regulation of Pklr and Gstm2 may result in net gain of mitochondrial ROS due to loss of antioxidant activity [236, 247]. TCDD-inducible poly (ADP-ribose) polymerase (Tiparp) gene expression is amplified and up-regulated in head-and-neck squamous cell carcinoma (HNSSC) [248]; enhanced gene expression detected in induced LSCs may contribute to malignant transformation as a consequence of enhanced, yet unfaithful, DNA repair resulting in genomic instability. Unbiased pathway analysis using Ingenuity Software revealed highly significant changes in pathways related to mitochondrial dysfunction, oxidative phosphorylation, glycolysis/gluconeogenesis, pyruvate and glutathione metabolism, and DNA repair (data not shown).

Table 3. Microarray analysis of the expression of genes potentially involved in the enhanced levels of ROS and repair of oxidative DNA damage in $\mathrm{Lin}^{-} \mathrm{c}-\mathrm{Kit}^{+} \mathrm{Sca}-{ }^{+} \mathrm{LSCs}$ from induced SCLtTA/BCR-ABL mice in comparison to non-induced counterparts

\begin{tabular}{lrrll}
\hline Gene symbol & Probe set ID & Fold change & P value & Function \\
\hline ROS & & & & \\
Paox & 1428859 at & 1.55 & 0.023794 & Catalyzes oxidation yielding $\mathrm{H}_{2} \mathrm{O}_{2}$ \\
Cox6a2 & $1417607 \_$at & 1.90 & 0.039070 & Mitochondrial electron transport \\
Pklr & 1421259 at & -1.65 & 0.004456 & Pyruvate synthesis \\
Gstm2 & 1416411 at & -2.01 & 0.012738 & Conjugates ROS with glutathione \\
\hline DNA repair & & & & \\
Tiparp & $1426721 \_$s_at & 1.58 & 0.042406 & DSB repair \\
\hline
\end{tabular}


These data show that deregulated expression of genes associated with ROS, i.e. elevated expression of genes that contribute to ROS formation and decreased expression of genes that inhibit ROS formation, and DNA repair may be underlying factors leading to elevated levels of ROS and oxidative DNA damage resulting in genomic instability originating from induced $\mathrm{Lin}^{-} \mathrm{c}-\mathrm{Kit}^{+} \mathrm{Sca}-{ }^{+}{ }^{+} \mathrm{LSCs}$ of the tetracycline-inducible SCLtTA transgenic mouse model of CML-CP.

\section{BCR-ABL exerts a dose- and kinase-dependent effect on ROS and oxidative DNA damage in BCR-ABL-transduced human $\mathrm{CD34}^{+}$cells}

Elevated mRNA and protein expression of BCR-ABL in $\mathrm{CD} 34^{+}$progenitor cells from CML patients has been associated with disease progression from $\mathrm{CP}$ to $\mathrm{BP}$, the acquisition of additional genetic abnormalities and IM resistance [192-197, 203]. These findings suggest that high expression of BCR-ABL may underlie mechanisms of genomic instability associated with CML progression and drug resistance, of which ROS and oxidative DNA damage are the primary suspects.

To investigate the effect of increased levels of BCR-ABL expression on ROS and oxidative DNA damage we employed healthy human donor $\mathrm{CD} 34^{+}$cells transduced with infectious particles (MIG R1, MIG 210) expressing GFP generated by transient transfection of 293 cells [217]. Cell populations were selected based on low (L) and high (H) GFP expression levels determined by FACS. First, we assessed whether BCR-ABL expression levels corresponded to GFP expression levels selected by FACS. Western blot analysis using anti-c-Abl antibody confirmed increased $\mathrm{BCR}-\mathrm{ABL}$ protein expression in MIG $210 \mathrm{H}$ cells compared to the MIG $210 \mathrm{~L}$ cells (Figure 5A, upper panel).

Additionally, MIG $210 \mathrm{H}$ cells demonstrated increased tyrosine kinase activity and 
altered patterns of tyrosine phosphorylation compared to MIG $210 \mathrm{~L}$ cells as assessed by Western blot analysis using anti-phosphotyrosine antibody (Figure 5A, center panel). Both MIG $210 \mathrm{~L}$ and MIG $210 \mathrm{H}$ cells exhibited increased phosphotyrosine levels compared to control MIG R1 L and MIG R1 H cells expressing GFP alone.

Next, we determined whether BCR-ABL expression levels affected ROS levels in transduced CD $34^{+}$cells (Figure 5B). As detected by DHE and analyzed by FACS, MIG $210 \mathrm{H}$ cells displayed elevated levels of $\bullet \mathrm{O}_{2}{ }^{-}(14,646.333 \pm 469.118)$ compared to MIG 210 L cells $(7,542.472 \pm 417.389, \mathrm{p}<0.001)$ and MIG R1 H cells expressing GFP alone $(5,562 \pm 736.996, \mathrm{p}<0.001)$ (Figure 5B, left panel). Additionally, MIG $210 \mathrm{~L}$ cells displayed elevated $\bullet \mathrm{O}_{2}{ }^{-}$levels compared to MIG R1 L cells $(5,104.667 \pm 276.553$, $\mathrm{p}=0.001)$. As detected by CC- 1 and analyzed by FACS, MIG $210 \mathrm{H}$ cells displayed elevated levels of $\bullet \mathrm{O}_{2}{ }^{-} / \mathrm{H}_{2} \mathrm{O}_{2}(2,229.056 \pm 213.705)$ compared to MIG $210 \mathrm{~L}$ cells $(1468.889 \pm 376.708, \mathrm{p}=0.038)$ and MIG R1 H cells $(1,423.5 \pm 157.622, \mathrm{p}=0.006)$ (Figure 5B, right panel). However, MIG p210 L cells failed to elevate $\bullet^{-\mathrm{O}_{2}}{ }^{-} / \mathrm{H}_{2} \mathrm{O}_{2}$ levels significantly above that of MIG R1 L cells.

Lastly, we determined whether BCR-ABL expression levels affected levels of oxidative DNA damage in transduced CD $34^{+}$cells (Figure 5C). As detected by immunostaining of anti-8-oxoG antibody in DAPI-counterstained nuclei, MIG $210 \mathrm{H}$ cells displayed enhanced nuclear staining of 8-oxoG $(12.64 \pm 7.67)$ compared to MIG 210 L cells $(7.24 \pm 4.303, \mathrm{p}=0.016)$ and MIG R1 H cells $(4.675 \pm 2.75, \mathrm{p}<0.001)$ (Figure 5C, left panel). Similarly, as detected by immunostaining with anti- $\gamma-\mathrm{H} 2 \mathrm{AX}$ antibody in DAPI-counterstained nuclei, MIG $210 \mathrm{H}$ cells displayed enhanced $\gamma$-H2AX foci $(24.038$ 
A

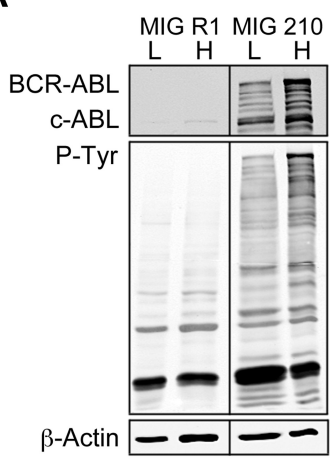

B

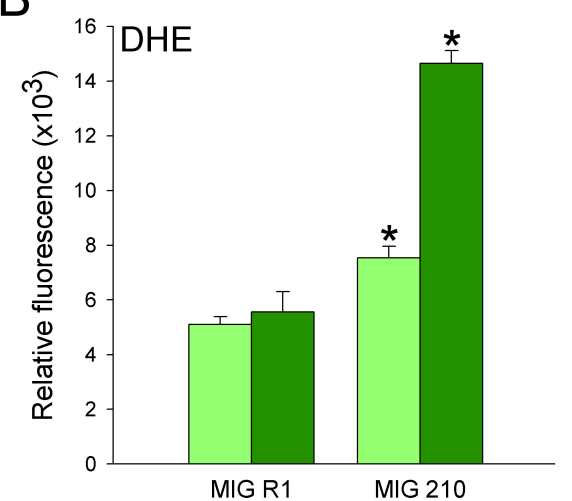

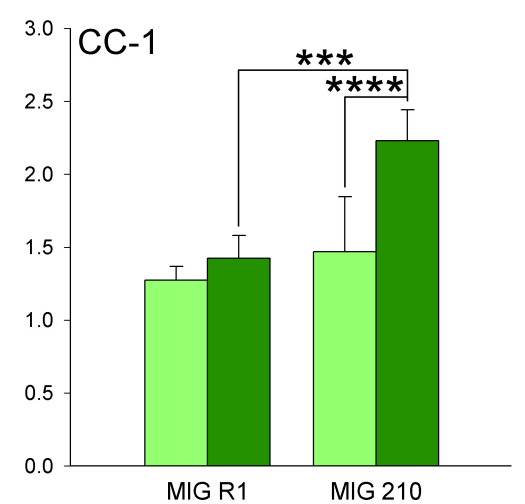

C
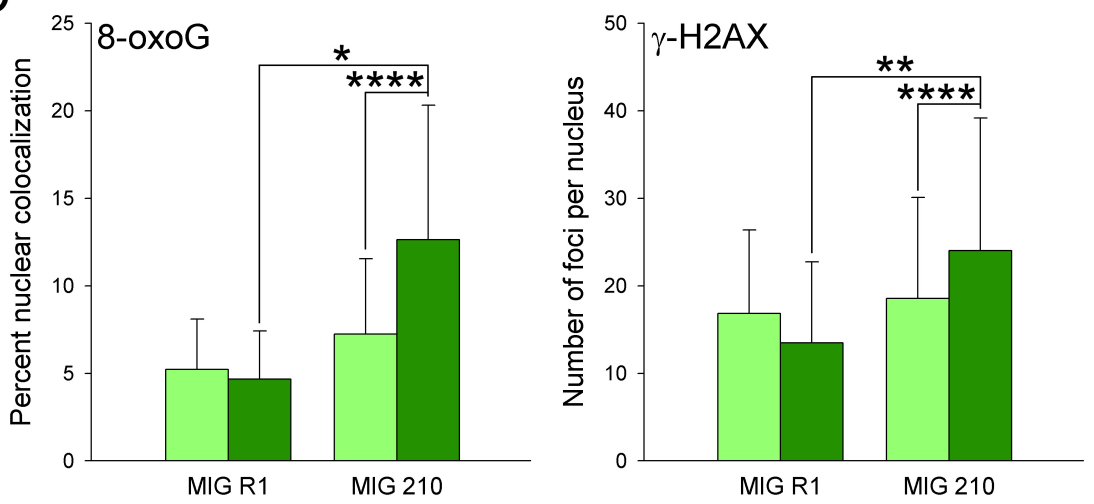

Figure 5. ROS and oxidative DNA damage are proportional to BCR-ABL protein expression and kinase activity in BCR-ABL-transduced human $\mathrm{CD34}^{+}$cells. Human $\mathrm{CD} 34^{+}$cells were transduced with pMIG-IRES-GFP (MIG R1) or pMIG-p210BCRABL-IRES-GFP (MIG 210) retroviral constructs. Cells were maintained in IMDM containing $10 \%$ FBS, $1 \%$ antibiotic-antimycotic solution, and growth factors (SCF, GMCSF) required to promote survival and proliferation. (A) Cells expressing the $15-20 \%$ lowest (L) and highest (H) GFP were sorted by FACS and analyzed by Western blot to detect $\mathrm{p} 210 \mathrm{BCR}-\mathrm{ABL}$ and c-ABL protein expression (upper panel), cellular protein tyrosine phosphorylation (p-Tyr; center panel), and $\beta$-Actin for loading control (lower panel). (B) Cellular $\bullet \mathrm{O}_{2}{ }^{-}$and $\bullet \mathrm{O}_{2}{ }^{-} / \mathrm{H}_{2} \mathrm{O}_{2}$ were detected in the $15-20 \%$ lowest (light green bars) and highest (dark green bars) GFP-expressing cells with DHE (left panel) and Redox Sensor CC-1 (right panel), respectively, and analyzed by FACS; $\mathrm{n}=3$ experiments per group. (C) Cells expressing the 15-20\% lowest (light green bars) and highest (dark green bars) GFP were sorted by FACS. left panel: 8-oxoG (MIG R1 L: $\mathrm{n}=15$ cells, MIG R1 H: $\mathrm{n}=31$ cells, MIG $210 \mathrm{~L}: \mathrm{n}=16$ cells, MIG $210 \mathrm{H}: \mathrm{n}=21$ cells) and right panel: $\gamma$ H2AX (MIG R1 L: $n=31$ cells, MIG R1 H: $n=24$ cells, MIG 210 L: $n=45$ cells, MIG 210 $\mathrm{H}: \mathrm{n}=53$ cells) were detected by immunofluorescence in DAPI-counterstained nuclei. Data are expressed as mean \pm standard deviation (SD). ${ }^{*} \mathrm{p} \leq 0.001,{ }^{* *} \mathrm{p} \leq 0.005, * * * \mathrm{p}$ $\leq 0.01, * * * * \mathrm{p} \leq 0.05$ in comparison to MIG R1 counterpart(s) and MIG $210 \mathrm{~L}$. 
$\pm 15.111)$ compared to MIG 210 L cells $(18.533 \pm 11.567, \mathrm{p}=0.049)$ and MIG R1 H cells $(13.5 \pm 9.217, \mathrm{p}=0.002)$ (Figure 5C, right panel). However, MIG p210 L cells failed to enhance both 8-oxoG lesions and DSB formation significantly above that of MIG R1 L cells.

The transformation potential and mutator phenotype of BCR-ABL has largely been attributed to its kinase activity $[175,180,184,249]$. To investigate the effect of BCR-ABL kinase activity on ROS and oxidative DNA damage we employed healthy human donor $\mathrm{CD} 34^{+}$cells transduced with infectious particles expressing GFP alone (MIG R1), co-expressing GFP and BCR-ABL (MIG 210), or co-expressing GFP and BCR-ABL kinase-deficient K1172R mutant (MIG KD) generated by transient transfection of 293 cells. Cell populations were selected based on total GFP expression determined by FACS. First, we determined whether BCR-ABL KD mutant affected $\bullet \mathrm{O}_{2}{ }^{-}$ levels in transduced CD34 $4^{+}$cells (Figure 6A). As detected by DHE and analyzed by FACS, MIG 210 cells displayed elevated levels of $\bullet^{\mathrm{O}_{2}}{ }^{-}(12,028 \pm 796)$ compared to MIG R1 cells $(7,072 \pm 1,437, \mathrm{p}<0.001)$ and MIG KD cells $(8,303 \pm 1,929, \mathrm{p}=0.004)$. Then, we determined whether BCR-ABL KD mutant affected levels of oxidative DNA damage in transduced CD34 $4^{+}$cells (Figure 6B). As detected by immunostaining of anti-8-oxoG antibody in DAPI-counterstained nuclei, MIG 210 cells displayed enhanced nuclear staining of 8 -oxoG $(0.842 \pm 0.714)$ compared to MIG R1 cells $(0.342 \pm 0.32, \mathrm{p}<0.001)$ and MIG KD cells $(0.434 \pm 0.279, \mathrm{p}=0.034)$. Similarly, as detected by immunostaining with anti- $\gamma-\mathrm{H} 2 \mathrm{AX}$ antibody in DAPI-counterstained nuclei, MIG 210 cells displayed enhanced $\gamma$-H2AX foci $(33.683 \pm 27.017)$ compared to MIG R1 cells $(21.475 \pm 20.262$, $\mathrm{p}=0.024)$ and MIG KD cells $(19.969 \pm 20.150, \mathrm{p}=0.019)$. MIG KD cells failed to enhance 
- $\mathrm{O}_{2}{ }^{-}$levels, 8-oxoG lesions and DSB formation significantly above that of MIG R1 cells, suggesting that BCR-ABL kinase activity is necessary for ROS-induced DNA damage to occur.
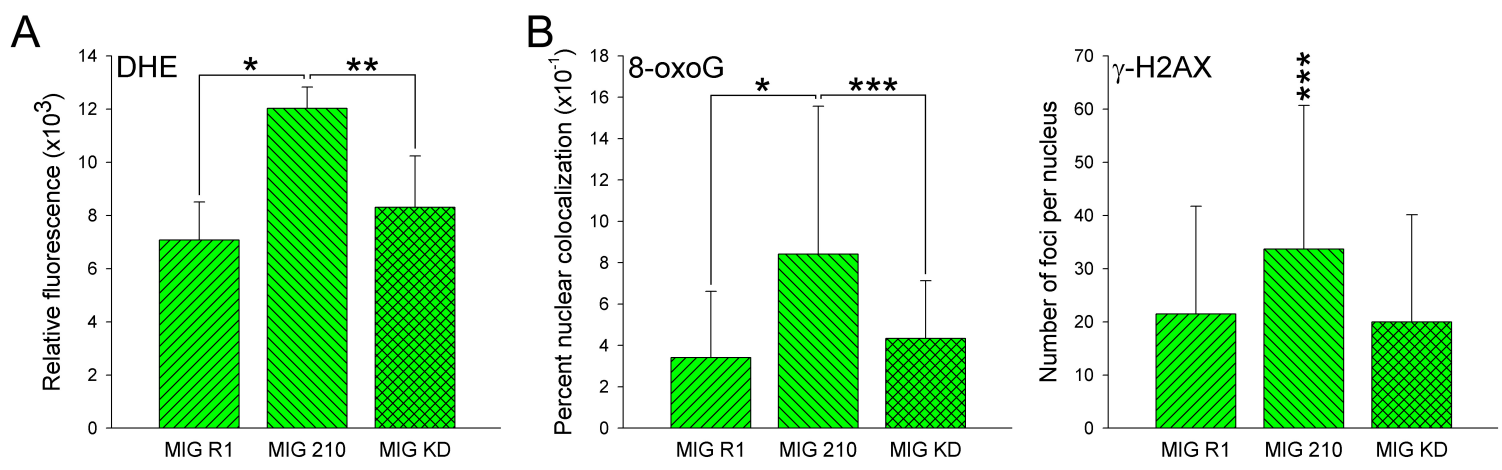

Figure 6. BCR-ABL kinase-deficient (KD) K1172R mutant does not induce ROS and oxidative DNA damage in transduced human $\mathrm{CD}^{+}{ }^{+}$cells. Human $\mathrm{CD} 34^{+}$cells were transduced with pMIG-IRES-GFP (MIG R1), pMIG-p210BCR-ABL-IRES-GFP (MIG 210), or pMIG-p210BCR-ABL(K1172R)-IRES-GFP (MIG KD) retroviral constructs. Cells were maintained in IMDM containing 10\% FBS, 1\% antibiotic-antimycotic solution, and growth factors (SCF, GM-CSF) required to promote survival and proliferation. (A) Cellular $\bullet \mathrm{O}_{2}{ }^{-}$was detected in GFP-positive cells with DHE and analyzed by FACS; $n=5$ experiments per group. (B) GFP-positive cells were sorted by FACS. left panel: 8 -oxoG (MIG R1: $\mathrm{n}=83$ cells, MIG 210: $\mathrm{n}=29$ cells, MIG KD: $\mathrm{n}=16$ cells) and right panel: $\gamma$-H2AX (MIG R1: $\mathrm{n}=40$ cells, MIG 210: $\mathrm{n}=41$ cells, MIG KD: $\mathrm{n}=32$ cells) were detected by immunofluorescence in DAPI-counterstained nuclei. Data are expressed as mean \pm standard deviation (SD). ${ }^{*} p \leq 0.001, * * p \leq 0.005,{ }^{* * *} p \leq 0.05$ in comparison to MIG R1 and MIG KD counterparts.

These data show that, in BCR-ABL-transformed human CD34 ${ }^{+}$cells, levels of BCR-ABL expression and/or kinase affect levels of ROS and oxidative DNA damage in a dose-dependent manner. Furthermore, these data suggest that there is a BCR-ABL kinase-dependent effect on levels of ROS and oxidative DNA damage. Therefore, elevated BCR-ABL expression levels and kinase activity may be underlying mechanisms contributing to elevated levels of ROS and oxidative DNA damage resulting in the accumulation of genomic instability. 


\section{CHAPTER 4}

\section{DISCUSSION}

Primary and acquired genomic instability leading to drug resistance and disease progression poses as a major obstacle to achieving a cure for CML $[68,250]$. To determine which subpopulation of leukemia cells, stem and/or progenitors, is responsible for the accumulation of genetic errors resulting in TKI-resistance and/or disease progression, we employed the tetracycline-inducible SCLtTA/BCR-ABL transgenic murine model of CML-CP which targets BCR-ABL expression to hematopoietic stem and progenitor cells. BCR-ABL mRNA expression in BM-derived inin $^{-} \mathrm{c}-\mathrm{Kit}^{+} \mathrm{Sca}-1^{+}$stem and Lin ${ }^{-} \mathrm{c}-\mathrm{Kit}{ }^{+} \mathrm{Sca}-1^{-}$progenitor cells of induced SCLtTA/BCR-ABL mice lead to splenomegaly and granulo-monocytic myeloid expansion in the bone marrow, spleen and peripheral blood, thereby recapitulating the disease phenotype of human CML-CP.

We show here that induced Lin ${ }^{-} \mathrm{c}-\mathrm{Kit}^{+} \mathrm{Sca}-1^{+}$leukemia stem cells (LSCs), including the TKI-refractory quiescent population, but not induced $\mathrm{Lin}^{-} \mathrm{c}-\mathrm{Kit}^{+} \mathrm{Sca}-\mathrm{1}^{-}$ leukemia progenitor cells (LPCs), display elevated levels of ROS and oxidative DNA damage, an effect recently reported in human CML-CP CD $34^{+} \mathrm{CD} 38^{-}$stem-enriched and $\mathrm{CD}_{4}{ }^{+}$quiescent cells [221]. Also, we detected genetic aberrations and deregulated expression in genes that regulate ROS (Gst, Cyp, Mao, Ndu, Ogdh, Uqcr, Cox, Paox, $P k l r)$ and DNA repair (Recql, Rnf, Xrcc, Parp), which may underlie the accumulation of ROS-induced oxidative DNA damage in induced Lin $^{-} \mathrm{c}-\mathrm{Kit}^{+} \mathrm{Sca}-1^{+} \mathrm{LSCs}$, including the quiescent population. Accumulation of ROS-induced DNA damage in induced Lin ${ }^{-} \mathrm{c}-$ $\mathrm{Kit}^{+} \mathrm{Sca}-1^{+} \mathrm{LSCs}$, including the quiescent population, resulted in the accumulation of clinically relevant point mutations in the BCR-ABL kinase domain (E255K, T315I, 
H396P) and genetic aberrations associated with TKI-resistance and disease progression in human CML (Ikzf1, Trp53, Idh1, Zfp423, etc.). Altogether, these findings are in accordance with previous reports that BCR-ABL enhances unfaithful repair of ROSinduced DNA damage leading to genomic instability [182-184, 187], and suggests that there is regulation at both the genetic and transcriptional level. Furthermore, these results indicate that genomic instability may originate from the LSC, including the most primitive quiescent LSC, but does not exclude the possibility that genomic instability may originate from the LPC.

Primitive CML-CP cells are unresponsive to many tyrosine kinase inhibitors (TKIs) [56, 77, 218, 251, 252]. Despite inhibition of BCR-ABL kinase, CML stem cells may be insensitive to TKIs independently of quiescence $[56,252,253]$, suggesting that there are other mechanisms underlying the insensitivity of quiescent CML stem cells to imatinib mesylate (IM). We show here that elevated levels of ROS and oxidative DNA damage in induced Lin $^{-} \mathrm{c}-\mathrm{Kit}^{+} \mathrm{Sca}^{-1}{ }^{+}$quiescent LSCs persist despite IM inhibition of BCR-ABL kinase; similarly, accumulation of clinically relevant point mutations in the BCR-ABL kinase domain and genetic aberrations associated with TKI-resistance and disease progression in human CML is not prevented by IM. Thus, quiescent LSCs may serve as a reservoir for unfaithfully repaired ROS-induced DNA damage resulting in genetic aberrations that fuel both TKI-resistance and CML progression. Additionally, despite inhibition of BCR-ABL kinase, CML stem cells, including the quiescent $\left(\mathrm{G}_{0}\right)$ population, may be insensitive to IM independently of mutation [56, 77, 252, 253]. Interestingly, BCR-ABL transcripts are more abundant in $\mathrm{G}_{0} \mathrm{CD} 34^{+} \mathrm{CML}$ cells than in $\mathrm{G}_{1} / \mathrm{S} / \mathrm{G}_{2} / \mathrm{M} \mathrm{CD} 34^{+} \mathrm{CML}$ cells [254]. Even though we didn't detect BCR-ABL transcripts 
in induced Linc-Kit ${ }^{+} \mathrm{Sca}-1^{+}$quiescent LSCs, BCR-ABL expression levels, or "dosage", may represent yet another mechanism underlying genomic instability in these cells.

In CML-CP patients, BCR-ABL transcripts and protein expression are more abundant in stem cells than in myeloid progenitors [77, 255], a characteristic that is mimicked in the induced Lin ${ }^{-} \mathrm{c}-\mathrm{Kit}{ }^{+} \mathrm{Sca}-1^{+}$LSCs and Lin ${ }^{-} \mathrm{c}-\mathrm{Kit}^{+} \mathrm{Sca}-1^{-} \mathrm{LPCs}$, respectively, of the SCLtTA/BCR-ABL mouse model; as a result, there appears to be a BCR-ABL dose-dependent effect on ROS levels in induced cells. However, non-induced Lin ${ }^{\top}$ $\mathrm{Kit}^{+} \mathrm{Sca}-1^{+}$stem cells display elevated levels of ROS in comparison to non-induced Lin ${ }^{-} \mathrm{c}-$ $\mathrm{Kit}^{+} \mathrm{Sca}-1^{-}$progenitors, suggesting that stem cells may be more prone to accumulate genomic instability due to intrinsic cellular properties, yet may also be better equipped to repair lesions $[256,257]$. Induced Lin $^{-} \mathrm{c}-\mathrm{Kit}^{+} \mathrm{Sca}-1^{-} \mathrm{LPCs}$ failed to recapitulate enhanced ROS levels previously reported in human $\mathrm{CD} 34^{+}$progenitor-enriched CML-CP cells [221], perhaps due to sub-threshold levels of BCR-ABL transcripts.

$\mathrm{BCR}-\mathrm{ABL}$ transcripts and protein expression in myeloid progenitors are more abundant in CML-BC than in CML-CP [77, 217, 255, 258, 259]. Progression from CML$\mathrm{CP}$ to $\mathrm{CML}-\mathrm{BC}$ also is associated with the accumulation of additional genetic aberrations [260]. Furthermore, BCR-ABL expression exerts a dose-dependent effect on recruitment of unfaithful DNA repair mechanisms, an effect that may result in the accelerated acquisition of IM-resistant point mutations $[187,258,261]$. We report here that BCRABL expression exerts a dose-dependent effect on ROS and oxidative DNA damage in BCR-ABL-transduced human $\mathrm{CD} 34^{+}$cells, thereby strengthening the link between BCRABL "dosage" and unfaithfully repaired ROS-dependent DNA damage resulting in genomic instability associated with TKI-resistance and CML progression. Also, we report 
that BCR-ABL exerts a kinase-dependent effect on ROS and oxidative DNA damage in transduced human $\mathrm{CD} 34^{+}$cells. However, IM inhibition of BCR-ABL kinase accompanied by persistently elevated levels of ROS and oxidative DNA damage in induced $\mathrm{Lin}^{-} \mathrm{c}-\mathrm{Kit}^{+} \mathrm{Sca}-1^{+}$quiescent LSCs from SCLtTA/BCR-ABL mice suggests that there are BCR-ABL kinase-independent mechanisms that maintain these elevated precursors to genomic instability; this notion is partially supported by a previous report suggesting that CML stem cells do not rely on BCR-ABL kinase activity for survival [262]. Accordingly, if BCR-ABL kinase-independent mechanisms of survival are either activated in response to the anti-proliferative effect of IM or already in place, both induced and innate quiescence may permit CML cells to accumulate genomic instability before re-entering the cell cycle as TKI-resistant and more aggressive CML cells leading to relapse.

Human CML CD34 ${ }^{+}$CD $38^{-}$stem-enriched cells and CD34 ${ }^{+}$progenitor-enriched cells display elevated levels of ROS and oxidative DNA damage, and the detection of mutations in patients diagnosed with CML-CP supports the idea that genomic instability may originate from either or both compartments. However, if genomic instability originates from either compartment, the acquired mutation(s) must confer resistance in order to survive therapeutic intervention, such as imatinib mesylate (IM). Additionally, if genomic instability originates from the CML stem cell compartment then the acquired mutation(s) must also reactivate the cell cycle within the quiescent fraction in order to propagate the mutation(s) that confers resistance into the expanding pool of CML cells; if genomic instability originates from the CML progenitor cell compartment then the acquired mutation(s) must also equip these cells with the capacity to self-renew in order 
to propagate the mutation(s) that confers resistance, which may otherwise be inconsequential upon terminal differentiation. Alternatively, CML cells may exhibit genomic instability that does not confer resistance to IM and/or induce progression to CML-AP/BP, thereby maintaining the susceptibility of CML cells to elimination by IM.

In the Phase III, open-label International Randomized Study of Interferon versus STI571 (IRIS), previously untreated CML-CP patients were randomized to receive treatment with imatinib mesylate (IM) or interferon- $\alpha$ (IFN- $\alpha$ ) plus cytarabine [263]. Data from five- and six-year follow-ups of patients randomized to receive IM as first-line therapy for newly diagnosed CML-CP show that, despite spikes in the second and third year of treatment with IM, there is an overall decline in the annual rate of detectable events, characterized as loss of complete hematologic response (CHR), loss of major cytogenetic response (MCyR), progression to accelerated phase (AP) or blast phase (BP) CML, or death, with nearly undetectable events in the sixth year of treatment with IM $[60,264]$. Furthermore, there is a steady decrease in the annual rate of detectable events over four years in patients who have achieved a complete cytogenetic response (CCyR) to treatment with IM, with nearly undetectable events in the fourth year.

The long-term success of IM in reducing the annual rate of detectable events may be due to the elimination of dividing CML cells perhaps displaying elevated ROS and oxidative DNA damage that results in irrelevant mutations that maintain the susceptibility of CML cells to IM rather than the inhibition of ROS and oxidative DNA damage and subsequent genomic instability resulting in resistance to IM and/or CML progression. Additionally, detectable events, of which genomic instability may be an underlying cause, are most likely manifested by the expanded CML progenitor population which is 
successfully eliminated by IM, whereas the CML stem cell population may display genetic mutations that are present yet undetectable due to the limited size and/or quiescent nature of the compartment. IM may also exert anti-proliferative effects on a small fraction of dividing CML cells and fails to eliminate quiescent CML stem cells. More recent data suggests that there is an increase in the annual rate of detectable events during the seventh and eighth year of treatment with IM $[60,264,265]$, which may be due to a resurgence of quiescent CML cells armed with mutations conferring IMresistance and/or inducing CML progression that are re-entering the cell cycle to expand the resistant/malignant clone.

Some CML-CP patients display genetic mutations at diagnosis, whereas others display genetic mutations later throughout the course of disease, and some may never develop genetic mutations while under treatment. Because genomic instability is manifested heterogeneously among CML patients it is likely that precursors of genomic instability, i.e. ROS and oxidative DNA damage, are displayed heterogeneously among CML patients as well. Accordingly, it is possible that the tetracycline-inducible SCLtTA/BCR-ABL mouse model of CML-CP recapitulates genomic instability exhibited by CML-CP patients at higher risk for developing resistance and/or CML progression. Alternatively, the SCLtTA/BCR-ABL mouse model may serve as a better tool for detection of genetic mutations and may thus accurately mimic the genomic instability exhibited by the majority of CML-CP patients.

In conclusion, $\mathrm{Lin}^{-} \mathrm{c}-\mathrm{Kit}^{+} \mathrm{Sca}-1^{+} \mathrm{LSCs}$, including the quiescent population, from induced SCLtTA/BCR-ABL mice exhibit ROS-induced DNA damage leading to genomic instability manifested by point mutations in the BCR-ABL kinase domain and 
genetic aberrations resulting in TKI-resistance and CML progression, an outcome that is not inhibited by IM in vivo or in vitro. Elevated ROS and oxidative DNA damage may be due partially to elevated BCR-ABL protein expression and kinase activity, however, kinase-independent mechanisms may also pose as contributing factors. These results support previous findings that IM-resistant leukemic cells emerge from CML stem cells that acquire BCR-ABL gene mutations even before exposure to BCR-ABL-targeted agents [218], and suggest that primary CML stem cells display a genetically unstable phenotype that predisposes them to develop resistance prior to treatment. As a result, therapeutic efforts should be targeted toward both BCR-ABL kinase-dependent and independent mechanisms of persistence and resistance in the CML stem cell compartment, including the quiescent fraction, in effort to eliminate every last CML stem cell. Although ROS, mechanisms that lead to ROS production, and redox-sensitive enzymes may be potential targets for therapeutic intervention in CML cells, these consist of signaling molecules that are also common to normal cells and therefore may not be ideal targets. Alternative DNA repair pathways and/or proteins that are enhanced by BCR-ABL-positive CML cells may serve as better therapeutic targets that would serve to eliminate CML cells while sparing normal cells. 


\section{REFERENCES CITED}

1. Marley, S.B. and M.Y. Gordon, Chronic myeloid leukaemia: stem cell derived but progenitor cell driven. Clin Sci (Lond), 2005. 109(1): p. 13-25.

2. Strife, A. and B. Clarkson, Biology of chronic myelogenous leukemia: is discordant maturation the primary defect? Semin Hematol, 1988. 25(1): p. 1-19.

3. Gordon, M.Y., et al., Altered adhesive interactions with marrow stroma of haematopoietic progenitor cells in chronic myeloid leukaemia. Nature, 1987. 328(6128): p. 342-4.

4. Aguayo, A., et al., Angiogenesis in acute and chronic leukemias and myelodysplastic syndromes. Blood, 2000. 96(6): p. 2240-5.

5. Faderl, S., H.M. Kantarjian, and M. Talpaz, Chronic myelogenous leukemia: update on biology and treatment. Oncology (Williston Park), 1999. 13(2): p. 16980; discussion 181, 184.

6. Kantarjian, H.M., et al., Chronic myelogenous leukemia: a concise update. Blood, 1993. 82(3): p. 691-703.

7. Kantarjian, H.M., et al., Chronic myelogenous leukemia: a multivariate analysis of the associations of patient characteristics and therapy with survival. Blood, 1985. 66(6): p. 1326-35.

8. Quintas-Cardama, A. and J.E. Cortes, Chronic myeloid leukemia: diagnosis and treatment. Mayo Clin Proc, 2006. 81(7): p. 973-88.

9. Cortes, J. and H. Kantarjian, Advanced-phase chronic myeloid leukemia. Semin Hematol, 2003. 40(1): p. 79-86.

10. Kurzrock, R., et al., Philadelphia chromosome-positive leukemias: from basic mechanisms to molecular therapeutics. Ann Intern Med, 2003. 138(10): p. 81930 .

11. Kantarjian, H.M., et al., Chronic myelogenous leukemia in blast crisis. Analysis of 242 patients. Am J Med, 1987. 83(3): p. 445-54.

12. Siegel, R., D. Naishadham, and A. Jemal, Cancer statistics, 2012. CA Cancer J Clin, 2012. 62(1): p. 10-29.

13. Deininger, M.W., J.M. Goldman, and J.V. Melo, The molecular biology of chronic myeloid leukemia. Blood, 2000. 96(10): p. 3343-56. 
14. Bizzozero, O.J., Jr., et al., Radiation-related leukemia in Hiroshima and Nagasaki 1946--1964. II. Ann Intern Med, 1967. 66(3): p. 522-30.

15. Nowell, P.C.H., D.A., A Minute Chromosome in Human Chronic Granulocytic Leukemia. Science, 1960. 132: p. 1497.

16. Rowley, J.D., Letter: A new consistent chromosomal abnormality in chronic myelogenous leukaemia identified by quinacrine fluorescence and Giemsa staining. Nature, 1973. 243(5405): p. 290-3.

17. de Klein, A., et al., A cellular oncogene is translocated to the Philadelphia chromosome in chronic myelocytic leukaemia. Nature, 1982. 300(5894): p. 765-7.

18. Groffen, J., et al., Philadelphia chromosomal breakpoints are clustered within a limited region, bcr, on chromosome 22. Cell, 1984. 36(1): p. 93-9.

19. Shtivelman, E., et al., Fused transcript of abl and bor genes in chronic myelogenous leukaemia. Nature, 1985. 315(6020): p. 550-4.

20. Teyssier, J.R., et al., c-abl Oncogene and chromosome 22 "bcr" juxtaposition in chronic myelogenous leukemia. N Engl J Med, 1985. 312(21): p. 1393-4.

21. Goldman, J.M. and J.V. Melo, BCR-ABL in chronic myelogenous leukemia--how does it work? Acta Haematol, 2008. 119(4): p. 212-7.

22. Melo, J.V. and M.W. Deininger, Biology of chronic myelogenous leukemia-signaling pathways of initiation and transformation. Hematol Oncol Clin North Am, 2004. 18(3): p. 545-68, vii-viii.

23. Sanchez-Garcia, I. and G. Grutz, Tumorigenic activity of the BCR-ABL oncogenes is mediated by BCL2. Proc Natl Acad Sci U S A, 1995. 92(12): p. 5287-91.

24. Sanchez-Garcia, I. and D. Martin-Zanca, Regulation of Bcl-2 gene expression by BCR-ABL is mediated by Ras. J Mol Biol, 1997. 267(2): p. 225-8.

25. Horita, M., et al., Blockade of the Bcr-Abl kinase activity induces apoptosis of chronic myelogenous leukemia cells by suppressing signal transducer and activator of transcription 5-dependent expression of Bcl-xL. J Exp Med, 2000. 191(6): p. 977-84.

26. Bedi, A., et al., Inhibition of apoptosis by BCR-ABL in chronic myeloid leukemia. Blood, 1994. 83(8): p. 2038-44.

27. Datta, S.R., et al., Akt phosphorylation of BAD couples survival signals to the cell-intrinsic death machinery. Cell, 1997. 91(2): p. 231-41. 
28. Selleri, C. and J.P. Maciejewski, The role of FAS-mediated apoptosis in chronic myelogenous leukemia. Leuk Lymphoma, 2000. 37(3-4): p. 283-97.

29. Selleri, C., et al., Fas-mediated modulation of Bcr/Abl in chronic myelogenous leukemia results in differential effects on apoptosis. Blood, 1998. 92(3): p. 981-9.

30. Donato, N.J., et al., Down-regulation of interleukin-3/granulocyte-macrophage colony-stimulating factor receptor beta-chain in BCR-ABL(+) human leukemic cells: association with loss of cytokine-mediated Stat-5 activation and protection from apoptosis after BCR-ABL inhibition. Blood, 2001. 97(9): p. 2846-53.

31. Ilaria, R.L., Jr. and R.A. Van Etten, $P 210$ and $P 190(B C R / A B L)$ induce the tyrosine phosphorylation and DNA binding activity of multiple specific STAT family members. J Biol Chem, 1996. 271(49): p. 31704-10.

32. Jiang, X., et al., Autocrine production and action of IL-3 and granulocyte colonystimulating factor in chronic myeloid leukemia. Proc Natl Acad Sci U S A, 1999. 96(22): p. 12804-9.

33. Wilson-Rawls, J., et al., P210 Bcr-Abl interacts with the interleukin 3 receptor beta(c) subunit and constitutively induces its tyrosine phosphorylation. Cancer Res, 1996. 56(15): p. 3426-30.

34. Dvorak, P., et al., Increased expression of fibroblast growth factor receptor 3 in $C D 34+B C R-A B L+$ cells from patients with chronic myeloid leukemia. Leukemia, 2003. 17(12): p. 2418-25.

35. Wetzler, M., et al., Altered levels of interleukin-1 beta and interleukin-1 receptor antagonist in chronic myelogenous leukemia: clinical and prognostic correlates. Blood, 1994. 84(9): p. 3142-7.

36. Wilson-Rawls, J., et al., P210 Bcr-Abl interacts with the interleukin-3 beta $\mathrm{c}$ subunit and constitutively activates Jak2. Leukemia, 1997. 11 Suppl 3: p. 428-31.

37. Cheng, K., et al., Reduced focal adhesion kinase and paxillin phosphorylation in BCR-ABL-transfected cells. Cancer, 2002. 95(2): p. 440-50.

38. Gotoh, A., et al., Tyrosine phosphorylation and activation of focal adhesion kinase (p125FAK) by BCR-ABL oncoprotein. Exp Hematol, 1995. 23(11): p. 1153-9.

39. Harnois, T., et al., Differential interaction and activation of Rho family GTPases by p210bcr-abl and p190bcr-abl. Oncogene, 2003. 22(41): p. 6445-54. 
40. McWhirter, J.R., D.L. Galasso, and J.Y. Wang, A coiled-coil oligomerization domain of Bcr is essential for the transforming function of Bcr-Abl oncoproteins. Mol Cell Biol, 1993. 13(12): p. 7587-95.

41. Tapon, N. and A. Hall, Rho, Rac and Cdc42 GTPases regulate the organization of the actin cytoskeleton. Curr Opin Cell Biol, 1997. 9(1): p. 86-92.

42. Pendergast, A.M., et al., BCR sequences essential for transformation by the BCR$A B L$ oncogene bind to the $A B L S H 2$ regulatory domain in a non-phosphotyrosinedependent manner. Cell, 1991. 66(1): p. 161-71.

43. Pendergast, A.M., et al., $B C R$ - $A B L$-induced oncogenesis is mediated by direct interaction with the SH2 domain of the GRB-2 adaptor protein. Cell, 1993. 75(1): p. $175-85$.

44. Pavlovsky, C., H. Kantarjian, and J.E. Cortes, First-line therapy for chronic myeloid leukemia: Past, present, and future. Am J Hematol, 2009. 84(5): p. 28793.

45. Hehlmann, R., et al., Randomized comparison of interferon-alpha with busulfan and hydroxyurea in chronic myelogenous leukemia. The German CML Study Group. Blood, 1994. 84(12): p. 4064-77.

46. Kantarian, H.M., et al., Prolonged survival in chronic myelogenous leukemia after cytogenetic response to interferon-alpha therapy. The Leukemia Service. Ann Intern Med, 1995. 122(4): p. 254-61.

47. Bonifazi, F., et al., Chronic myeloid leukemia and interferon-alpha: a study of complete cytogenetic responders. Blood, 2001. 98(10): p. 3074-81.

48. Kantarjian, H.M., et al., Complete cytogenetic and molecular responses to interferon-alpha-based therapy for chronic myelogenous leukemia are associated with excellent long-term prognosis. Cancer, 2003. 97(4): p. 1033-41.

49. Talpaz, M., et al., Interferon-alpha produces sustained cytogenetic responses in chronic myelogenous leukemia. Philadelphia chromosome-positive patients. Ann Intern Med, 1991. 114(7): p. 532-8.

50. Guilhot, F., et al., Interferon alfa-2b combined with cytarabine versus interferon alone in chronic myelogenous leukemia. French Chronic Myeloid Leukemia Study Group. N Engl J Med, 1997. 337(4): p. 223-9.

51. Kantarjian, H.M., et al., Treatment of Philadelphia chromosome-positive early chronic phase chronic myelogenous leukemia with daily doses of interferon alpha and low-dose cytarabine. J Clin Oncol, 1999. 17(1): p. 284-92. 
52. Buchdunger, E., et al., Inhibition of the Abl protein-tyrosine kinase in vitro and in vivo by a 2-phenylaminopyrimidine derivative. Cancer Res, 1996. 56(1): p. 100-4.

53. Carroll, M., et al., CGP 57148, a tyrosine kinase inhibitor, inhibits the growth of cells expressing BCR-ABL, TEL-ABL, and TEL-PDGFR fusion proteins. Blood, 1997. 90(12): p. 4947-52.

54. Heinrich, M.C., et al., Inhibition of c-kit receptor tyrosine kinase activity by STI 571, a selective tyrosine kinase inhibitor. Blood, 2000. 96(3): p. 925-32.

55. Gambacorti-Passerini, C.B., et al., Molecular mechanisms of resistance to imatinib in Philadelphia-chromosome-positive leukaemias. Lancet Oncol, 2003. 4(2): p. 75-85.

56. Graham, S.M., et al., Primitive, quiescent, Philadelphia-positive stem cells from patients with chronic myeloid leukemia are insensitive to STI571 in vitro. Blood, 2002. 99(1): p. 319-25.

57. Holtz, M.S., et al., Imatinib mesylate (STI571) inhibits growth of primitive malignant progenitors in chronic myelogenous leukemia through reversal of abnormally increased proliferation. Blood, 2002. 99(10): p. 3792-800.

58. Kantarjian, H., et al., Hematologic and cytogenetic responses to imatinib mesylate in chronic myelogenous leukemia. N Engl J Med, 2002. 346(9): p. 645-52.

59. de Lavallade, H., et al., Imatinib for newly diagnosed patients with chronic myeloid leukemia: incidence of sustained responses in an intention-to-treat analysis. J Clin Oncol, 2008. 26(20): p. 3358-63.

60. Druker, B.J., et al., Five-year follow-up of patients receiving imatinib for chronic myeloid leukemia. N Engl J Med, 2006. 355(23): p. 2408-17.

61. Hochhaus, A., et al., Favorable long-term follow-up results over 6 years for response, survival, and safety with imatinib mesylate therapy in chronic-phase chronic myeloid leukemia after failure of interferon-alpha treatment. Blood, 2008. 111(3): p. 1039-43.

62. Sawyers, C.L., et al., Imatinib induces hematologic and cytogenetic responses in patients with chronic myelogenous leukemia in myeloid blast crisis: results of a phase II study. Blood, 2002. 99(10): p. 3530-9.

63. Talpaz, M., et al., Imatinib induces durable hematologic and cytogenetic responses in patients with accelerated phase chronic myeloid leukemia: results of a phase 2 study. Blood, 2002. 99(6): p. 1928-37. 
64. Shah, N.P., et al., Multiple BCR-ABL kinase domain mutations confer polyclonal resistance to the tyrosine kinase inhibitor imatinib (STI571) in chronic phase and blast crisis chronic myeloid leukemia. Cancer Cell, 2002. 2(2): p. 117-25.

65. Jabbour, E., et al., Frequency and clinical significance of BCR-ABL mutations in patients with chronic myeloid leukemia treated with imatinib mesylate. Leukemia, 2006. 20(10): p. 1767-73.

66. O'Hare, T., C.A. Eide, and M.W. Deininger, Bcr-Abl kinase domain mutations, drug resistance, and the road to a cure for chronic myeloid leukemia. Blood, 2007. 110(7): p. 2242-9.

67. Soverini, S., et al., Contribution of ABL kinase domain mutations to imatinib resistance in different subsets of Philadelphia-positive patients: by the GIMEMA Working Party on Chronic Myeloid Leukemia. Clin Cancer Res, 2006. 12(24): p. 7374-9.

68. Roche-Lestienne, C., et al., Several types of mutations of the Abl gene can be found in chronic myeloid leukemia patients resistant to STI571, and they can preexist to the onset of treatment. Blood, 2002. 100(3): p. 1014-8.

69. Hochhaus, A., et al., Molecular and chromosomal mechanisms of resistance to imatinib (STI571) therapy. Leukemia, 2002. 16(11): p. 2190-6.

70. Dai, Y., et al., A Bcr/Abl-independent, Lyn-dependent form of imatinib mesylate (STI-571) resistance is associated with altered expression of Bcl-2. J Biol Chem, 2004. 279(33): p. 34227-39.

71. Donato, N.J., et al., BCR-ABL independence and LYN kinase overexpression in chronic myelogenous leukemia cells selected for resistance to STI571. Blood, 2003. 101(2): p. 690-8.

72. Thomas, J., et al., Active transport of imatinib into and out of cells: implications for drug resistance. Blood, 2004. 104(12): p. 3739-45.

73. Wendel, H.G., et al., Loss of 553 impedes the antileukemic response to $B C R-A B L$ inhibition. Proc Natl Acad Sci U S A, 2006. 103(19): p. 7444-9.

74. Lombardo, L.J., et al., Discovery of N-(2-chloro-6-methyl-phenyl)-2-(6-(4-(2hydroxyethyl)- piperazin-1-yl)-2-methylpyrimidin-4- ylamino)thiazole-5carboxamide (BMS-354825), a dual Src/Abl kinase inhibitor with potent antitumor activity in preclinical assays. J Med Chem, 2004. 47(27): p. 6658-61.

75. O'Hare, T., et al., In vitro activity of Bcr-Abl inhibitors AMN107 and BMS354825 against clinically relevant imatinib-resistant Abl kinase domain mutants. Cancer Res, 2005. 65(11): p. 4500-5. 
76. Tokarski, J.S., et al., The structure of Dasatinib (BMS-354825) bound to activated ABL kinase domain elucidates its inhibitory activity against imatinib-resistant ABL mutants. Cancer Res, 2006. 66(11): p. 5790-7.

77. Copland, M., et al., Dasatinib (BMS-354825) targets an earlier progenitor population than imatinib in primary CML but does not eliminate the quiescent fraction. Blood, 2006. 107(11): p. 4532-9.

78. Weisberg, E., et al., Characterization of AMN107, a selective inhibitor of native and mutant Bcr-Abl. Cancer Cell, 2005. 7(2): p. 129-41.

79. Cortes, J., et al., Dasatinib induces complete hematologic and cytogenetic responses in patients with imatinib-resistant or -intolerant chronic myeloid leukemia in blast crisis. Blood, 2007. 109(8): p. 3207-13.

80. Guilhot, F., et al., Dasatinib induces significant hematologic and cytogenetic responses in patients with imatinib-resistant or -intolerant chronic myeloid leukemia in accelerated phase. Blood, 2007. 109(10): p. 4143-50.

81. Hochhaus, A., et al., Dasatinib induces durable cytogenetic responses in patients with chronic myelogenous leukemia in chronic phase with resistance or intolerance to imatinib. Leukemia, 2008. 22(6): p. 1200-6.

82. Kantarjian, H., et al., Nilotinib in imatinib-resistant CML and Philadelphia chromosome-positive ALL. N Engl J Med, 2006. 354(24): p. 2542-51.

83. Kantarjian, H.M., et al., Nilotinib (formerly AMN107), a highly selective BCRABL tyrosine kinase inhibitor, is effective in patients with Philadelphia chromosome-positive chronic myelogenous leukemia in chronic phase following imatinib resistance and intolerance. Blood, 2007. 110(10): p. 3540-6.

84. le Coutre, P., et al., Nilotinib (formerly AMN107), a highly selective BCR-ABL tyrosine kinase inhibitor, is active in patients with imatinib-resistant or intolerant accelerated-phase chronic myelogenous leukemia. Blood, 2008. 111(4): p. 1834-9.

85. Shah, N.P., et al., Intermittent target inhibition with dasatinib $100 \mathrm{mg}$ once daily preserves efficacy and improves tolerability in imatinib-resistant and-intolerant chronic-phase chronic myeloid leukemia. J Clin Oncol, 2008. 26(19): p. 3204-12.

86. Cortes, J., et al., Dynamics of BCR-ABL kinase domain mutations in chronic myeloid leukemia after sequential treatment with multiple tyrosine kinase inhibitors. Blood, 2007. 110(12): p. 4005-11. 
87. Winterbourn, C.C., Superoxide as an intracellular radical sink. Free Radic Biol Med, 1993. 14(1): p. 85-90.

88. Suzuki, Y.J., H.J. Forman, and A. Sevanian, Oxidants as stimulators of signal transduction. Free Radic Biol Med, 1997. 22(1-2): p. 269-85.

89. Fridovich, I., Biological effects of the superoxide radical. Arch Biochem Biophys, 1986. 247(1): p. 1-11.

90. Sattler, M., et al., Hematopoietic growth factors signal through the formation of reactive oxygen species. Blood, 1999. 93(9): p. 2928-35.

91. Valko, M., et al., Role of oxygen radicals in DNA damage and cancer incidence. Mol Cell Biochem, 2004. 266(1-2): p. 37-56.

92. Sallmyr, A., J. Fan, and F.V. Rassool, Genomic instability in myeloid malignancies: increased reactive oxygen species (ROS), DNA double strand breaks (DSBs) and error-prone repair. Cancer Lett, 2008. 270(1): p. 1-9.

93. Chance, B., H. Sies, and A. Boveris, Hydroperoxide metabolism in mammalian organs. Physiol Rev, 1979. 59(3): p. 527-605.

94. Cadenas, E. and K.J. Davies, Mitochondrial free radical generation, oxidative stress, and aging. Free Radic Biol Med, 2000. 29(3-4): p. 222-30.

95. Buettner, G.R. and B.A. Jurkiewicz, Catalytic metals, ascorbate and free radicals: combinations to avoid. Radiat Res, 1996. 145(5): p. 532-41.

96. Kalyanaraman, B., K.M. Morehouse, and R.P. Mason, An electron paramagnetic resonance study of the interactions between the adriamycin semiquinone, hydrogen peroxide, iron-chelators, and radical scavengers. Arch Biochem Biophys, 1991. 286(1): p. 164-70.

97. Shi, X., et al., Reduction of chromium(VI) and its relationship to carcinogenesis. J Toxicol Environ Health B Crit Rev, 1999. 2(1): p. 87-104.

98. Stohs, S.J. and D. Bagchi, Oxidative mechanisms in the toxicity of metal ions. Free Radic Biol Med, 1995. 18(2): p. 321-36.

99. Rodriguez, A.M., et al., Mitochondrial or cytosolic catalase reverses the MnSODdependent inhibition of proliferation by enhancing respiratory chain activity, net ATP production, and decreasing the steady state levels of $H(2) O(2)$. Free Radic Biol Med, 2000. 29(9): p. 801-13.

100. Salmeen, A. and D. Barford, Functions and mechanisms of redox regulation of cysteine-based phosphatases. Antioxid Redox Signal, 2005. 7(5-6): p. 560-77. 
101. Denu, J.M. and K.G. Tanner, Specific and reversible inactivation of protein tyrosine phosphatases by hydrogen peroxide: evidence for a sulfenic acid intermediate and implications for redox regulation. Biochemistry, 1998. 37(16): p. 5633-42.

102. Agatsuma, S., et al., Hydroxyl radical-induced characteristic chemiluminescent spectra from plasma of hemodialysis patients. Clin Chem, 1992. 38(1): p. 48-55.

103. Hempel, S.L., et al., Extracellular iron (II) can protect cells from hydrogen peroxide. Arch Biochem Biophys, 1996. 330(2): p. 401-8.

104. Lloyd, R.V., P.M. Hanna, and R.P. Mason, The origin of the hydroxyl radical oxygen in the Fenton reaction. Free Radic Biol Med, 1997. 22(5): p. 885-8.

105. Schafer, F.Q., S.Y. Qian, and G.R. Buettner, Iron and free radical oxidations in cell membranes. Cell Mol Biol (Noisy-le-grand), 2000. 46(3): p. 657-62.

106. Karanjawala, Z.E., et al., Oxygen metabolism causes chromosome breaks and is associated with the neuronal apoptosis observed in DNA double-strand break repair mutants. Curr Biol, 2002. 12(5): p. 397-402.

107. Dizdaroglu, M., et al., Free radical-induced damage to DNA: mechanisms and measurement. Free Radic Biol Med, 2002. 32(11): p. 1102-15.

108. Zastawny, T.H., et al., DNA base modifications and membrane damage in cultured mammalian cells treated with iron ions. Free Radic Biol Med, 1995. 18(6): p. 1013-22.

109. Wiseman, H. and B. Halliwell, Damage to DNA by reactive oxygen and nitrogen species: role in inflammatory disease and progression to cancer. Biochem J, 1996. 313 ( Pt 1): p. 17-29.

110. Rodrigues, M.S., M.M. Reddy, and M. Sattler, Cell cycle regulation by oncogenic tyrosine kinases in myeloid neoplasias: from molecular redox mechanisms to health implications. Antioxid Redox Signal, 2008. 10(10): p. 1813-48.

111. Boveris, A. and B. Chance, The mitochondrial generation of hydrogen peroxide. General properties and effect of hyperbaric oxygen. Biochem J, 1973. 134(3): p. 707-16.

112. Matsuzawa, A., et al., Physiological roles of ASK1-mediated signal transduction in oxidative stress- and endoplasmic reticulum stress-induced apoptosis: advanced findings from ASK1 knockout mice. Antioxid Redox Signal, 2002. 4(3): p. 415-25. 
113. Bedard, K. and K.H. Krause, The NOX family of ROS-generating NADPH oxidases: physiology and pathophysiology. Physiol Rev, 2007. 87(1): p. 245-313.

114. Hanukoglu, I., et al., Electron leakage from the mitochondrial NADPHadrenodoxin reductase-adrenodoxin-P450scc (cholesterol side chain cleavage) system. Arch Biochem Biophys, 1993. 305(2): p. 489-98.

115. Salvador, A., J. Sousa, and R.E. Pinto, Hydroperoxyl, superoxide and $p H$ gradients in the mitochondrial matrix: a theoretical assessment. Free Radic Biol Med, 2001. 31(10): p. 1208-15.

116. Andreyev, A.Y., Y.E. Kushnareva, and A.A. Starkov, Mitochondrial metabolism of reactive oxygen species. Biochemistry (Mosc), 2005. 70(2): p. 200-14.

117. Barja, G., Mitochondrial oxygen radical generation and leak: sites of production in states 4 and 3, organ specificity, and relation to aging and longevity. $\mathrm{J}$ Bioenerg Biomembr, 1999. 31(4): p. 347-66.

118. Herrero, A. and G. Barja, Localization of the site of oxygen radical generation inside the complex I of heart and nonsynaptic brain mammalian mitochondria. $\mathrm{J}$ Bioenerg Biomembr, 2000. 32(6): p. 609-15.

119. Lenaz, G., The mitochondrial production of reactive oxygen species: mechanisms and implications in human pathology. IUBMB Life, 2001. 52(3-5): p. 159-64.

120. Sipos, I., L. Tretter, and V. Adam-Vizi, Quantitative relationship between inhibition of respiratory complexes and formation of reactive oxygen species in isolated nerve terminals. J Neurochem, 2003. 84(1): p. 112-8.

121. Van Heerebeek, L., et al., NADPH oxidase(s): new source(s) of reactive oxygen species in the vascular system? J Clin Pathol, 2002. 55(8): p. 561-8.

122. Vignais, P.V., The superoxide-generating NADPH oxidase: structural aspects and activation mechanism. Cell Mol Life Sci, 2002. 59(9): p. 1428-59.

123. Thannickal, V.J. and B.L. Fanburg, Reactive oxygen species in cell signaling. Am J Physiol Lung Cell Mol Physiol, 2000. 279(6): p. L1005-28.

124. Quinn, M.T. and K.A. Gauss, Structure and regulation of the neutrophil respiratory burst oxidase: comparison with nonphagocyte oxidases. J Leukoc Biol, 2004. 76(4): p. 760-81.

125. Butler, J. and B.M. Hoey, The one-electron reduction potential of several substrates can be related to their reduction rates by cytochrome $P-450$ reductase. Biochim Biophys Acta, 1993. 1161(1): p. 73-8. 
126. Borges, F., E. Fernandes, and F. Roleira, Progress towards the discovery of xanthine oxidase inhibitors. Curr Med Chem, 2002. 9(2): p. 195-217.

127. Harrison, R., Structure and function of xanthine oxidoreductase: where are we now? Free Radic Biol Med, 2002. 33(6): p. 774-97.

128. Fahl, W.E., et al., DNA damage related to increased hydrogen peroxide generation by hypolipidemic drug-induced liver peroxisomes. Proc Natl Acad Sci U S A, 1984. 81(24): p. 7827-30.

129. Mills, K.D., D.O. Ferguson, and F.W. Alt, The role of DNA breaks in genomic instability and tumorigenesis. Immunol Rev, 2003. 194: p. 77-95.

130. Fleck, O. and O. Nielsen, DNA repair. J Cell Sci, 2004. 117(Pt 4): p. 515-7.

131. Steenken, S., Structure, acid/base properties and transformation reactions of purine radicals. Free Radic Res Commun, 1989. 6(2-3): p. 117-20.

132. Kim, J.E., et al., 8-Oxoguanine induces intramolecular DNA damage but free 8oxoguanine protects intermolecular DNA from oxidative stress. FEBS Lett, 2004. 556(1-3): p. 104-10.

133. Breen, A.P. and J.A. Murphy, Reactions of oxyl radicals with DNA. Free Radic Biol Med, 1995. 18(6): p. 1033-77.

134. Dizdaroglu, M., Oxidative damage to DNA in mammalian chromatin. Mutat Res, 1992. 275(3-6): p. 331-42.

135. Kasai, H., et al., Formation, inhibition of formation, and repair of oxidative 8hydroxyguanine DNA damage. Basic Life Sci, 1993. 61: p. 257-62.

136. Buchko, G.W., et al., Methylene blue-mediated photooxidation of 7,8-dihydro-8oxo-2'-deoxyguanosine. Biochim Biophys Acta, 1995. 1263(1): p. 17-24.

137. Burney, S., et al., DNA damage in deoxynucleosides and oligonucleotides treated with peroxynitrite. Chem Res Toxicol, 1999. 12(6): p. 513-20.

138. Niles, J.C., et al., Peroxynitrite reaction products of 3',5'-di-O-acetyl-8-oxo-7, 8dihydro-2'-deoxyguanosine. Proc Natl Acad Sci U S A, 1999. 96(21): p. 1172934 .

139. Uppu, R.M., et al., Competitive reactions of peroxynitrite with 2'-deoxyguanosine and 7,8-dihydro-8-oxo-2'-deoxyguanosine (8-oxodG): relevance to the formation of 8-oxodG in DNA exposed to peroxynitrite. Free Radic Biol Med, 1996. 21(3): p. 407-11. 
140. Bruner, S.D., D.P. Norman, and G.L. Verdine, Structural basis for recognition and repair of the endogenous mutagen 8-oxoguanine in DNA. Nature, 2000. 403(6772): p. 859-66.

141. Loft, S., et al., 8-Hydroxydeoxyguanosine as a urinary biomarker of oxidative DNA damage. J Toxicol Environ Health, 1993. 40(2-3): p. 391-404.

142. Shigenaga, M.K., C.J. Gimeno, and B.N. Ames, Urinary 8-hydroxy-2'deoxyguanosine as a biological marker of in vivo oxidative DNA damage. Proc Natl Acad Sci U S A, 1989. 86(24): p. 9697-701.

143. Dreher, D. and A.F. Junod, Role of oxygen free radicals in cancer development. Eur J Cancer, 1996. 32A(1): p. 30-8.

144. Marnett, L.J., Oxyradicals and DNA damage. Carcinogenesis, 2000. 21(3): p. 361-70.

145. Wallace, S.S., Enzymatic processing of radiation-induced free radical damage in DNA. Radiat Res, 1998. 150(5 Suppl): p. S60-79.

146. Bessho, T., et al., Evidence for two DNA repair enzymes for 8-hydroxyguanine (7,8-dihydro-8-oxoguanine) in human cells. J Biol Chem, 1993. 268(26): p. 19416-21.

147. Lunec, J., et al., Urinary 8-oxo-2'-deoxyguanosine: redox regulation of DNA repair in vivo? Free Radic Biol Med, 2002. 33(7): p. 875-85.

148. Wang, D., D.A. Kreutzer, and J.M. Essigmann, Mutagenicity and repair of oxidative DNA damage: insights from studies using defined lesions. Mutat Res, 1998. 400(1-2): p. 99-115.

149. Kurz, E.U. and S.P. Lees-Miller, DNA damage-induced activation of ATM and ATM-dependent signaling pathways. DNA Repair (Amst), 2004. 3(8-9): p. 889900.

150. Scherthan, H., et al., Accumulation of DSBs in gamma-H2AX domains fuel chromosomal aberrations. Biochem Biophys Res Commun, 2008. 371(4): p. 6947.

151. Riballo, E., et al., A pathway of double-strand break rejoining dependent upon ATM, Artemis, and proteins locating to gamma-H2AXfoci. Mol Cell, 2004. 16(5): p. 715-24.

152. Lieber, M.R., Warner-Lambert/Parke-Davis Award Lecture. Pathological and physiological double-strand breaks: roles in cancer, aging, and the immune system. Am J Pathol, 1998. 153(5): p. 1323-32. 
153. Lieber, M.R., The biochemistry and biological significance of nonhomologous DNA end joining: an essential repair process in multicellular eukaryotes. Genes Cells, 1999. 4(2): p. 77-85.

154. Takata, M., et al., Homologous recombination and non-homologous end-joining pathways of DNA double-strand break repair have overlapping roles in the maintenance of chromosomal integrity in vertebrate cells. EMBO J, 1998. 17(18): p. 5497-508.

155. Rogakou, E.P., et al., Megabase chromatin domains involved in DNA doublestrand breaks in vivo. J Cell Biol, 1999. 146(5): p. 905-16.

156. Rogakou, E.P., et al., DNA double-stranded breaks induce histone H2AX phosphorylation on serine 139. J Biol Chem, 1998. 273(10): p. 5858-68.

157. Fernandez-Capetillo, O., et al., H2AX: the histone guardian of the genome. DNA Repair (Amst), 2004. 3(8-9): p. 959-67.

158. Sedelnikova, O.A., et al., Quantitative detection of (125)IdU-induced DNA double-strand breaks with gamma-H2AX antibody. Radiat Res, 2002. 158(4): p. 486-92.

159. Sattler, M. and R. Salgia, Activation of hematopoietic growth factor signal transduction pathways by the human oncogene BCR/ABL. Cytokine Growth Factor Rev, 1997. 8(1): p. 63-79.

160. Sattler, M., et al., The BCR/ABL tyrosine kinase induces production of reactive oxygen species in hematopoietic cells. J Biol Chem, 2000. 275(32): p. 24273-8.

161. Kim, J.H., et al., Activation of the PI3K/mTOR pathway by BCR-ABL contributes to increased production of reactive oxygen species. Blood, 2005. 105(4): p. 171723.

162. Warburg, O., [On the facultative anaerobiosis of cancer cells and its use in chemotherapy]. Munch Med Wochenschr, 1961. 103: p. 2504-6.

163. Ahmed, N. and M.V. Berridge, Regulation of glucose transport by interleukin-3 in growth factor-dependent and oncogene-transformed bone marrow-derived cell lines. Leuk Res, 1997. 21(7): p. 609-18.

164. Bentley, J., et al., Glucose transport regulation by $210 \mathrm{Bcr}$-Abl in a chronic myeloid leukaemia model. Br J Haematol, 2001. 112(1): p. 212-5.

165. Hickey, F.B. and T.G. Cotter, Identification of transcriptional targets associated with the expression of p210 Bcr-Abl. Eur J Haematol, 2006. 76(5): p. 369-83. 
166. Sattler, M., et al., Critical role for Gab2 in transformation by BCR/ABL. Cancer Cell, 2002. 1(5): p. 479-92.

167. Gordan, J.D., C.B. Thompson, and M.C. Simon, HIF and c-Myc: sibling rivals for control of cancer cell metabolism and proliferation. Cancer Cell, 2007. 12(2): p. 108-13.

168. Mayerhofer, M., et al., BCR/ABL induces expression of vascular endothelial growth factor and its transcriptional activator, hypoxia inducible factor-1alpha, through a pathway involving phosphoinositide 3-kinase and the mammalian target of rapamycin. Blood, 2002. 100(10): p. 3767-75.

169. Skorski, T., et al., Transformation of hematopoietic cells by BCR/ABL requires activation of a PI-3k/Akt-dependent pathway. EMBO J, 1997. 16(20): p. 6151-61.

170. Zou, X., et al., Induction of c-myc transcription by the v-Abl tyrosine kinase requires Ras, Rafl, and cyclin-dependent kinases. Genes Dev, 1997. 11(5): p. 654-62.

171. Bassermann, F., et al., Association of Bcr-Abl with the proto-oncogene Vav is implicated in activation of the Rac-1 pathway. J Biol Chem, 2002. 277(14): p. 12437-45.

172. Skorski, T., et al., BCR/ABL-mediated leukemogenesis requires the activity of the small GTP-binding protein Rac. Proc Natl Acad Sci U S A, 1998. 95(20): p. 11858-62.

173. Slupianek, A., et al., Fusion tyrosine kinases induce drug resistance by stimulation of homology-dependent recombination repair, prolongation of $G(2) / M$ phase, and protection from apoptosis. Mol Cell Biol, 2002. 22(12): p. 4189-201.

174. Canitrot, Y., et al., p210 BCR/ABL kinase regulates nucleotide excision repair (NER) and resistance to UV radiation. Blood, 2003. 102(7): p. 2632-7.

175. Canitrot, Y., et al., Mutator phenotype of BCR--ABL transfected Ba/F3 cell lines and its association with enhanced expression of DNA polymerase beta. Oncogene, 1999. 18(17): p. 2676-80.

176. Deutsch, E., et al., BCR-ABL down-regulates the DNA repair protein DNA-PKcs. Blood, 2001. 97(7): p. 2084-90.

177. Deutsch, E., et al., Down-regulation of BRCA1 in BCR-ABL-expressing hematopoietic cells. Blood, 2003. 101(11): p. 4583-8.

178. Ilaria, R., Jr., Bcr/Abl, leukemogenesis, and genomic instability: a complex partnership. Leuk Res, 2002. 26(11): p. 971-3. 
179. Klucher, K.M., D.V. Lopez, and G.Q. Daley, Secondary mutation maintains the transformed state in BaF3 cells with inducible BCR/ABL expression. Blood, 1998. 91(10): p. 3927-34.

180. Salloukh, H.F. and P. Laneuville, Increase in mutant frequencies in mice expressing the BCR-ABL activated tyrosine kinase. Leukemia, 2000. 14(8): $\mathrm{p}$. $1401-4$.

181. Shet, A.S., B.N. Jahagirdar, and C.M. Verfaillie, Chronic myelogenous leukemia: mechanisms underlying disease progression. Leukemia, 2002. 16(8): p. 1402-11.

182. Nowicki, M.O., et al., $B C R / A B L$ oncogenic kinase promotes unfaithful repair of the reactive oxygen species-dependent DNA double-strand breaks. Blood, 2004. 104(12): p. 3746-53.

183. Koptyra, M., et al., BCR/ABL promotes accumulation of chromosomal aberrations induced by oxidative and genotoxic stress. Leukemia, 2008. 22(10): p. 1969-72.

184. Koptyra, M., et al., $B C R / A B L$ kinase induces self-mutagenesis via reactive oxygen species to encode imatinib resistance. Blood, 2006. 108(1): p. 319-27.

185. Skorski, T., $B C R / A B L$ regulates response to $D N A$ damage: the role in resistance to genotoxic treatment and in genomic instability. Oncogene, 2002. 21(56): p. 8591-604.

186. Pytel, D., T. Wysocki, and I. Majsterek, Comparative study of DNA damage, cell cycle and apoptosis in human K562 and CCRF-CEM leukemia cells: role of $B C R / A B L$ in therapeutic resistance. Comp Biochem Physiol C Toxicol Pharmacol, 2006. 144(1): p. 85-92.

187. Cramer, K., et al., $B C R / A B L$ and other kinases from chronic myeloproliferative disorders stimulate single-strand annealing, an unfaithful DNA double-strand break repair. Cancer Res, 2008. 68(17): p. 6884-8.

188. Slupianek, A., et al., $B C R / A B L$ kinase interacts with and phosphorylates the RAD51 paralog, RAD51B. Leukemia, 2009. 23(12): p. 2308-10.

189. Slupianek, A., et al., BCR/ABL modifies the kinetics and fidelity of DNA doublestrand breaks repair in hematopoietic cells. DNA Repair (Amst), 2006. 5(2): p. $243-50$.

190. Slupianek, A., et al., BCR/ABL regulates mammalian RecA homologs, resulting in drug resistance. Mol Cell, 2001. 8(4): p. 795-806. 
191. Stoklosa, T., et al., BCR/ABL inhibits mismatch repair to protect from apoptosis and induce point mutations. Cancer Res, 2008. 68(8): p. 2576-80.

192. Andrews, D.F., 3rd and S.J. Collins, Heterogeneity in expression of the bcr-abl fusion transcript in CML blast crisis. Leukemia, 1987. 1(10): p. 718-24.

193. Collins, S.J., et al., Altered transcription of the c-abl oncogene in K-562 and other chronic myelogenous leukemia cells. Science, 1984. 225(4657): p. 72-4.

194. Gaiger, A., et al., Increase of bcr-abl chimeric mRNA expression in tumor cells of patients with chronic myeloid leukemia precedes disease progression. Blood, 1995. 86(6): p. 2371-8.

195. Elmaagacli, A.H., et al., The amount of BCR-ABL fusion transcripts detected by the real-time quantitative polymerase chain reaction method in patients with Philadelphia chromosome positive chronic myeloid leukemia correlates with the disease stage. Ann Hematol, 2000. 79(8): p. 424-31.

196. Lin, F., et al., Kinetics of increasing BCR-ABL transcript numbers in chronic myeloid leukemia patients who relapse after bone marrow transplantation. Blood, 1996. 87(10): p. 4473-8.

197. Guo, J.Q., J.Y. Wang, and R.B. Arlinghaus, Detection of BCR-ABL proteins in blood cells of benign phase chronic myelogenous leukemia patients. Cancer Res, 1991. 51(11): p. 3048-51.

198. Campbell, L.J., et al., BCR/ABL amplification in chronic myelocytic leukemia blast crisis following imatinib mesylate administration. Cancer Genet Cytogenet, 2002. 139(1): p. 30-3.

199. Gadzicki, D., et al., BCR-ABL gene amplification and overexpression in a patient with chronic myeloid leukemia treated with imatinib. Cancer Genet Cytogenet, 2005. 159(2): p. 164-7.

200. Gorre, M.E., et al., Clinical resistance to STI-571 cancer therapy caused by BCRABL gene mutation or amplification. Science, 2001. 293(5531): p. 876-80.

201. le Coutre, P., et al., Induction of resistance to the Abelson inhibitor STI571 in human leukemic cells through gene amplification. Blood, 2000. 95(5): p. 1758-66.

202. Morel, F., et al., Double minutes containing amplified bcr-abl fusion gene in a case of chronic myeloid leukemia treated by imatinib. Eur J Haematol, 2003. 70(4): p. 235-9. 
203. Branford, S., et al., Real-time quantitative PCR analysis can be used as a primary screen to identify patients with CML treated with imatinib who have BCR-ABL kinase domain mutations. Blood, 2004. 104(9): p. 2926-32.

204. Keeshan, K., et al., Elevated Bcr-Abl expression levels are sufficient for a haematopoietic cell line to acquire a drug-resistant phenotype. Leukemia, 2001. 15(12): p. 1823-33.

205. Sloma, I., et al., Insights into the stem cells of chronic myeloid leukemia. Leukemia, 2010. 24(11): p. 1823-33.

206. Koschmieder, S., et al., Inducible chronic phase of myeloid leukemia with expansion of hematopoietic stem cells in a transgenic model of $B C R-A B L$ leukemogenesis. Blood, 2005. 105(1): p. 324-34.

207. Sanchez, M., et al., An SCL 3' enhancer targets developing endothelium together with embryonic and adult haematopoietic progenitors. Development, 1999. 126(17): p. 3891-904.

208. Sanchez, M.J., et al., Selective rescue of early haematopoietic progenitors in Scl(/-) mice by expressing Scl under the control of a stem cell enhancer. Development, 2001. 128(23): p. 4815-27.

209. Huettner, C.S., et al., Reversibility of acute B-cell leukaemia induced by BCR$A B L 1$. Nat Genet, 2000. 24(1): p. 57-60.

210. Schemionek, M., et al., BCR-ABL enhances differentiation of long-term repopulating hematopoietic stem cells. Blood, 2010. 115(16): p. 3185-95.

211. Ernst, T., et al., Dynamics of BCR-ABL mutated clones prior to hematologic or cytogenetic resistance to imatinib. Haematologica, 2008. 93(2): p. 186-92.

212. Lange, T., et al., BCR-ABL kinase domain mutations in chronic myeloid leukemia: not quite enough to cause resistance to imatinib therapy? Cell Cycle, 2005. 4(12): p. 1761-6.

213. Willis, S.G., et al., High-sensitivity detection of BCR-ABL kinase domain mutations in imatinib-naive patients: correlation with clonal cytogenetic evolution but not response to therapy. Blood, 2005. 106(6): p. 2128-37.

214. Pelz-Ackermann, O., et al., Highly sensitive and quantitative detection of BCRABL kinase domain mutations by ligation PCR. Leukemia, 2008. 22(12): p. 228891.

215. Yang, H., et al., A customized and versatile high-density genotyping array for the mouse. Nat Methods, 2009. 6(9): p. 663-6. 
216. Ivanova, N.B., et al., A stem cell molecular signature. Science, 2002. 298(5593): p. 601-4.

217. Modi, H., et al., Role of $B C R / A B L$ gene-expression levels in determining the phenotype and imatinib sensitivity of transformed human hematopoietic cells. Blood, 2007. 109(12): p. 5411-21.

218. Jiang, X., et al., Chronic myeloid leukemia stem cells possess multiple unique features of resistance to BCR-ABL targeted therapies. Leukemia, 2007. 21(5): $\mathrm{p}$. 926-35.

219. Mahon, F.X., et al., Selection and characterization of BCR-ABL positive cell lines with differential sensitivity to the tyrosine kinase inhibitor STI571: diverse mechanisms of resistance. Blood, 2000. 96(3): p. 1070-9.

220. Weisberg, E. and J.D. Griffin, Mechanism of resistance to the ABL tyrosine kinase inhibitor STI571 in BCR/ABL-transformed hematopoietic cell lines. Blood, 2000. 95(11): p. 3498-505.

221. Nieborowska-Skorska, M., et al., Rac2-MRC-cIII-generated ROS cause genomic instability in chronic myeloid leukemia stem cells and primitive progenitors. Blood, 2012. 119(18): p. 4253-63.

222. Grossmann, V., et al., A deep-sequencing study of chronic myeloid leukemia patients in blast crisis (BC-CML) detects mutations in $76.9 \%$ of cases. Leukemia, 2011. 25(3): p. 557-60.

223. Joha, S., et al., Genomic characterization of Imatinib resistance in CD34+ cell populations from chronic myeloid leukaemia patients. Leuk Res, 2011. 35(4): p. 448-58.

224. Khorashad, J.S., et al., Multiple sub-microscopic genomic lesions are a universal feature of chronic myeloid leukaemia at diagnosis. Leukemia, 2008. 22(9): p. 1806-7.

225. Makishima, H., et al., CBL, CBLB, TET2, ASXL1, and IDH1/2 mutations and additional chromosomal aberrations constitute molecular events in chronic myelogenous leukemia. Blood, 2011. 117(21): p. e198-206.

226. Nowak, D., et al., SNP array analysis of tyrosine kinase inhibitor-resistant chronic myeloid leukemia identifies heterogeneous secondary genomic alterations. Blood, 2010. 115(5): p. 1049-53. 
227. Genova, M.L., et al., Mitochondrial production of oxygen radical species and the role of Coenzyme $Q$ as an antioxidant. Exp Biol Med (Maywood), 2003. 228(5): p. 506-13.

228. Maas, E. and H. Bisswanger, Localization of the alpha-oxoacid dehydrogenase multienzyme complexes within the mitochondrion. FEBS Lett, 1990. 277(1-2): p. 189-90.

229. Trumpower, B.L., The protonmotive $Q$ cycle. Energy transduction by coupling of proton translocation to electron transfer by the cytochrome bcl complex. J Biol Chem, 1990. 265(20): p. 11409-12.

230. Boveris, A., E. Cadenas, and A.O. Stoppani, Role of ubiquinone in the mitochondrial generation of hydrogen peroxide. Biochem J, 1976. 156(2): p. 43544.

231. Dionisi, O., et al., Superoxide radicals and hydrogen peroxide formation in mitochondria from normal and neoplastic tissues. Biochim Biophys Acta, 1975. 403(2): p. 292-300.

232. Loschen, G., et al., Superoxide radicals as precursors of mitochondrial hydrogen peroxide. FEBS Lett, 1974. 42(1): p. 68-72.

233. Turrens, J.F. and A. Boveris, Generation of superoxide anion by the NADH dehydrogenase of bovine heart mitochondria. Biochem J, 1980. 191(2): p. 421-7.

234. Muller, F.L., Y. Liu, and H. Van Remmen, Complex III releases superoxide to both sides of the inner mitochondrial membrane. J Biol Chem, 2004. 279(47): p. 49064-73.

235. Rich, P.R. and W.D. Bonner, The sites of superoxide anion generation in higher plant mitochondria. Arch Biochem Biophys, 1978. 188(1): p. 206-13.

236. Dringen, R., Metabolism and functions of glutathione in brain. Prog Neurobiol, 2000. 62(6): p. 649-71.

237. Sharma, S., K.M. Doherty, and R.M. Brosh, Jr., Mechanisms of RecQ helicases in pathways of DNA metabolism and maintenance of genomic stability. Biochem J, 2006. 398(3): p. 319-37.

238. Shiloh, Y., et al., RNF20-RNF40: A ubiquitin-driven link between gene expression and the DNA damage response. FEBS Lett, 2011. 585(18): p. 2795802. 
239. Karahalil, B., V. Bohr, and D. Wilson, 3rd, Impact of DNA polymorphisms in key DNA base excision repair proteins on cancer risk. Hum Exp Toxicol, 2012. 31(10): p. 981-1005.

240. Nishimura, K., et al., Mcm8 and Mcm9 form a complex that functions in homologous recombination repair induced by DNA interstrand crosslinks. Mol Cell, 2012. 47(4): p. 511-22.

241. Oei, S.L., C. Keil, and M. Ziegler, Poly(ADP-ribosylation) and genomic stability. Biochem Cell Biol, 2005. 83(3): p. 263-9.

242. Wu, M. and H.B. Shu, MLL1/WDR5 complex in leukemogenesis and epigenetic regulation. Chin J Cancer, 2011. 30(4): p. 240-6.

243. Sasaki, M., et al., IDH1(R132H) mutation increases murine haematopoietic progenitors and alters epigenetics. Nature, 2012. 488(7413): p. 656-9.

244. Nakayama, H., et al., Decreases in Ikaros activity correlate with blast crisis in patients with chronic myelogenous leukemia. Cancer Res, 1999. 59(16): p. 39314.

245. Miyazaki, K., et al., Enhanced expression of $210 B C R / A B L$ and aberrant expression of Zfp423/ZNF423 induce blast crisis of chronic myelogenous leukemia. Blood, 2009. 113(19): p. 4702-10.

246. Yoda, H., Y. Hiroi, and H. Sano, Polyamine oxidase is one of the key elements for oxidative burst to induce programmed cell death in tobacco cultured cells. Plant Physiol, 2006. 142(1): p. 193-206.

247. Wang, X., et al., Pyruvate protects mitochondria from oxidative stress in human neuroblastoma SK-N-SH cells. Brain Res, 2007. 1132(1): p. 1-9.

248. Katoh, M. and M. Katoh, Identification and characterization of human TIPARP gene within the CCNL amplicon at human chromosome 3q25.31. Int J Oncol, 2003. 23(2): p. 541-7.

249. Lugo, T.G., et al., Tyrosine kinase activity and transformation potency of bcr-abl oncogene products. Science, 1990. 247(4946): p. 1079-82.

250. Haferlach, C., et al., Similar patterns of chromosome abnormalities in CML occur in addition to the Philadelphia chromosome with or without tyrosine kinase inhibitor treatment. Leukemia, 2010. 24(3): p. 638-40.

251. Jorgensen, H.G., et al., Nilotinib exerts equipotent antiproliferative effects to imatinib and does not induce apoptosis in CD34+CML cells. Blood, 2007. 109(9): p. 4016-9. 
252. Corbin, A.S., et al., Human chronic myeloid leukemia stem cells are insensitive to imatinib despite inhibition of BCR-ABL activity. J Clin Invest, 2011. 121(1): p. 396-409.

253. La Rosee, P., et al., No correlation between the proliferative status of Bcr-Abl positive cell lines and the proapoptotic activity of imatinib mesylate (Gleevec/Glivec). Hematol J, 2003. 4(6): p. 413-9.

254. Holyoake, T., et al., Isolation of a highly quiescent subpopulation of primitive leukemic cells in chronic myeloid leukemia. Blood, 1999. 94(6): p. 2056-64.

255. Jamieson, C.H., et al., Granulocyte-macrophage progenitors as candidate leukemic stem cells in blast-crisis CML. N Engl J Med, 2004. 351(7): p. 657-67.

256. Mandal, P.K., C. Blanpain, and D.J. Rossi, DNA damage response in adult stem cells: pathways and consequences. Nat Rev Mol Cell Biol, 2011. 12(3): p. 198202.

257. Mohrin, M., et al., Hematopoietic stem cell quiescence promotes error-prone DNA repair and mutagenesis. Cell Stem Cell, 2010. 7(2): p. 174-85.

258. Barnes, D.J., et al., Bcr-Abl expression levels determine the rate of development of resistance to imatinib mesylate in chronic myeloid leukemia. Cancer Res, 2005. 65(19): p. 8912-9.

259. Barnes, D.J., et al., Dose-dependent effects of Bcr-Abl in cell line models of different stages of chronic myeloid leukemia. Oncogene, 2005. 24(42): p. 643240 .

260. Bacher, U., et al., Additional clonal abnormalities in Philadelphia-positive ALL and CML demonstrate a different cytogenetic pattern at diagnosis and follow different pathways at progression. Cancer Genet Cytogenet, 2005. 157(1): p. 5361.

261. Slupianek, A., et al., Targeting RAD51 phosphotyrosine-315 to prevent unfaithful recombination repair in BCR-ABL1 leukemia. Blood, 2011. 118(4): p. 1062-8.

262. Hamilton, A., et al., Chronic myeloid leukemia stem cells are not dependent on Bcr-Abl kinase activity for their survival. Blood, 2012. 119(6): p. 1501-10.

263. O'Brien, S.G., et al., Imatinib compared with interferon and low-dose cytarabine for newly diagnosed chronic-phase chronic myeloid leukemia. N Engl J Med, 2003. 348(11): p. 994-1004. 
264. Hochhaus, A., et al., Six-year follow-up of patients receiving imatinib for the firstline treatment of chronic myeloid leukemia. Leukemia, 2009. 23(6): p. 1054-61.

265. Deininger, M., et al., International Randomized Study of Interferon Vs. STI571 (IRIS) 8-Year Follow up: Sustained Survival and Low Risk for Progression or Events in Patients with Newly Diagnosed Chronic Myeloid Leukemia in Chronic Phase (CML-CP) Treated with Imatinib. Blood (ASH Annual Meeting Abstracts), 2009. 114(22): p. 462. 